\title{
EXPANSÃO RÁPIDA DA MAXILA ASSISTIDA CIRURGICAMENTE SOB ANESTESIA LOCAL EM ADULTOS - AVALIAÇÃO CLÍNICA E RADIOGRÁFICA DE DUAS TÉCNICAS CIRÚRGICAS.
}

LUÍS FERNANDO DE MELLO SANT'ANA

\begin{abstract}
Tese apresentada à Faculdade de Odontologia de Bauru, da Universidade de São Paulo, como parte dos requisitos para a obtenção do título de Doutor em Estomatologia.
\end{abstract}

(Edição Revisada)

BAURU

2006 


\section{EXPANSÃO RÁPIDA DA MAXILA ASSISTIDA CIRURGICAMENTE SOB ANESTESIA LOCAL EM ADULTOS - AVALIAÇÃO CLÍNICA E RADIOGRÁFICA DE DUAS TÉCNICAS CIRÚRGICAS.}

LUÍS FERNANDO DE MELLO SANT'ANA

Tese apresentada à Faculdade de Odontologia de Bauru, da Universidade de São Paulo, como parte dos requisitos para a obtenção do título de Doutor em Estomatologia.

(Edição Revisada)

Orientador: Prof. Dr. Paulo Sérgio Perri de Carvalho

BAURU

2006 
Ficha Técnica

Luís Fernando de Mello Sant'Ana: Concepção original, redação, digitação, layout, formatação e impressão.

Paulo Sérgio Perri de Carvalho: Orientação geral e revisão final.

Maria Regina de Mello Rusconi: Vernáculo.

José Roberto Pereira Lauris: Análise estatística.

Sant'Ana, Luís Fernando de Mello

Sa59a Expansão rápida da maxila assistida cirurgicamente sob anestesia local em adultos - Avaliação clínica e radiográfica de duas técnicas cirúrgicas./ Luís Fernando de Mello Sant'Ana. - Bauru, 2006.

xviii , 192 p. : il. ; 30 cm.

Tese (Doutorado) - Faculdade de Odontologia de Bauru. USP.

Orientador: Prof. Dr. Paulo Sérgio Perri de Carvalho

Autorizo a reprodução total ou parcial, da referida Tese de Doutorado.

Luís Fernando de Mello Sant'Ana

Autor.

Aprovado pelo Comitê de Ética em Pesquisa desta Faculdade.

Processo n. 66/2004 
Luís Fernando de Mello Sant'Ana

01 de maio de 1975

Nascimento

São Paulo - SP

$1995-1998$

$1999-2000$

$2001-2002$

2003

2005

2006
Curso de Odontologia Faculdade de Odontologia de Bauru da Universidade de São Paulo.

Estágio junto à Disciplina de Cirurgia da Faculdade de Odontologia de Bauru - USP.

Curso de Pós-Graduação em Estomatologia, em nível de Mestrado, na Faculdade de Odontologia de Bauru - USP.

Curso de Pós-Graduação em Estomatologia, em nível de Doutorado, na Faculdade de Odontologia de Bauru - USP.

Professor das disciplinas de Cirurgia da Faculdade de Odontologia da Pontifícia Universidade Católica de Campinas - PUCCAMP.

Professor das disciplinas de Radiologia da Faculdade de Odontologia da Pontifícia Universidade Católica de Campinas - PUCCAMP. 


\section{Dedicatória}

Aos meus pais Lourival e Helena, meu irmão Paulo Henrique e sua esposa Aline. Dedico também à mais nova razão de buscar forças para todas minhas realizações, o meu sobrinho Gabriel. Teria que escrever outro volume como o deste trabalho para conseguir expressar tudo o que vocês significam para mim.

Dedico a vocês este trabalho

Do filho, irmão e tio que ama vocês mais do que a própria vida. 
Agradecimentos Especiais 


\section{Agradecimentos Especiais}

Aos meus eternos amigos de Americana, Alexandre, Rafael, Marcos, Luís Marcelo e Guilherme. Hoje já não compartilhamos o mesmo sonho, a mesma sala de aula e espaço, mas nunca deixaremos de compartilhar a amizade. Adoro todos vocês!!!

Ao meu colega de consultório e amigo, Marco Antônio Ferreira Barberi. Pessoa que tem meu respeito e admiração. Um dos melhores profissionais que conheci. Sinto-me sempre honrado pela confiança depositada em mim.

Aos meus novos amigos da Faculdade de Odontologia da Pontifícia Universidade Católica de Campinas, Prof. José Inácio de Toledo Jr., Prof. Silas de Túlio, Profa Fabiana Pastana Dias e Prof. Roberto Abdalla. A convivência harmoniosa e os preceitos de ética, dedicação e bondade fazem com que minha admiração por vocês seja maior a cada dia. Sua amizade é muito importante para mim. Obrigado. 
Ao antigo diretor do Centro de Ciências da Vida da PUCCampinas Prof. Luiz Maria Pinto e a atual Diretora do Centro de Ciências da Vida da PUC-Campinas Profa Miralva Aparecida J. Silva, pela confiança depositada durante este tempo, fazendo-me sentir a PUC-Campinas como minha nova casa.

À minha amiga, conselheira e orientadora de vida Prof ${ }^{a}$. Dra. Ana Lúcia Álvares Capelozza. O carinho com que sempre fui recebido por você e toda sua família,fizeram com que me sentisse um pouco em casa nos momentos de dificuldade. Com certeza você é uma das melhores pessoas que eu conheço. Minha eterna gratidão e admiração.

Ao meu grande amigo e mestre Prof. Dr. Júlio de Araújo Gurgel. Às vezes Deus coloca pessoas durante a nossa trajetória de vida que são especiais. Com certeza você é uma delas. Minha eterna gratidão pelas orientações e ensinamentos e minha eterna admiração pelo profissional, homem e pai de família. Obrigado por tudo!!! 
Agradecimentos Especiais

Ao meu orientador Prof. Dr. Paulo Sérgio Perri de Carvalho, exemplo que, desde a primeira aula assistida durante a graduação, procuro seguir. Sei que se um dia conquistar metade de sua didática em aula e visão científica, serei um excelente professor. Minha admiração por tudo o que representa em minha formação.

Ao meu primo Cássio Augusto de Mello Rusconi. Pessoa esta que sempre foi e será exemplo de vida, caráter e bondade. Irmão mais velho, amigo e companheiro. Pessoa que também estendeu a mão amiga em momentos de dificuldades, conflitos e incertezas. Com certeza, a pessoa com o maior coração que conheço.

À todos meus familiares, em especial à minha tia Inês e meus tios Tadeu e Vilma. Vocês abriram as portas de seus lares para que por um breve período eu pudesse ter um teto e acima de tudo pudesse conviver diariamente com pessoas maravilhosas como vocês. Sem seu precioso auxílio nestes momentos, este trabalho não seria concluído. Minha eterna gratidão.

A minha tia Maria Regina de Mello Rusconi, pela presença em minha vida, exemplo de determinação e pela preciosa correção ortográfica deste trabalho. 
Ao meu tio e padrinho José Maria Rusconi, e meus queridos "Vô" Moacyr, "Vó" Lourdes e "Vô" Lourival, que estão junto de Deus, olhando por mim e acompanhando todos os meus passos. Vocês que durante a vida foram fonte de segurança, sabedoria e alegria, sei que estão orgulhosos por esta conquista, mas sinto falta do sorriso e do abraço de vocês. Muitas Saudades!!!. 


\section{Agradecimentos}

Agradeço a Deus, acima de tudo, por Sua Sabedoria ao me indicar os caminhos corretos da vida, por Seu amor incondicional e, acima de tudo pela generosidade de fazer passar pela minha existência pessoas que tive o privilégio e a honra de conhecer pelos caminhos de minha vida.

Ao Diretor da Faculdade de Odontologia de Bauru, Prof. Dr.Luiz Fernando Pegoraro.

Ao presidente da Comissão de Pós-Graduação da Faculdade de Odontologia de Bauru, Prof. Dr.José Carlos Pereira.

Aos funcionários do Departamento de Estomatologia da Faculdade de Odontologia de Bauru, Marília, Reinaldo, Luciana, Fernanda, Roberto, Hebe, Patrícia, Josieli e a Camila. Obrigado pela presteza, carinho e profissionalismo.

Aos colegas de pós-graduação, o Cláudio, Flávio, Eduardo, Cássia e Fernando. Estes três anos foram inesqueciveis, obrigado! 
Aos novos colegas da pós-graduação em Estomatologia,Etiene, Renato, Melissa, Marcelo, Carla, Josiane, Renata, Tadeu, Gustavo, Dani, Letícia e Marta. Obrigado pelo apoio e amizade.

A todos os amigos que fiz durante o curso de PósGraduação. Foi um privilégio poder conviver com todos vocês desde nossos passos iniciais. Espero que a distância imposta pelos caminhos que iremos trilhar seja sempre menor do que a amizade forjada nesses anos de convivência.

Aos funcionários da Faculdade de Odontologia de Bauru

Aos funcionários da Biblioteca da Faculdade de Odontologia de Bauru

Aos estagiários da Disciplina de Cirurgia da Faculdade de Odontologia de Bauru, Renan, Gabriel e Murilo. Obrigado pela ajuda, pela disponibilidade e dedicação com que sempre me atenderam. 
A todos os professores que tive durante a minha graduação e PósGraduação na Faculdade de Odontologia de Bauru. Levo um pouco de todos para tentar tornar-me um 6om professor. Espero conseguir ser importante na vida de alguém assim como vocês foram importantes para mim.

Aos professores do Departamento de Estomatologia da Faculdade de Odontologia de Bauru, Prof. Dr. José Humberto Damante, Prof. Dr. Luiz Eduardo Montenegro Chinelatto, Profa $\mathcal{D r}^{a}$ Ana Lúcia Álvares Capelozza, Prof. Dr. Eduardo Sant'Ana, Prof. Dr. Osny Ferreira Jr., Prof. Dr.Paulo Sérgio Perri de Carvalho e Profa. Dr ${ }^{a}$ Isabel Regina Fischer Rubira.

A todos os professores e funcionários da Faculdade de Odontologia da PUC-Campinas pela calorosa recepção, carinho e amizade.

Aos pacientes que, gentilmente, concordaram em participar deste trabalho. 
"And in the end, the love you take, is equal to the love you make" John Lennon e' Paul McCartney - Golden Slumbers

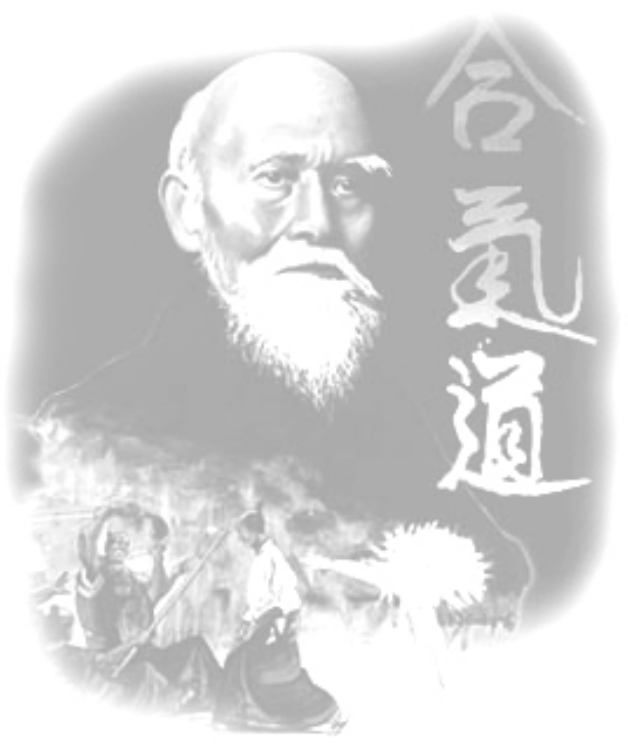

"O aikido é a arte da reconciliação. O homem que deseja brigar perde sua ligação com o universo - $e$ aquele que tenta dominar as pessoas termina dominado. Estamos aqui estudando a arte de resolver os conflitos e não iniciá-los" (Morihei Veshiba Sensei, o Fundador do Aikido)

O aikido nos ensina a utilizar a energia do agressor a fim de nos harmonizarmos com o universo, logo, agradeço a todas as pessoas que quiseram me prejudicar durante minha jornada. Muitas e muitas vezes o que vocês fizeram foi apenas dar a energia que eu precisava para ir mais adiante e conquistar meus espaços. Com certeza, vocês foram muito importantes para minha conquista. Obrigado. 


\section{SUMÁRIO}

RESUMO XVi

1. INTRODUÇÃO 1

2. REVISÃO DE LITERATURA 7

2.1 - Expansão Rápida da Maxila 9

2.2 - Técnicas Cirúrgicas para Realização da ERMAC 42

2.3 - Escalas Analíticas de Dor 57

3. PROPOSIÇÃO 59

4. MATERIAL E MÉTODOS 63

4.1 - Material 65

4.2 - Métodos 71

5. RESULTADOS 95

$\begin{array}{ll}\text { 6. DISCUSSÃO } & 119\end{array}$

$\begin{array}{ll}\text { 7. CONCLUSÕES } & 159\end{array}$

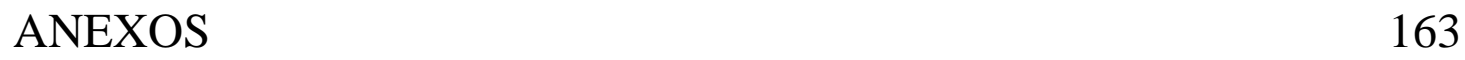

$\begin{array}{ll}\text { REFERÊNCIAS BIBLIOGRÁFICAS } & 171\end{array}$

$\begin{array}{lr}\text { ABSTRACT } & 189\end{array}$ 


\section{RESUMO}

A expansão rápida da maxila assistida cirurgicamente em pacientes adultos há muito é conhecida pelos cirurgiões e ortodontistas. Seu benefício se mostra em longo prazo através da correção da deficiência transversal da maxila e conseqüente correção da mordida cruzada posterior, melhora da estética facial e aumento do volume nasal, conseqüentemente, melhorando a respiração. O objetivo deste trabalho é a comparação de duas formas de tratamento da deficiência transversal maxilar sob anestesia local, utilizando-se dos mesmos parâmetros de controle de eficácia de técnica cirúrgica, controles radiográficos e avaliação da percepção do paciente quanto à cirurgia que foi submetido e ao período pósoperatório. Para isto, foram selecionados 24 pacientes adultos, com indicação para expansão rápida da maxila assistida cirurgicamente, divididos em 2 grupos. O grupo I foi submetido à técnica proposta por BELL ${ }^{12}$ e o grupo II à técnica proposta por GLASSMAN ${ }^{31}$. Após a obtenção dos dados através de radiografias e de um questionário aplicado aos pacientes ao fim da cirurgia e no primeiro controle pós-operatório podemos concluir que: (1) Todos os pacientes submetidos à técnica cirúrgica proposta por BELL ${ }^{12}$ 
obtiveram resultados cirúrgicos e ortopédicos satisfatórios, enquanto que apenas $30 \%$ dos pacientes submetidos à técnica de GLASSMAN ${ }^{31}$ obtiveram êxito; (2) Ambas técnicas mostraram-se toleráveis aos pacientes para a realização do procedimento sob anestesia local; (3) A técnica proposta por GLASSMAN ${ }^{31}$ obteve resultados piores quanto a dor pós-operatória e desconforto durante a ativação do aparelho expansor, enquanto que pacientes submetidos à técnica de BELL ${ }^{12}$ tiveram pouco ou quase nenhum desconforto; (4) Não houve diferença entre as duas técnicas quanto à percepção do paciente ao edema pós-operatório formado. 


\section{1- INTRODUÇÃO}

Para uma oclusão normal é necessário que a morfologia do arco dentário superior tenha dimensões compativelmente maiores do que as do arco dentário inferior, permitindo assim que, em oclusão, as cúspides palatinas dos pré-molares e molares superiores se adaptem adequadamente às fossas oclusais dos pré-molares e molares inferiores 4 , 8, 9, 10-13, 17-19, 23, 25, 27-31, 34-37, 41, 43, 44, 46, 49, 50, 55-57, 59-61, 67, 68, 70, 73, 76, 7981,83

Ao depararmos com dimensões transversais superiores reduzidas, observamos o quadro clínico de mordida cruzada posterior, que pode ter origem dentária ou esquelética.

As discrepâncias transversais de origem dentária, normalmente afetam um ou dois dentes, enquanto que as de origem esquelética apresentam maior grau de complexidade ${ }^{35-37}$. 
As discrepâncias transversais de origem esquelética, ou deficiências transversais da maxila, são resultados de uma deficiência no desenvolvimento, ou falta de estímulo de desenvolvimento, da largura da base da maxila, causando uma diferença negativa das medidas

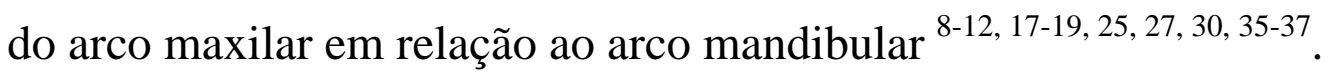

Têm-se como principais fatores etiológicos das eficiências transversais da maxila, o hábito de sucção digital e respiração bucal, deste modo sendo recomendado como parte do tratamento precoce a interrupção destes estímulos ${ }^{35-37}$.

A atresia maxilar está associada a diversos fatores que comprometem tanto a função quanto estética facial do paciente.

A correção da deficiência transversal da maxila, em pacientes adultos, deve ser feita com a utilização de procedimentos cirúrgicos, sendo que existem, basicamente, duas técnicas de tratamento: a multisegmentação maxilar e a expansão rápida da maxila assistida cirurgicamente $^{8,10-12,31,54,67}$.

A multisegmentação maxilar está indicada, principalmente, nos casos de discrepância transversal inferior a 7 mm entre os arcos dentários em que tenha o paciente, associadamente, deficiências outras como as vertical e sagital; devendo esta cirurgia ser realizada sob 
anestesia geral e a necessária osteotomia Le Fort I completa para reposicionamento maxilar ${ }^{15}$.

As cirurgias de expansão rápida da maxila assistida cirurgicamente estão indicadas para pacientes que somente tenham a deficiência transversal da maxila e em casos onde a quantidade dee expansão seja superior a $7 \mathrm{~mm}$. Esta cirurgia é passível de ser realizada sob anestesia local, já que não há necessidade de reposicionamento da maxila ${ }^{10-}$ 12, 18, 19, 27, 29, 31, 33, 49, 51, 53

Os benefícios descritos na literatura aos pacientes submetidos a este procedimento são: aumento do espaço aéreo superior, alterações faciais, como a atenuação significante do sulco naso-labial e a estabilidade das mudanças ao longo dos anos 1, 4, 6, 7, 9, 11-14, 17-19, 25, 26, 31, 33-37, 46, 49, 51, 52, 54-57, 61, 62, 65-67, 70, 73, 75, 76, 78, 80 .

Tradicionalmente, as expansões maxilares assistidas cirurgicamente são conhecidas pela sua relativa baixa morbidade cirúrgica, mas como toda cirurgia, oferece riscos. Entre as principais complicações deste procedimento podem-se destacar: a necrose da mucosa palatina associada às ativações incorretas do aparelho expansor e as hemorragias nasais $21,47,48,53$. 
$\mathrm{Na}$ literatura específica, encontram-se várias técnicas cirúrgicas descritas para a realização da expansão rápida da maxila assistida cirurgicamente. Todas estas técnicas referem como principais vantagens a manutenção da saúde periodontal, melhora na respiração nasal, melhora na estética facial, pequena morbidade trans e pós-operatória e estabilidade dos resultados ao longo prazo ${ }^{10-12,31}$.

Porém, relatos mostram que um fator limitante para a realização destes procedimentos sob anestesia local é o grande estresse causado pela cirurgia ao paciente ${ }^{31}$. Uma cuidadosa revisão de literatura mostra que os trabalhos envolvendo a expansão rápida da maxila assistida cirurgicamente não seguem observações padronizadas, o que torna impossível a comparação de resultados de diferentes trabalhos.

Após esta leitura e implementação de um protocolo de atendimento e acompanhamento de pacientes submetidos à expansão rápida da maxila assistida cirurgicamente, feito pela Disciplina de Cirurgia da FOB-USP, procurou-se avaliar a sintomatologia trans e pósoperatória dos pacientes submetidos a este procedimento cirúrgico e a efetividade das técnicas cirúrgicas preconizadas por BELL ${ }^{12}$ e GLASSMAN $^{31}$. 


\section{2 - REVISÃO DE LITERATURA}

Este capítulo apresentará os relatos dos trabalhos científicos utilizados na presente pesquisa. Para maior facilidade de compreensão, estes trabalhos serão divididos nos seguintes tópicos: 2.1 Expansão rápida da maxila; 2.2 Técnicas cirúrgicas para realização da expansão rápida da maxila assistida cirurgicamente; 2.3 Escalas analíticas de dor.

\section{1 - Expansão Rápida da Maxila.}

ANGELL $^{3}$, em 1860, apud HAAS ${ }^{34}$, foi o primeiro a descrever a possibilidade da abertura da sutura palatina mediana. Seu trabalho mostra o uso de um dispositivo com parafuso instalado entre os prémolares de uma menina de 14 anos, com a finalidade de promover a 
separação dos ossos maxilares. Após 14 dias de ativação deste dispositivo foi observado um diastema entre os incisivos centrais superiores, o que comprovaria a separação dos ossos maxilares. Porém devido ao fato de não se conseguirem evidências científicas de tal feito, a técnica não foi aceita. Um dos fatos relevantes da não aceitação do procedimento se deve à época em que fora realizado. Caso o procedimento tivesse sido feito após a descoberta dos raios X por Röntgen ${ }^{2}$ em 1895, a história poderia ter sido diferente.

DAVIS \& KRONMAN ${ }^{26}$, em 1961, reportam em seu estudo que todos os pacientes submetidos à expansão rápida da maxila (ERM), finalizaram com um posicionamento mais anteriorizado do ponto A na maxila. WERTZ ${ }^{76}$, em 1970, e BIEDERMAN ${ }^{16}$, em 1973, acreditam que o posicionamento anteriorizado do ponto A durante a expansão rápida da maxila se deve à disjunção da sutura pterigopalatina. WERTZ ${ }^{76}$ ainda afirma que a resistência do arco zigomático impede que a maxila se abra paralelamente após a separação da sutura palatina mediana.

ISAACSON \& MURPHY ${ }^{39}$, em 1964, relataram o uso de expansão rápida da maxila em 5 pacientes com fissura lábio palatal. Em um dos pacientes, com 22 anos, não houve expansão maxilar. Pela lógica, os autores concluíram que a expansão neste paciente não ocorreu devido à 
fusão da sutura palatina mediana, já que o paciente não a possuía. Concluíram, portanto, que a rigidez do esqueleto facial era um fator mais importante do que a sutura palatina mediana nos casos onde a expansão rápida da maxila não ocorre.

ISSACSON $^{40}$, em 1964, advoga que o esqueleto facial de pacientes mais jovens são menos resistentes à expansão, concluindo que a resistência destas estruturas às movimentações ortopédicas aumentam conforme a idade do paciente avança. ZIMRING \& ISAACSON ${ }^{83}$, em 1965, provaram esta teoria. Um medidor de força foi colocado junto aos aparelhos expansores, mensurando as forças produzidas durante a expansão maxilar. Os autores mostraram que seus pacientes mais velhos tiveram um nível de resistência maior ao movimento maxilar do que pacientes mais jovens. Os pacientes mais velhos tiveram uma quantidade maior de ativações para a mesma expansão quando comparados com pacientes mais jovens, e, a dissipação desta força também era mais lenta nestes pacientes.

HAAS ${ }^{35}$, em 1965, publicou uma revisão sobre a expansão rápida da maxila, onde se reporta ao seu estudo previamente publicado em $1961^{34}$, em que tratou 45 pacientes com a abertura da sutura palatina mediana. Segundo este autor, a expansão palatina é encorajadora e responde a muitos dos maiores desafios aos ortodontistas, dentre eles a 
Classe III, tratada sem cirurgia; os casos de real e relativa deficiência transversal maxilar; estenose nasal típica de respiradores bucais; pacientes adultos com fissura palatina. $\mathrm{O}$ autor destaca, em seus dois trabalhos, que $\mathrm{o}$ procedimento de disjunção palatina facilita o tratamento ortodôntico.

HAAS ${ }^{36}$, em 1970, explicou que o movimento inferoanterior da maxila durante a expansão rápida da maxila ocorre devido à localização das suturas maxilo-craniais. Ele advoga que metade de seus pacientes tratados com expansão rápida da maxila diz sentir uma sensação de pressão na região da sutura zigomático-maxilar. O autor acredita que a razão da maxila se separar, inclinando-se ao invés de se movimentar paralelamente, se deve a espessura e força do osso zigomático.

GARDNER \& KRONMAN ${ }^{28}$, em 1971, descobriram, em estudo com macacos, que a sincondrose esfeno-occpital abre-se durante a expansão rápida da maxila. Eles atribuem este fator como sendo a causa do posicionamento mais anteriorizado do ponto A. Os autores ainda mostram que as suturas zigomaticomaxilares, zigomáticotemporais e a sutura palatina mediana possuem um aumento significativo de atividade celular quando a expansão rápida da maxila foi utilizada.

LINES e cols ${ }^{50}$, em 1975, após uma extensa revisão de literatura chegaram a duas conclusões: (1) A expansão rápida da maxila tem 
sido usada, com uma alta taxa de sucesso, em pacientes na sua fase de crescimento e (2) que as falhas ocorridas nas tentativas de expansão rápida da maxila em adultos pode ser atribuída primariamente ao aumento da rigidez do esqueleto facial e do grau de fusão das suturas zigomaticomaxilares, zigomáticotemporais, frontomaxilares e zigomáticofrontal. A rigidez das articulações do complexo zigomático na maxila tende a ser o ponto de maior resistência à expansão, sendo portanto, um dos fatos que explicam o alto índice de insucesso da expansão rápida da maxila em pacientes adultos.

KENNEDY e cols ${ }^{43}$, em 1976, estudaram os efeitos de osteotomias maxilares selecionadas como coadjuvantes de expansão rápida maxilar em macacos Rhesus. Seus resultados mostraram uma diferença estatisticamente significante entre 2 grupos: um grupo tratado com osteotomia lateral de maxila, pterigomaxilar e palatal ou simplesmente osteotomia lateral de maxila e pterigomaxilar. Outro grupo foi o que não se submeteu a nenhum procedimento cirúrgico ou somente osteotomia palatal. Estes autores concluíram que o movimento maxilar feito pela expansão rápida da maxila deve ser realizado reduzindo a resistência do movimento lateral via osteotomia maxilar, pterigomaxilar e nasomaxilar. 
PERSSON \& THILANDER ${ }^{58}$, em 1977, em seu estudo sobre o fechamento da sutura intermaxilar encontraram indícios de fechamento da sutura em pacientes a partir dos 20 anos, sendo que em apenas casos isolados esta sutura pode ser encontrada aberta em idades mais avançadas. Neste trabalho, os autores encontraram um padrão de ossificação da sutura palatina mediana, onde a porção bucal possui um fechamento prematuro em relação à porção nasal, sendo que a porção posterior é a que sofre o fechamento antes da anterior. Não houve correlação, para estes autores, entre o fechamento da sutura palatina mediana e das outras suturas craniais.

EPKER, FISH \& PAULUS ${ }^{27}$, em 1978, fizeram uma extensa revisão de literatura envolvendo os aspectos de correção de todas as deficiências maxilares. Neste trabalho os autores propõem uma seqüência a ser seguida durante o exame do paciente, onde o cirurgião deve avaliar a face do paciente em norma frontal, lateral e proporção dos terços faciais e somente então o padrão oclusal. Para estes autores a deficiência transversal maxilar pode ser efetivamente corrigida com cirurgia.

MESSER, BOLLINGER \& KELLER ${ }^{54}$, em 1979, citam em seu trabalho que com o advento das osteotomias maxilares o ajuste das relações maxilares com o perfil facial tornaram-se mais fácies. Durante 
seu trabalho, citaram que a maioria dos cirurgiões já se deparou com o seguinte problema: paciente com retrognatia mandibular associada a atresia maxilar. Estes casos eram tratados com o avanço mandibular, resolvendo principalmente o problema estético do paciente, mas a diferença de largura dos arcos acaba causando uma mordida cruzada posterior. Para estes autores, a utilização da então batizada osteotomia sub-total Le Fort I, combinada com o avanço mandibular resolve este tipo de insucesso de tratamento, onde a mordida cruzada posterior não pode mais ser aceita como efeito desta terapia. Para eles o maior objetivo da osteotomia sub-total Le Fort I é a separação da maxila de seus “attachments” laterais e posteriores, seguida de uma pressão lateral feita com um dispositivo mecânico.

HAAS ${ }^{37}$, em 1980, publicou algo raro, até então, um controle comprovando a estabilidade dos pacientes submetidos à expansão

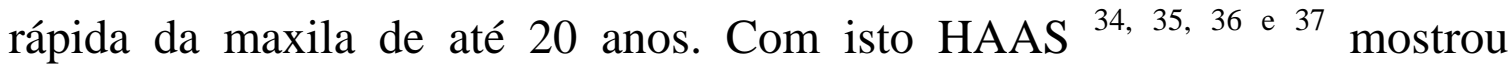
estabilidade do aumento de cerca de 9 a 12 mm da distância intercanina, muitos anos após a contenção. Todos os casos mostrados neste trabalho estão estáveis, estando os pacientes em uma condição esquelética melhor do que quando começaram o tratamento. De acordo com o autor, a expansão rápida da maxila é um procedimento biomecanicamente e biologicamente aceitável, devendo fazer parte do dia a dia dos ortodontistas. Para tanto, 
HAAS ${ }^{37}$ advoga que existem 6 indicações para a expansão rápida da maxila: (1) Para correção dos casos onde haja deficiência transversal maxilar real e relativa, (2) estenose nasal causada por respiração bucal, (3) todos os tipos de Classe III, (4) pacientes adultos portadores de fissura palatina, (5) deficiências maxilares ântero-posteriores e (6) casos selecionados de discrepância de largura de arcos dentários com padrão normal morfogenético.

JACOBS e cols ${ }^{41}$, em 1980, afirmam que o tratamento de pacientes adultos portadores de deformidades dento-faciais é freqüentemente complicado pela existência de discrepâncias nas dimensões horizontais. Segundo estes autores, o aumento da circunferência do arco maxilar possibilita a correção de apinhamentos e dentes mal posicionados sem a utilização de extrações. Concluem afirmando que o controle das dimensões transversais com as técnicas cirúrgicas disponíveis, em pacientes adultos, é válido durante a elaboração do plano de tratamento adequado àquele caso e que isso traz ao paciente resultados duradouros, funcionais e estáveis.

TIMMS, ORTH e VERO ${ }^{73}$, em 1981, afirmaram que as evidências de expansão lateral maxilar por meios do uso da expansão rápida (cerca de 2,5 mm por semana) sugerem melhores resultados. Segundo estes 
autores a expansão rápida promove mudanças anatômicas significantes, pois o movimento da maxila é translatório em comparação ao movimento transformativo da expansão lenta da maxila.

KRAUT $^{44}$, em 1984, relatou os resultados da expansão rápida da maxila assistida cirurgicamente (ERMAC) de 25 pacientes. O autor conclui seu trabalho afirmando que a osteotomia da parede lateral da maxila combinada com a disjunção pterigomaxilar e da sutura palatina mediana no trans-operatório, permitiram o sucesso do procedimento em 23 pacientes. Os outros dois pacientes que não obtiveram resposta positiva ao tratamento possuíam sutura palatina mediana extremamente espessa e que depois de osteotomizadas foram corretamente expandidas.

SCHWARZ e cols ${ }^{65}$, em 1985, avaliaram os efeitos da ERMAC com relação ao desvio de septo nasal em 9 pacientes. A avaliação do septo nasal foi feita através e tomografia computadorizada. Os resultados mostraram um aumento do espaço aéreo nasal, porém não houveram alterações sobre o septo nasal quando comparado os dados pré e pósoperatórios.

WARREN e cols ${ }^{75}$, em 1987, realizaram uma pesquisa onde avaliaram se existe aumento do espaço aéreo nasal após expansões maxilares. Segundo estes autores, existem sugestões de que expansões 
maxilares podem ser indicadas apenas com base no espaço aéreo nasal. Os resultados desta pesquisa mostraram que tanto a expansão rápida da maxila (ERM) quanto a ERMAC melhoram o espaço aéreo nasal, mas não o suficiente para eliminar o hábito, ou necessidade, da respiração bucal. Segundo estes autores, as expansões maxilares não devem servir como indicação isolada para melhora do espaço aéreo nasal. O que o trabalho defende é que as expansões maxilares diminuem a resistência à passagem do ar pelo nariz ao dar uma nova, e mais ampla, conformação à base alar e às narinas no pós-operatório.

BISHARA \& STALEY ${ }^{17}$, em 1987, avaliaram, através de revisão de literatura, as implicações da expansão maxilar nas estruturas faciais, dentição e periodonto. Segundo estes autores, ao ativar o aparelho expansor, estes fazem uma compressão no ligamento periodontal, forçando o processo alveolar causando inclinações dentárias e gradualmente abre a sutura palatina mediana. TEN CATE, FREEMAN \& DICKINSON ${ }^{72}$, em 1977, apud BISHARA \& STALEY ${ }^{17}$, descobriram que a abertura da sutura palatina mediana envolve uma agressão tecidual, seguido de fenômenos de proliferação celular e reparo que leva à regeneração da sutura.

LEHMAN \& HAAS ${ }^{49}$, em 1990, fazem um estudo retrospectivo de 56 pacientes submetidos a ERMAC. Todos foram 
submetidos à cirurgia sob anestesia geral e a técnica consistia basicamente em uma osteotomia lateral da maxila, semelhante à técnica descrita por GLASSMAN ${ }^{31}$. Uma das diferenças é que estes autores utilizaram um aparelho expansor dento-muco suportado (Haas), sendo esta a provável causa de 2 pacientes terem desenvolvido necrose da mucosa palatina. Destes pacientes 17 necessitaram de osteotomia da sutura palatina mediana com a utilização de cinzel e martelo na região da sutura intermaxilar abaixo da espinha nasal anterior.

ZAHROWSKI \& TURLEY ${ }^{82}$, em 1992, avaliaram como a magnitude das forças produzidas durante a expansão maxilar afetariam as células osteoprogenitoras. Segundo estes autores, enquanto o tecido conectivo da sutura cicatriza através de uma resposta proliferativa, não se consegue obter um complexo maxilar estável enquanto existirem forças residuais que tendam ao colapso dos segmentos expandidos. Portanto, para estes autores, o período de contenção pós-expansão deve ser longo (até 6 meses), a fim de permitir a reorganização da sutura palatina mediana, minimizando as recidivas.

Estes autores instalaram aparelhos expansores em ratos, dividindo-os em grupos conforme o tempo de ativação do aparelho e a força aplicada ao mesmo. No grupo onde a força exercida foi de $100 \mathrm{~g}$, os autores 
obtiveram uma força de expansão otimizada com o máximo de estímulo de formação de células osteoprogenitoras e em seqüência neoformação óssea. No grupo onde a força aplicada foi de 200 g, não houve neoformação óssea, pelo fato de que as fibras colágenas entre os segmentos expandidos foram quebradas. Os autores concluem afirmando que forças excessivas podem atrapalhar o processo de neoformação óssea e reorganização da sutura palatina mediana.

MOSSAS, BYLOFF \& RICHTER ${ }^{56}$, em 1992, descreveram em seu artigo as expansões dentárias e esqueléticas dos pacientes submetidos a ERMAC, bem como as recidivas e as inclinações maxilares e dos primeiros molares durante a expansão maxilar. A amostra consistiu de 4 pacientes, onde ao aparelho expansor de Hyrax foi soldado um tubo para a colocação de marcadores radiográficos para o controle das inclinações. Os controles foram realizados ao final da expansão e 12 meses após o término da contenção, comparando-se dados obtidos no préoperatório. Nos 2 casos onde foram realizadas osteotomias bilaterais, a quantidade de expansão esquelética foi observada nos dois lados. As mudanças angulares dos primeiros molares mostraram um aumento de inclinação importante bilateralmente, que tende a amenizar-se durante o período de contenção e pós-contenção. Nos outros 2 casos, onde foi 
realizada osteotomia unilateral, o lado onde a intervenção foi realizada mostrou o dobro de expansão esquelética em comparação ao lado não operado. As inclinações dentárias também se mostraram 2 vezes mais acentuadas no lado operado em comparação ao lado não operado. Os autores concluíram que a estabilidade do procedimento é satisfatória em todos os casos.

BAYS \& GRECO ${ }^{9}$, em 1992, apresentaram o resultado de um controle de 2 anos em 30 pacientes submetidos a ERMAC. Os autores utilizaram uma técnica cirúrgica semelhante à descrita por BELL \& EPKER 10, com a modificação de não se realizar a osteotomia da sutura pterigomaxilar. Seus resultados mostraram uma taxa de recidiva próxima de 9\%, mostrando que este procedimento é estável com o passar do tempo.

CAPELOZZA FILHO e cols ${ }^{18}$, em 1994, relataram parte de sua experiência clínica com expansão rápida da maxila assistida cirurgicamente. Para estes autores, pacientes com idade superior a 30 anos, portadores de deficiência transversal maxilar devem ser submetidos à expansão rápida da maxila assistida cirurgicamente, enquanto que seus pacientes com idades inferiores aos 20 anos não necessitaram da realização da cirurgia, obtendo a expansão maxilar por meios ortopédicos convencionais. Para pacientes entre 20 e 30 anos, estes autores preconizam a 
tentativa de expansão rápida maxilar por meio de aparelhos ortodônticos convencionais e lançar mão do procedimento cirúrgico apenas nos casos em que haja falha da primeira tentativa. Para estes autores um ponto favorável da ERMAC é o conforto e a previsibilidade do tratamento, onde apesar da agressão cirúrgica inicial, o paciente executa a expansão maxilar sem dor. Foi destacado também neste trabalho, o uso de ERMAC em pacientes que tenham perda óssea vestibular na região posterior da maxila, o que inviabilizaria a expansão maxilar convencional.

SHETTY e cols ${ }^{67}$, em 1994, estudaram através de 3 modelos fotoelásticos as forças aplicadas pelo aparelho expansor de Hyrax e suas repercussões anatômicas quanto às áreas de maior estresse em uma ERMAC. Após cada registro das áreas de maior estresse, uma osteotomia era feita e em seguida novos registros destas áreas eram feitos. A seqüência de osteotomias foram,: lateral de maxila, sutura palatina mediana e sutura pterigomaxilar. Os padrões obtidos mostram que as forças produzidas pelo aparelho expansor de Hyrax têm profundos efeitos anatômicos, incluindo regiões distantes ao aparelho. Os autores concluíram que as osteotomias, da sutura palatina mediana e pterigomaxilar, são fundamentais para que o prognóstico do tratamento da ERMAC seja favorável em adultos. 
CAPELOZZA FILHO e cols ${ }^{19}$, em 1996, apud STUART $^{70}$, 2003, realizaram ERM em 38 pacientes adultos. Apesar do sucesso clínico do procedimento, os autores relatam que os pacientes tiveram uma experiência de dor intensa durante a ativação do aparelho expansor e 5 pacientes tiveram que ser submetidos à ERMAC.

\section{Segundo PROFFIT, TURVEY \& PHILLIPS ${ }^{61}$, em} 1996, a estabilidade e a predictibilidade dos procedimentos ortodônticocirúrgicos variam conforme a direção do movimento, tipo de fixação e a técnica cirúrgica empregada, nesta ordem de importância. Para estes autores o movimento mais estável é o reposicionamento superior da maxila, seguido de avanço mandibular, sendo que o método de fixação seja a interna semirígida e que a expansão lateral da maxila é o movimento mais instável e passível de recidivas. Entretanto, os autores concordam que a ERMAC é uma alternativa mais estável do que a osteotomia segmentada Le Fort I, apesar de que a real estabilidade comparativa destes dois procedimentos não tenha sido efetivamente realizada

BANNING e cols ${ }^{6}$, em 1996, concluíram que revisão da literatura sobre a ERMAC como forma de tratamento da deficiência transversal maxilar em pacientes adultos apresentam bons resultados. A experiência destes autores ao realizar a técnica proposta por BELL \& 
EPKER ${ }^{10}$, como o trabalho afirma ser um bom protocolo a ser seguido, enfatiza os bons resultados descritos pela literatura.

SILVERSTEIN \& QUINN ${ }^{68}$, em 1997, afirmam em seu trabalho que a ativação dos aparelhos expansores contra suturas fechadas e/ou fusionadas, podem levar ao paciente sensação de dor ou pressão, além de poder causar necrose da mucosa palatina conforme o tipo de aparelho expansor que está sendo utilizado. Estas forças podem também causar ao paciente defeitos periodontais graves à medida que os dentes são empurrados pela cortical vestibular, levando a recessões gengivais e defeitos ósseos.

BAILEY e cols ${ }^{5}$, em 1997, reportam em seu trabalho que 9,4\% da população norte-americana possuem mordida cruzada posterior em decorrência de atresia maxilar. PROFFIT e cols ${ }^{60}$, em 1990, reportam que $30 \%$ dos adultos que procuram tratamento para correção de deformidades dento-faciais possuem deficiência transversal maxilar. Entretanto, não existem trabalhos que mostrem quantos pacientes possuem apenas a deficiência transversal maxilar, sem outros comprometimentos verticais ou antero-posteriores. Contudo, para estes autores, está claro que este tipo de deficiência ocorre freqüentemente em pacientes com excesso vertical maxilar, não importando se o paciente é Classe II ou III. 
WOODS, WIESENFELD \& PROBERT ${ }^{79}$, em 1997, acreditam que a ERMAC deve ser indicada nos seguintes casos: (1) aumentar a largura do arco maxilar visando a correção da mordida cruzada posterior quando nenhum outro movimento cirúrgico do complexo maxilofacial está planejado; (2) para aumentar a largura do arco maxilar previamente à outras cirurgias ortognáticas, a fim de se evitar os riscos associados à multisegmentação maxilar, ou que a extensão da expansão seja superior a $8 \mathrm{~mm}$, o que inviabiliza a multisegmentação maxilar. Segundo estes autores a ERMAC é um tipo de distração osteogênica que minimiza os riscos de uma necrose isquêmica da maxila que pode ocorrer durante a multisegmentação maxilar.

VARDIMON e cols ${ }^{74}$, em 1998, avaliaram o padrão de ossificação da sutura palatina mediana em gatos submetidos à ERM. De acordo com estes autores, o tempo de contenção para obtenção da ossificação da região da pré-maxila é maior do que o tempo necessário para a ossificação da região posterior da maxila devido ao formato de "zíper aberto” (Figura 2.1) que a maxila toma após a expansão. Provavelmente, segundo os autores, esta deve ser uma das causas da maior taxa de recidiva da diminuição da distância intercanina quando comparada com a região de molares após a fase de contenção da ERM. 


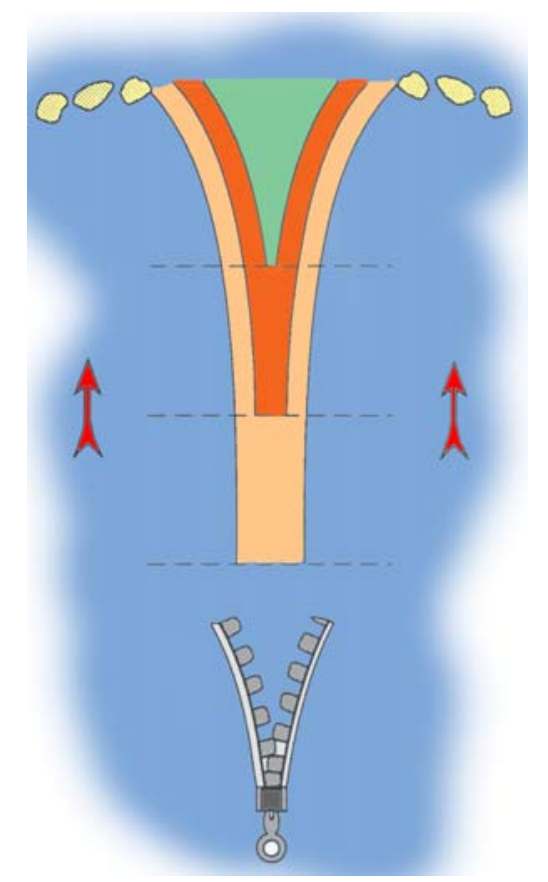

Figura 2.1 - Maxila aberta em forma de zíper aberto. As setas apontam o sentido da ossificação, começando de posterior para anterior.

BERGER e cols ${ }^{13}$, em 1998, avaliaram a estabilidade da ERM em pacientes dos 6 aos 12 anos e da ERMAC em pacientes com mais de 13 anos. Em ambos os grupos os procedimentos de expansão maxilar levaram a resultados estáveis e duradouros.

CURETON \& CUENIN ${ }^{25}$, em 1999, realizaram o primeiro estudo envolvendo alguns aspectos relevantes da expansão maxilar cirurgicamente assistida, até então ignorados. Este trabalho visou principalmente o enfoque do preparo ortodôntico prévio à ERMAC e as implicações clínicas envolvidas em cada passo. Primeiramente os autores mostraram a importância do grau de apinhamento entre incisivos superiores 
e sua relação com defeitos periodontais associados ao pós-operatório destes pacientes. Este tipo de condição clínica favorece a formação de fraturas chamadas assimétricas (Figura 2.3 B), onde a separação maxilar ocorre entre o osso e raiz de um dos incisivos centrais. Este tipo de separação também favorece a desinserção gengival entre incisivos centrais superiores, propiciando a formação de uma profunda bolsa periodontal. Conforme estes autores, se a resistência a separação da sutura intermaxilar entre os dois incisivos centrais superiores é maior do que a resistência da porção palatina e mesial do alvéolo dos incisivos centrais superiores, a fratura não ocorrerá simetricamente. Esta fratura será feita ao longo do caminho de menor resistência, o que ocorre com maior freqüência no incisivo central superior mais vestibularizado, que possui menos tecido ósseo protegendo a raiz. CURETON \& CUENIN ${ }^{25}$ ainda advogam que é imperativa a realização de uma radiografia periapical ou oclusal ao pós-operatório imediato a fim de que o tipo de fratura seja diagnosticado. A fratura simétrica é aquela que ocorre exatamente na sutura intermaxilar (Figura 2.3 A), existindo igual quantidade de osso na face mesial das raízes dos dois incisivos centrais superiores. Segundo estes autores existem 4 protocolos diferentes a serem seguidos de expansão conforme os parâmetros de saúde da gengiva inserida entre os incisivos centrais superiores e tipo de fratura ocorrida são 
combinados durante o diagnóstico; (1) para casos de fraturas simétricas com saúde gengival entre incisivos superiores, ativação diária do aparelho expansor com 4 ativações (1 mm); (2) fratura simétrica com desinserção da gengiva inserida entre os incisivos centrais superiores, aguardar a cicatrização gengival e em seguida ativação diária do aparelho expansor com 4 ativações diárias ( $1 \mathrm{~mm}$ ); (3) em casos de fratura assimétrica com saúde gengival entre os incisivos centrais superiores, 2 ativações do aparelho expansor $(0,5 \mathrm{~mm})$ com intervalo de 24 a 48 h para aproxima ativação; (4) na ocorrência de fratura assimétrica com desinserção da gengiva inserida entre os incisivos centrais, aguardar o restabelecimento da saúde gengival e 2 ativações do aparelho expansor (0,5 mm) com intervalo de 24 a 48 h para a próxima ativação. Os autores deste trabalham advogam que a prevenção deste problema se faz com movimentos ortodônticos dos incisivos centrais superiores buscando a divergência radicular previamente à realização da ERMAC (Figura 2.2). 


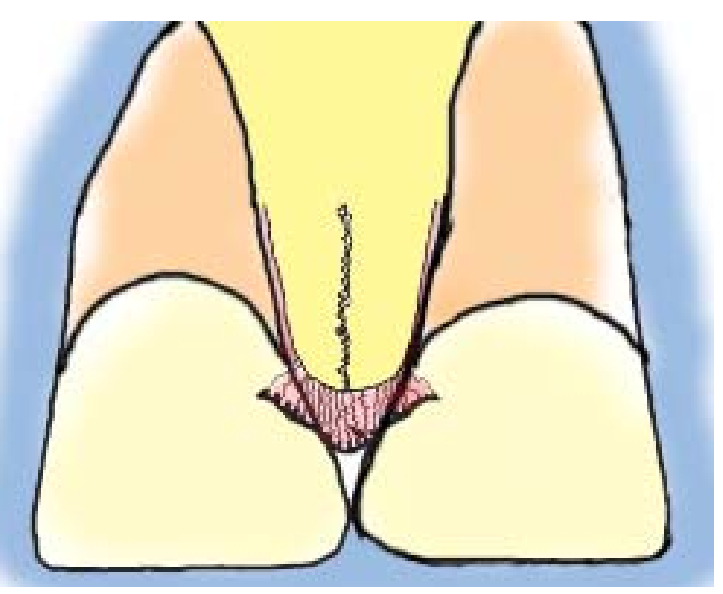

Figura 2.2 - Situação clínica inicial ideal, com a presença de divergência radicular.
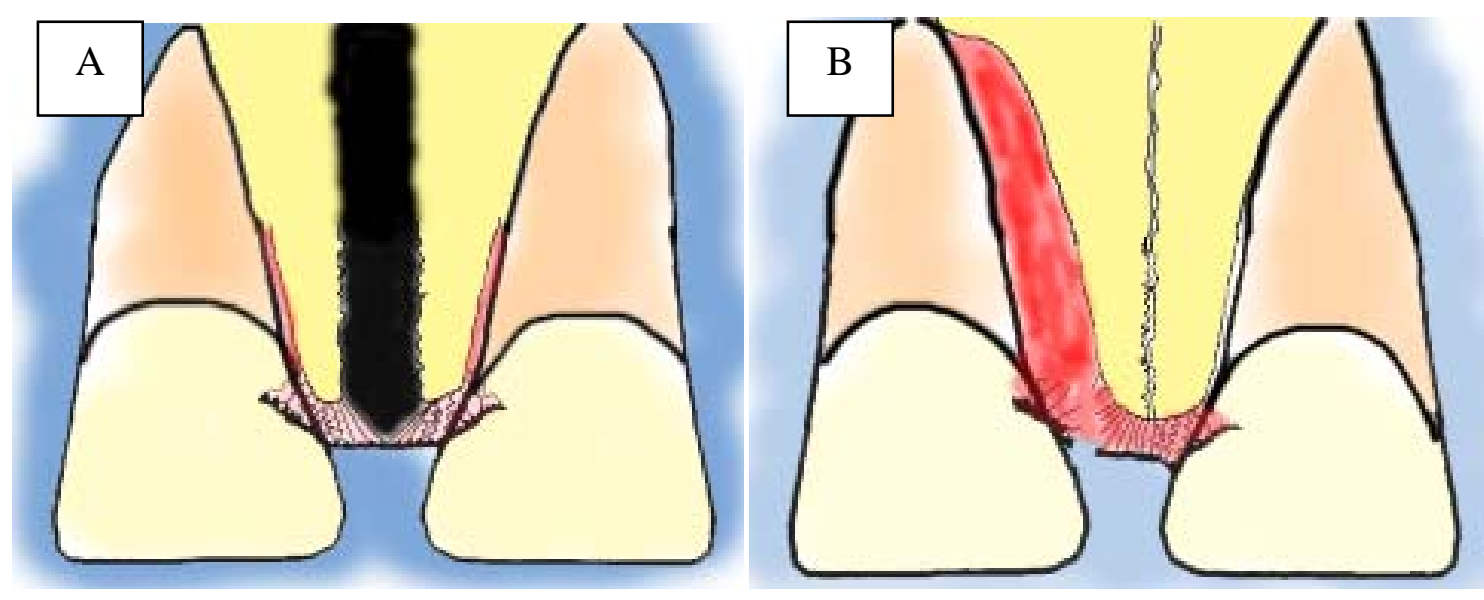

Figura 2.3 A e B - Esquema de uma fratura simétrica (A) e de uma fratura assimétrica (B).

BERGER e cols ${ }^{14}$, em 1999, avaliaram por meio de fotografia frontal mudanças faciais associadas à expansão maxilar, cirúrgica ou não, em pacientes adultos, por um período de 1 ano pós-tratamento. Os autores concluíram que o comprimento do lábio superior, lábio inferiormento, largura de terço facial superior e inferior e vermelhão labial superior e inferior mostram mudanças durante o período de observação (prétratamento, cimentação do aparelho expansor, pós-ativação, remoção de 
aparelho expansor e controle de 1 ano), mas não houve mudança estatisticamente significante entre o período inicial e o final. Somente a largura nasal (tecido mole) aumentou durante o período de tratamento (tanto no grupo cirúrgico quanto não cirúrgico), permanecendo estável ao longo de 1 ano.

SCHIMMING, R. e cols ${ }^{66}$, em 2000, citam em sua revisão de literatura que inicialmente a sutura palatina mediana era uma das áreas de resistência à expansão palatina em jovens adultos devido à sua ossificação. Outros estudos, como os de KENNEDY e cols ${ }^{43}$, em 1976, indicaram que a sutura zigomáticomaxilar é a área mais crítica no que se refere à resistência expansão maxilar.

CHUNG e cols ${ }^{22}$, em 2001, avaliaram os efeitos induzidos pela ERMAC verticalmente e sagitalmente. Após avaliarem as telerradiografias laterais pré-cirúrgicas e pós-expansão, os autores não encontraram diferenças significantes quanto ao deslocamento vertical da maxila. Concluíram que a ERMAC não afeta a maxila no sentido vertical. Entretanto, os autores encontraram uma tendência de um leve deslocamento maxilar para anterior e uma discreta retroinclinação dos incisivos centrais superiores sagitalmente. 
TAVARES \& SCHEFFER ${ }^{71}$, em 2001, afirmam em seu trabalho que a realização da ERMAC antes da cirurgia envolvendo a osteotomia Le Fort I é uma alternativa interessante nos casos onde exista uma deficiência transversal maxilar. Dentre as principais vantagens, os autores destacam a estabilidade do procedimento e a simplificação da cirurgia ortognática a ser feita depois.

$$
\text { MORGAN \& FRIDRICH }{ }^{55} \text {, em 2001, fazem uma }
$$
comparação dos efeitos da osteotomia Le Fort I multissegmentar da maxila sobre o periodonto. Estes autores concluíram que se a técnica é realizada corretamente, não existem ou são desprezíveis os efeitos sobre o periodonto nas regiões onde a osteotomia vertical é realizada. Porém estes autores também fazem uma abordagem sobre a expansão rápida da maxila assistida cirurgicamente. Neste trabalho os autores traçam com clareza as indicações tanto da ERMAC quanto da osteotomia Le Fort I multissegmentada da maxila (OLFMM). Dentre os fatores de indicação de cada técnica, os autores destacam a magnitude da deficiência transversal, a morfologia do arco dentário, as discrepâncias de largura do arco dentário, mordida aberta esquelética, inclinação dos incisivos centrais e estabilidade pós-operatória. Segundo estes autores, deficiências maiores do que $10 \mathrm{~mm}$ devem ser tratadas com ERMAC, enquanto que menores do que $10 \mathrm{~mm}$ podem ser 
razoavelmente corrigidas com a osteotomia Lê Fort I multissegmentar da maxila. Pacientes que tenham somente a deficiência transversal maxilar, sem nenhuma outra deformidade dentofacial, também devem ser tratados com a ERMAC, bem como pacientes que possuam o palato muito profundo e atrésico, mesmo que a magnitude da deficiência seja menor do que $10 \mathrm{~mm}$ e tenham outras deformidades dentofaciais. Isto se deve ao fator de que a mucosa palatina pode não suportar a quantidade necessária de expansão durante a osteotomia Lê Fort I multissegmentar da maxila.

Outro fator destacado neste trabalho são as osteotomias verticais, que se realizadas dentro de uma técnica específica não causam os transtornos periodontais relatados nos trabalhos revisados por estes autores. Para a realização desta técnica, os autores não fazem o rebatimento do retalho total até a papila interdental, fazem uma osteotomia monocortical por vestibular entre as raízes dos dentes onde a fratura vertical será realizada e em seguida colocam um cinzel nesta região fazendo a clivagem desta região até a cortical palatina.

WRIEDT e cols ${ }^{80}$, em 2001, analisaram 10 pacientes submetidos a ERMAC por meio de rinometria acústica, modelos de gesso e sonografia. Os autores concluíram que a ERMAC influenciou o aumento do volume das estruturas nasais e esqueléticas do terço médio da face. 
LANIGAN \& MINTZ ${ }^{48}$, em 2002, após revisão de literatura apresentam um caso de uma fratura anômala na base do esfenóide como conseqüência da ERMAC. Após a realização da cirurgia sob anestesia geral, o aparelho expansor foi ativado 8 vezes (2mm). No segundo dia pósoperatório o paciente queixou-se de visão borrada, e a movimentação ocular era quase inexistente. Após a realização de uma tomografia computadorizada, verificou-se a fratura do osso esfenóide. Foi diagnosticada, também, a paralisia do nervo óculomotor. O paciente foi medicado com dexametasona, e seus sintomas foram melhorando com o passar dos dias. Após 2 meses o quadro de oftalmoplegia regrediu completamente e após 10 meses o paciente foi submetido à cirurgia ortognática para avanço maxilar, sem complicações. Os autores atribuem esta fratura à ativação excessiva do aparelho expansor durante a cirurgia.

$$
\text { CONLEY e LEGAN }{ }^{24} \text {, em 2002, descrevem na }
$$
apresentação de um caso clínico de mordida aberta esquelética, associada a uma severa deficiência transversal maxilar, o uso de 2 técnicas cirúrgicas para a resolução do caso. Primeiramente, a paciente é submetida à expansão rápida da maxila assistida cirurgicamente, para, somente após a estabilização pós-operatória desta cirurgia e conclusão do tratamento ortodôntico précirúrgico, a osteotomia Le Fort I multissegmentar da maxila foi realizada. 
Com isto estes autores mostraram em um controle pós-operatório de 2 anos a estabilidade do caso.

BASCIFTCI e cols ${ }^{7}$, em 2002, analisaram se os tipos de expansão maxilar, ortopédica ou cirúrgica, alteram as dimensões nasais de maneiras diferentes. Os 30 pacientes deste trabalho foram divididos em 2 grupos, 15 pacientes a serem submetidos a ERM e 15 pacientes à ERMAC. Nos dois grupos, a área nasofaringeal (analisada por meio de telerradiografia P.A. e lateral) aumentou após a expansão maxilar, sem existir diferença significantemente estatística entre os dois grupos. Segundo estes autores isto ocorre devido ao fato de que conforme as estruturas maxilares são separadas, outras paredes da cavidade nasal também são movidas lateralmente, resultando neste aumento de volume intranasal.

CHUNG \& GOLDMAN ${ }^{23}$, em 2003, avaliaram as inclinações e rotações dentárias associadas à expansão rápida da maxila assistida cirurgicamente. Os autores concluíram que, apesar da remoção das áreas de reforço maxilar durante a cirurgia, incluindo a sutura palatina mediana, há uma inclinação média nos primeiros pré-molares de $6,5^{\circ}$ e nos primeiros molares de $7,0^{\circ}$, enquanto que existe também uma rotação de $8,3^{\circ}$ e 5,9 $9^{\circ}$ nos primeiros pré-molares e primeiros molares respectivamente. 
Portanto, estes autores sugerem que nos pacientes submetidos a ERMAC seja sempre feita uma sobrecorreção.

JAFARI, SHETTY \& KUMAR ${ }^{42}$, em 2003, ao realizarem um estudo, utilizando modelo finito, chegaram à conclusão de que uma das razões da ocorrência de sensações de pressão em várias regiões craniofaciais, relatada por pacientes submetidos à ERM ou ERMAC, pode ser relacionadas as áreas de maior concentração de forças encontradas neste estudo (processo pterigóide, corpo do osso esfenóide, processo zigomático da maxila e processo frontonasal).

MAO, WANG \& KOPHER ${ }^{52}$, em 2003, avaliaram as implicações clínicas da biomecânica presente no estímulo às suturas craniofaciais. Segundo estes autores, todos os dispositivos ortopédicos geram forças que são transmitidas ao tecido ósseo e suturas e que um dos parâmetros para se verificar se o estímulo biomecânico está correto é o crescimento da sutura.

STUART ${ }^{70}$, em 2003, apresenta um caso clínico de ERM em um paciente adulto que se recusou a realização de ERMAC. Após o paciente ser devidamente advertido, inclusive da possibilidade de realização da cirurgia, no caso de falha desta tentativa não cirúrgica, a ERM foi iniciada. Após o $24^{\circ}$ dia de ativação do aparelho expansor, o paciente 
apresentou-se com um diastema de 3mm, enquanto que o aparelho expansor tinha sido ativado $7 \mathrm{~mm}$.

BETTS, STURTZ e ALDRICH ${ }^{15}$, em 2004, descrevem em seu trabalho parâmetros para indicação cirúrgica de expansão maxilar. Os autores explicam que o correto diagnóstico de uma discrepância lateral maxilomandibular é difícil de ser obtido, pois estas discrepâncias podem mascarar outros tipos de deformidades dentofaciais. Logo, somente a inspeção clínica é insuficiente para a caracterização de uma deficiência transversal maxilar. O julgamento clínico para indicação de uma cirurgia de expansão maxilar, tanto ERMAC ou Osteotomia Le Fort I Multissegmentada da Maxila (OLFMM), começa com a determinação da severidade da discrepância e diferenciação entre deformidades esqueléticas das dentárias. Estes autores ainda mostram que as deficiências transversais maxilomandibulares se manifestam em 3 diferentes padrões, sendo o primeiro a maxila atrésica e a mandíbula normal, o segundo padrão com a mandíbula larga e maxila normal e o terceiro a maxila atrésica e mandíbula larga, esta última representando os maiores desafios de diagnóstico e tratamento. Os autores ainda mostram que seu parâmetro de eleição entre a ERMAC ou OLFMM se dá nos casos de discrepâncias de até $7 \mathrm{~mm}$. 
GILL e cols ${ }^{30}$, em 2004, fizeram uma breve revisão de todos os métodos de correção da deficiência transversal maxilar, bem como de suas indicações. Os autores concluíram que a expansão maxilar é indicada em uma variedade de situações clínicas e que o método a ser escolhido pelo cirurgião-dentista depende primariamente da natureza da mordida cruzada posterior (dentária ou esquelética), seguida pela idade do paciente e tamanho da discrepância.

KOUDSTALL e cols ${ }^{46}$, em 2005, fizeram uma extensa revisão de literatura envolvendo a expansão rápida da maxila assistida cirurgicamente. Dentre as indicações para a ERMAC os autores destacam a maturidade do esqueleto do paciente, a atresia maxilar, o apinhamento dos dentes anteriores superiores e a presença de um corredor bucal escuro quando o paciente sorri. Estes autores também fazem um relato aprofundado da evolução científica da expansão rápida da maxila e da expansão rápida da maxila assistida cirurgicamente, bem como das técnicas cirúrgicas envolvidas nesta última.

RAMIERI e cols ${ }^{63}$, em 2005, ao descreverem sua técnica com o uso de um disjuntor ancorado ao palato duro do paciente, citam como principais vantagens desta técnica a ausência de efeitos periodontais comuns a ERMAC com aparelhos expansores dento-suportados 
(inclinação e extrusão dentária onde o aparelho está ancorado). Dos 29 pacientes submetidos a este procedimento, o único efeito periodontal notado foi entre incisivos superiores de 4 pacientes, onde radiograficamente foi notado um defeito ósseo em uma das raízes devido à linha de fratura, mas não houve formação de bolsa periodontal durante o período de controle pósoperatório de 1 ano. Os autores preconizam cuidado durante a expansão e um dos parâmetros de cuidado é a saúde da gengiva marginal dos incisivos centrais superiores.

GERLACH \& ZAHL ${ }^{29}$, em 2005, relatam em seu trabalho que a ERMAC é um método eficiente para o tratamento de deficiência transversal maxilar em pacientes adultos. Para os autores, mesmo que a técnica cirúrgica apresente pouca morbidade com a utilização das técnicas mais convencionais e utilização de aparelhos expansores como Hass e Hyrax, estes procedimentos podem ser acompanhados de efeitos indesejados como inclinações ou extrusões dentárias, recessões gengivais, reabsorções radiculares ou fenestração óssea. Estas intercorrências se devem ao fato de que os aparelhos expansores estão ancorados aos dentes, transmitindo forças diretamente a eles ao invés de transmiti-las aos tecidos ósseos. Portanto, os autores preconizam o uso de um novo dispositivo de 
expansão palatina, fixado ao palato duro com parafusos através da mucosa palatina (Figuras 2.4 A, B e C).
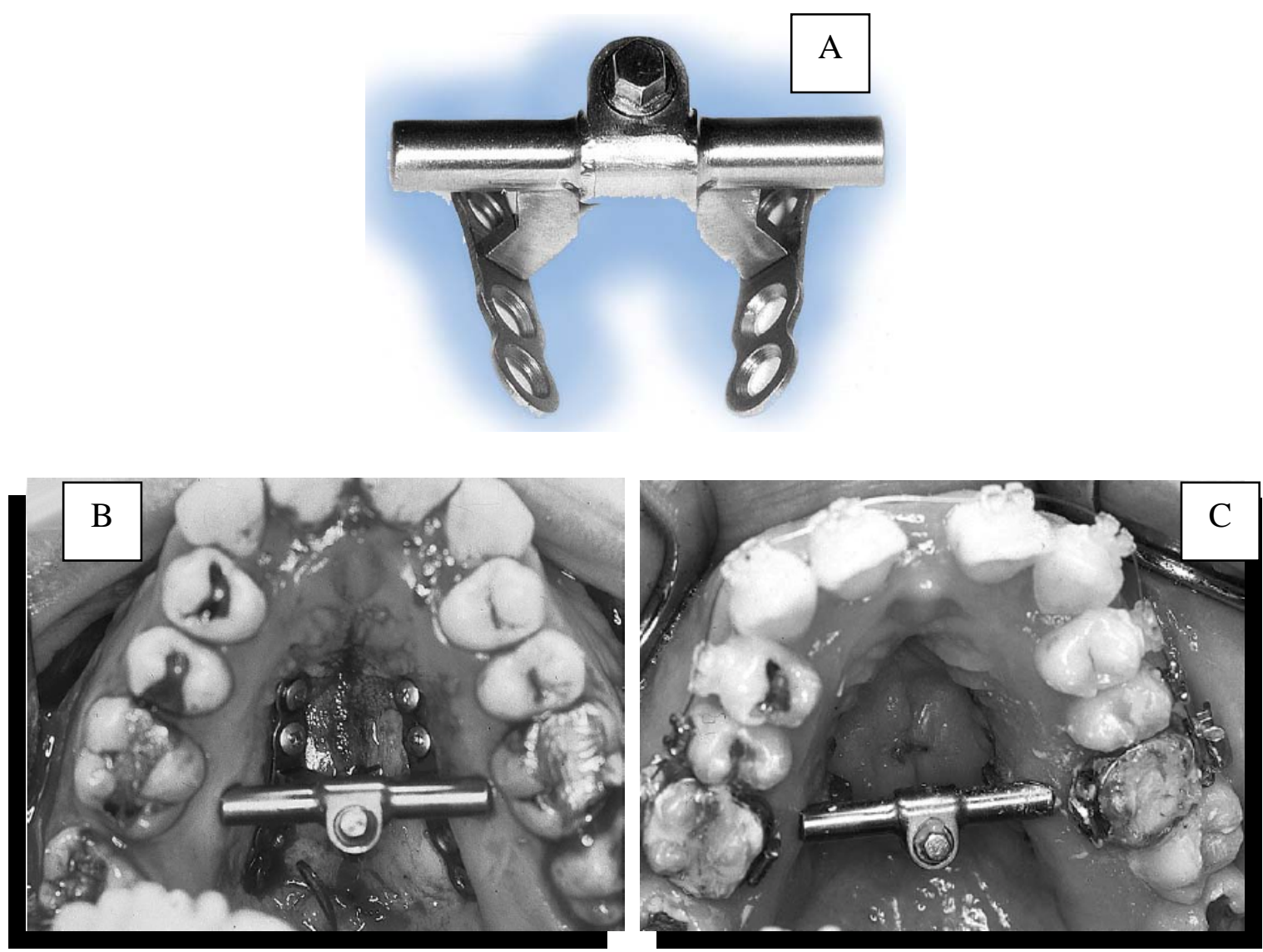

Figuras 2.4 A, B e C - Dispositivo utilizado na pesquisa de GERLACH \& ZAHL (A); após a instalação do aparelho no trans-operatório (B); após a expansão (C).

GERLACH \& ZAHL ${ }^{29}$, em 2005, ao utilizarem em seus pacientes um dispositivo ancorado diretamente ao palato duro, citam como principal vantagem a transmissão de forças ortopédicas diretamente ao osso ao invés dos dentes. Citam também a possibilidade de uma redução do tempo de tratamento destes pacientes, já que a terapia ortodôntica pode ser 
instituída concomitante ao período de contenção da expansão, pois a mesma não está relacionada com os dentes de suporte de um aparelho expansor.

MALMSTRÖM ${ }^{51}$, em 2005, avaliou a neoformação óssea na região da sutura palatina mediana, por meio de densidade óptica em radiografias oclusais digitalizadas, obtidas no pré-operatório e nos controles periódicos de pacientes adultos submetidos à ERMAC. A autora constatou que os valores de densidade óptica foram significantemente inferiores do que os valores iniciais, ao período de 120 dias de contenção fixa. A autora conclui que apesar de um aumento gradual da densidade óptica na região da sutura palatina mediana, não houve equiparação dos valores de pixel da fase final de contenção aos valores iniciais do pré-operatório.

GURGEL e cols ${ }^{33}$, em 2005, avaliaram a viabilidade e a confiabilidade do uso de marcadores metálicos para avaliação de posicionamento dentário em telerradiografias póstero-anteriores. Segundo os autores a ERM ou a ERMAC tem se mostrado um eficaz método para a correção da mordida cruzada posterior esquelética. Para eles, as osteotomias utilizadas na ERMAC tornam mais eficientes as forças geradas pelo aparelho expansor, pois estas aliviam as tensões geradas pelos pilares maxilares, liberando a sutura palatina mediana. Por meio desta conduta de tratamento, o efeito ortopédico torna-se preponderante, minimizando ao 
máximo os efeitos dentários indesejados, representados pelas inclinações dentárias. Porém, para estes autores, a falta de padronização das telerradiografias P.A. e a dificuldade de localização das estruturas anatômicas dificultam a observação dos efeitos promovidos por meio de aparelhos expansores. Foram utilizados 3 crânios secos com aparelhos expansores de Hyrax cimentados aos primeiros molares superiores e primeiros pré-molares. Braquetes ortodônticos foram soldados às bandas e marcadores metálicos foram confeccionados para cada braquete. Para cada crânio foram realizadas 3 telerradiografias póstero-anteriores e entre cada tomada radiográfica, os marcadores foram removidos e recolocados. Os crânios eram fixados ao aparelho com o uso de um cefalostato. Os autores concluem afirmando que o emprego dos marcadores proporcionam um método simplificado para melhor interpretar o comportamento dentário e esquelético frente ao uso de expansores maxilares e que este método pode ser empregado em estudos longitudinais dos efeitos da expansão maxilar em diferentes idades. 


\section{2 - Técnicas Cirúrgicas para Realização da Expansão}

\section{Rápida da Maxila Assistida Cirurgicamente.}

STAINHAUSER ${ }^{69}$, em 1972, descreveu uma técnica cirúrgica que consiste em uma incisão em fundo de vestíbulo do canino até a tuberosidade maxilar, rebatimento do retalho e exposição da maxila. Realização da osteotomia maxilar desde a chanfradura piriforme, passando pelo processo zigomático da maxila até a tuberosidade maxilar, preservandose a integridade da mucosa do seio maxilar. Uma incisão realizada no palato duro, desde a lateral da papila incisiva, seguindo pela sutura palatina mediana até a espinha nasal posterior. Rebatimento do retalho palatino de 3 a $4 \mathrm{~mm}$ de cada lado da incisão e duas osteotomias paralelas à sutura palatina mediana de forma que a maxila fique isolada do septo nasal e vômer. Realização de sutura e colocação de uma placa de Hawley por 3 semanas a fim de propiciar proteção à mucosa palatina que deve estar completamente cicatrizada para dar início às ativações do aparelho expansor. (Figura 2.5) 


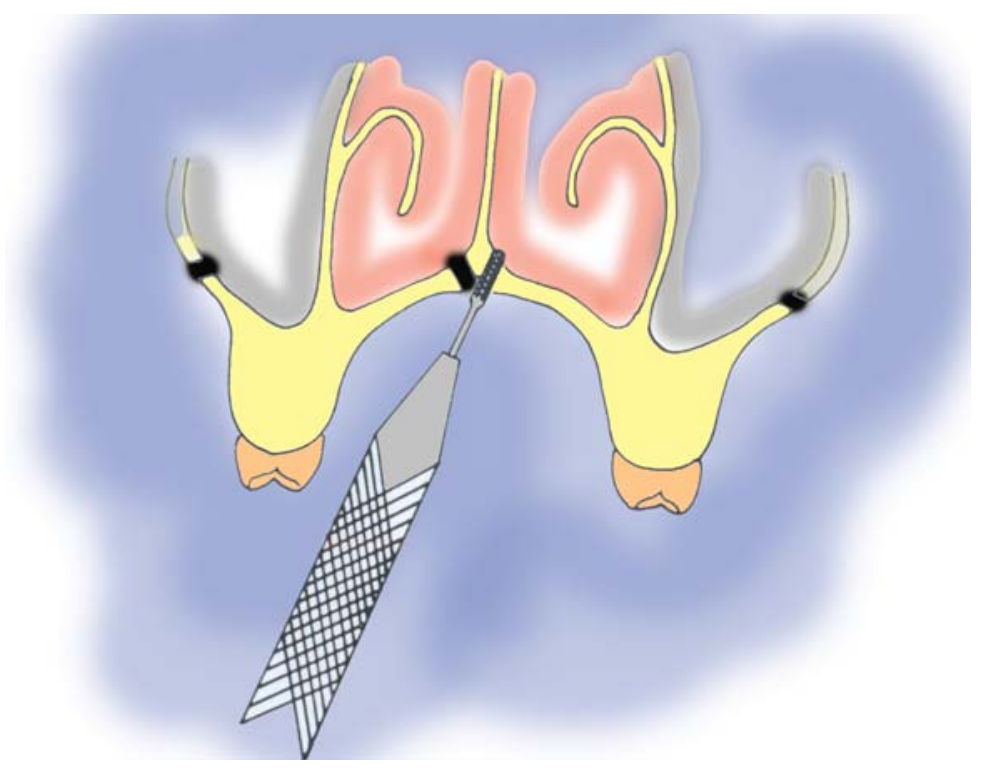

Figura 2.5 - Osteotomia do palato proposta por Stainhauser.

KENNEDY III e cols ${ }^{43}$, em 1976, afirmam que as várias combinações de osteotomias vêm sido utilizadas para facilitar a expansão da maxila em adultos. Entretanto as bases científicas de tais procedimentos permanecem obscuras e empíricas, pois não existem provas clínicas e laboratoriais do uso das osteotomias como facilitadores dos movimentos da expansão rápida da maxila.

BELL \& EPKER ${ }^{10}$, em 1976, descrevem uma das mais usadas técnicas de expansão rápida da maxila assistida cirurgicamente. Esta técnica consiste em incisão em fundo de vestíbulo de canino a segundo molar superior, rebatimento de retalho e realização de osteotomia com instrumento rotatório sob refrigeração com soro fisiológico da chanfradura piriforme até a tuberosidade maxilar. Colocação de um cinzel entre os 
incisivos superiores e realização da clivagem da crista alveolar e sutura palatina mediana com o auxílio de um martelo. Colocação de um cinzel na tuberosidade maxilar e separação do processo pterigóide da maxila. Após a separação da maxila é realizada a sutura e ativação do aparelho expansor previamente colocado à cirurgia. Sendo a ativação pós-operatória realizada 3 dias após a cirurgia com até 4 ativações diárias (Figura 2.6 A, B, C e D).
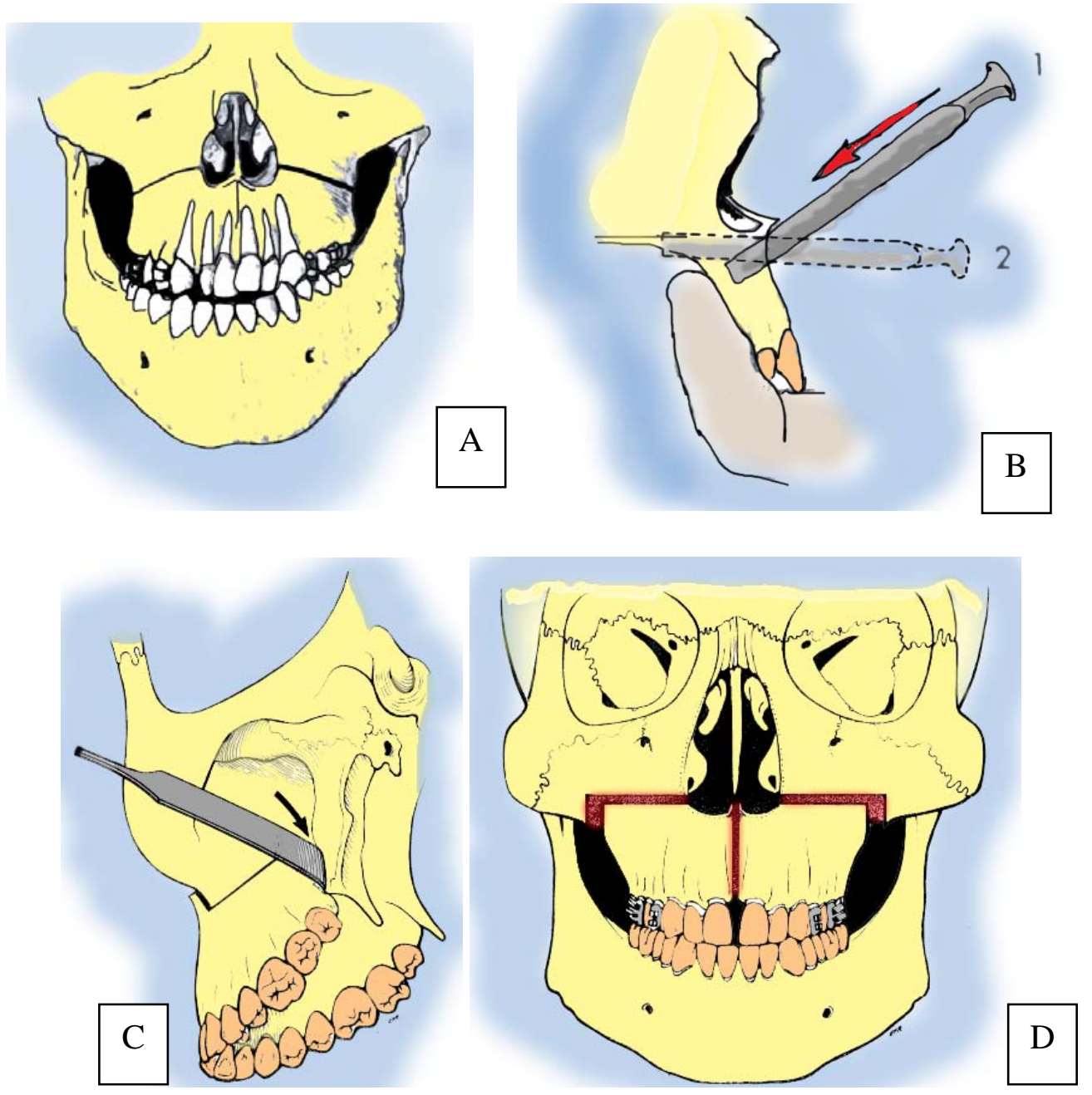
Figuras 2.6 A, B, C e D - (A) Osteotomia da parede lateral da maxila; (B) Clivagem da sutura palatina mediana e suas inclinações; (C) Separação da sutura pterigomaxilar; (D) Resultado final.

BELL \& JACOBS ${ }^{11}$, em 1979, descrevem uma modificação da técnica cirúrgica proposta por BELL \& EPKER ${ }^{10}$. Pela primeira vez na literatura um autor relata que a osteotomia lateral da maxila e a disjunção palatina podem ser realizadas sob anestesia local com pouca morbidade pós-operatória, ainda que todos seus pacientes sejam tratados sob anestesia geral. Estes autores relatam que, se a técnica de osteotomia da parede lateral maxilar tiver sido realizada dentro da técnica apropriada (desde a tuberosidade maxilar até a chanfradura piriforme), a disjunção da sutura pterigomaxilar é desnecessária. Com este procedimento, os autores afirmam que a expansão maxilar se dá com mínimo desconforto ou sensação de pressão nas áreas de articulação maxilares.

MESSER, BOLLINGER \& KELLER ${ }^{54}$, em 1979, adotaram pela primeira vez o nome de Osteotomia Sub-Total Le Fort I para os procedimentos de expansão rápida da maxila assistida cirurgicamente. A técnica consiste nos mesmos parâmetros já descritos por BELL \& EPKER ${ }^{10}$. GLASSMAN e cols ${ }^{31}$, em 1984, descrevem uma nova técnica, considerada conservativa à manipulação dos tecidos, passível de ser realizada com anestesia local. A técnica consiste na cimentação de um 
aparelho expansor do tipo Hyrax e realização de osteotomias laterais na maxila desde a tuberosidade maxilar à chanfradura piriforme. Após a conclusão da osteotomia o aparelho é ativado 4 vezes, sendo novamente ativado após 3 dias de pós-operatório com uma ativação pela manhã e outra à noite até alcançar a quantidade de expansão desejada. Em seguida o aparelho é mantido em posição por 12 semanas como contenção. Estes autores conseguiram sucesso em todos os casos, porém, em um dos pacientes houve avulsão do primeiro pré-molar superior correspondente ao local onde o aparelho expansor estava cimentado (Figura 2.7).

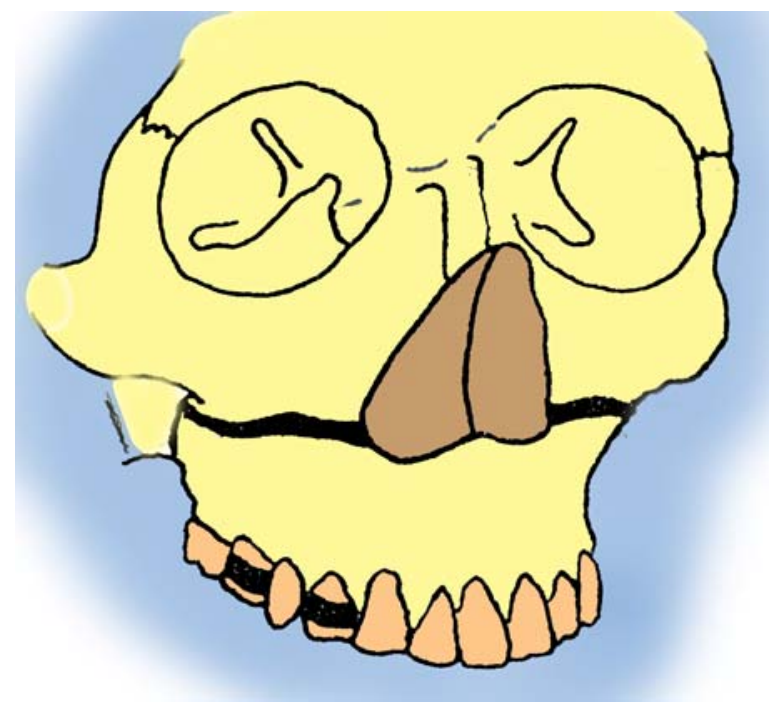

Figura 2.7 - Técnica proposta por Glassman.

SCHWARZ e cols ${ }^{65}$, em 1985, ao utilizarem a técnica proposta por BELL \& EPKER ${ }^{10}$, mostraram que a mesma não influencia a posição do septo nasal, mas que aumenta o espaço aéreo nasal. 
ALPERN \& YUROSKO ${ }^{1}$, em 1987, descreveram uma técnica cirúrgica onde a mudança se dá pelo uso de aparelhos expansores com blocos de mordida, com a justificativa de a oclusão não dificultar a expansão maxilar. Os autores trataram 25 pacientes com ERMAC, onde a técnica cirúrgica utilizada é a descrita por LEHMAN ${ }^{49}$ com a realização de clivagem da sutura palatina mediana.

LANIGAN, HEEY \& WEST ${ }^{47}$, em 1990, descrevem uma série de complicações pós-operatórias relacionadas às osteotomias maxilares, relatando 36 casos de necrose de alguma região maxilar. Os autores relatam que as seqüelas de uma deficiência vascular após a realização de alguma cirurgia ortognática podem variar desde a perda da vitalidade de um dente até a perda de um segmento maxilar. Ainda relatam que dos procedimentos envolvendo às osteotomias maxilares, a ERMAC é a que oferece menor riscos de seqüelas pós-operatórias, enquanto que, osteotomias maxilares multisegmentadas com finalidade de impacção posterior e expansão em um único tempo cirúrgico, são as que mais oferecem este tipo de risco. Os autores finalizam seu artigo com um guia aos cirurgiões de como evitar este tipo de seqüela pós-operatória. 
BELL 12, em 1992, descreve em seu livro uma modificação em sua técnica, onde a separação do processo pterigóide é considerado um passo opcional da cirurgia.

\section{MOSSAS, BYLOF \& RICHTER ${ }^{56}$, em 1992,} realizaram ERMAC em 4 pacientes. Em 2 pacientes, houve necessidade de apenas a realização de osteotomia unilateral, para a correção de mordida cruzada posterior unilateral, e nos outros 2 pacientes a osteotomia foi bilateral, para correção de mordida cruzada bilateral. As cirurgias foram realizadas sob anestesia geral, com osteotomias da parede lateral maxilar, osteotomia da sutura pterigomaxilar com o uso de cinzéis curvos e osteotomia da sutura palatina mediana com o uso de cinzel reto. Os pacientes foram submetidos ao mesmo regime de ativação do aparelho expansor (4 ativações no trans-operatório e uma ativação diária até a obtenção da expansão desejada).

\section{BASDRA, ZÖLLER \& KOMPOSCH ${ }^{8}$, em 1995,} descrevem uma técnica utilizada em 16 pacientes durante um período de 5 anos. A técnica consiste em uma incisão paramediana na mucosa palatina, a fim de se expor a sutura palatina mediana, que é separada com um corte de até 3mm de profundidade não chegando até o forame incisivo. Em seguida, dois cortes são feitos lateralmente na maxila apenas para enfraquecer o 
processo zigomático da maxila. Segundo os autores, após a realização das osteotomias, a maxila não está completamente separada, mas com o uso dos aparelhos expansores cimentados logo após a cirurgia, a expansão rápida é obtida. É preconizada para esta técnica uma sobrecorreção de 5mm, pois foi observada uma taxa de recidiva de 2 a $3 \mathrm{~mm}$ nos pacientes submetidos à cirurgia após o período de contenção, que neste caso, são de 3 meses (Figura 2.8 A e B).


Figura 2.8 A e B - Osteotomias propostas por BASDRA, ZÖLLER \& KOMPOSCH.

Osteotomia lateral da maxila restrita apenas ao processo zigomático da maxila (A); Osteotomia do palato, a linha contínua representa a incisão de mucosa e a pontilha a o local da osteotomia (B).

BANNING e cols ${ }^{6}$, em 1996, mostram sua experiência com a ERMAC ao utilizar este tipo de tratamento em 40 pacientes ao longo de 8 anos. Os autores utilizam a técnica proposta por BELL \& EPKER ${ }^{10}$, 
com algumas modificações. A técnica mostrada por este trabalho, além das osteotomias propostas por BELL \& EPKER ${ }^{10}$, os autores utilizam-se de um cinzel para a separação do osso nasal e vômer da sutura palatina mediana, além de utilizar um cinzel fino para osteotomizar a parede lateral nasal. Estes autores também realizam a ERMAC sob anestesia geral.

NORTHWAY \& MEADE ${ }^{57}$, em 1997, trataram 43 pacientes adultos com expansão rápida da maxila assistida cirurgicamente. Estes pacientes foram controlados com 5 pacientes adultos submetidos à expansão rápida da maxila, seguindo o protocolo proposto por HAAS ${ }^{35}$. O grupo dos pacientes submetidos à cirurgia foi dividido em 2 sub-grupos, um onde foi feita a corticotomia lateral da maxilar, seguida da clivagem com cinzel da sutura palatina mediana e outro grupo com a realização da corticotomia lateral da maxila e osteotomia do palato. Todos os pacientes foram submetidos à sedação e anestesia local. Com relação à estabilidade, resultados estatisticamente significantes foram obtidos ao comparar-se os grupos controle e tratamento cirúrgico. Nos pacientes submetidos à ERMAC, a quantidade de expansão obtida em região de molares e caninos foi maior do que nos pacientes submetidos à ERM, e, segundo opinião do autor, os pacientes submetidos à ERM resultou em um período prolongado de dor e desconforto, seguido de um aumento significante de recessões 
gengivais. Entre os dois sub-grupos da ERMAC, não houve diferença quanto a quantidade de expansão e estabilidade obtida, sendo que o autor não vê a necessidade da utilização da osteotomia do palato.

ROBIONY e cols ${ }^{64}$, em 1998, descrevem em seu artigo as vantagens da realização da anestesia troncular para bloqueio do nervo maxilar. Os autores descrevem que os pacientes submetidos a ERMAC, sob esta técnica anestésica, não tiveram nenhum tipo de desconforto, recomendando este bloqueio não só para a ERMAC, mas também para drenagens de seio maxilar, realização do acesso cirúrgico de Caldwell-Luc e septoplastia, sendo uma boa alternativa à anestesia geral.

MEHRA e cols ${ }^{53}$, em 1999, relataram um caso clínico de hemorragia tardia associada a ERMAC que colocou a vida do paciente em risco. Segundo estes autores hemorragias associadas às cirurgia maxilares não são freqüentes frente ao número de procedimentos feitos. O caso em questão mostra uma hemorragia oriunda da região posterior nasal. Provavelmente, a causa da hemorragia foi um trauma na artéria palatina descendente durante a separação do processo pterigóide da maxila com cinzel curvo. Segundo a revisão de literatura deste trabalho, a artéria palatina descendente é particularmente vulnerável durante a separação do processo pterigóide da maxila, ou durante a osteotomia da parede lateral do nariz em 
sua região mais posterior. Estes autores concluem afirmando que as ERMAC realizadas em consultórios devem ser realizadas sem osteotomia da parede lateral do nariz e separação do processo pterigóide da maxila.

SCHIMMING e cols ${ }^{66}$, em 2000, relataram o uso da técnica de Glassman em 21 pacientes adultos portadores de deficiência transversal maxilar, obtendo sucesso em 20 pacientes.

WILTFANG \& KESSLER ${ }^{77}$, em 2002, descrevem uma técnica cirúrgica, considerada por eles, atraumática com a utilização de um endoscópio no interior do seio maxilar (Figura 2.9). A cirurgia é realizada sob anestesia geral e, após a inserção de um endoscópio no interior do seio maxilar, a osteotomia da parede lateral da maxila é realizada com a utilização de cinzéis curvos e retos. Em seguida é realizada a clivagem da sutura palatina mediana com a utilização de um cinzel e martelo colocados na sutura intermaxilar entre os incisivos centrais superiores. O dispositivo utilizado por estes autores é um distrator osteogênico, instalado nas paredes nasais e maxilares. Segundo os autores, a cirurgia demora cerca de 90 minutos para sua execução e a amostra deste trabalho foi de 4 cadáveres e 3 pacientes. 


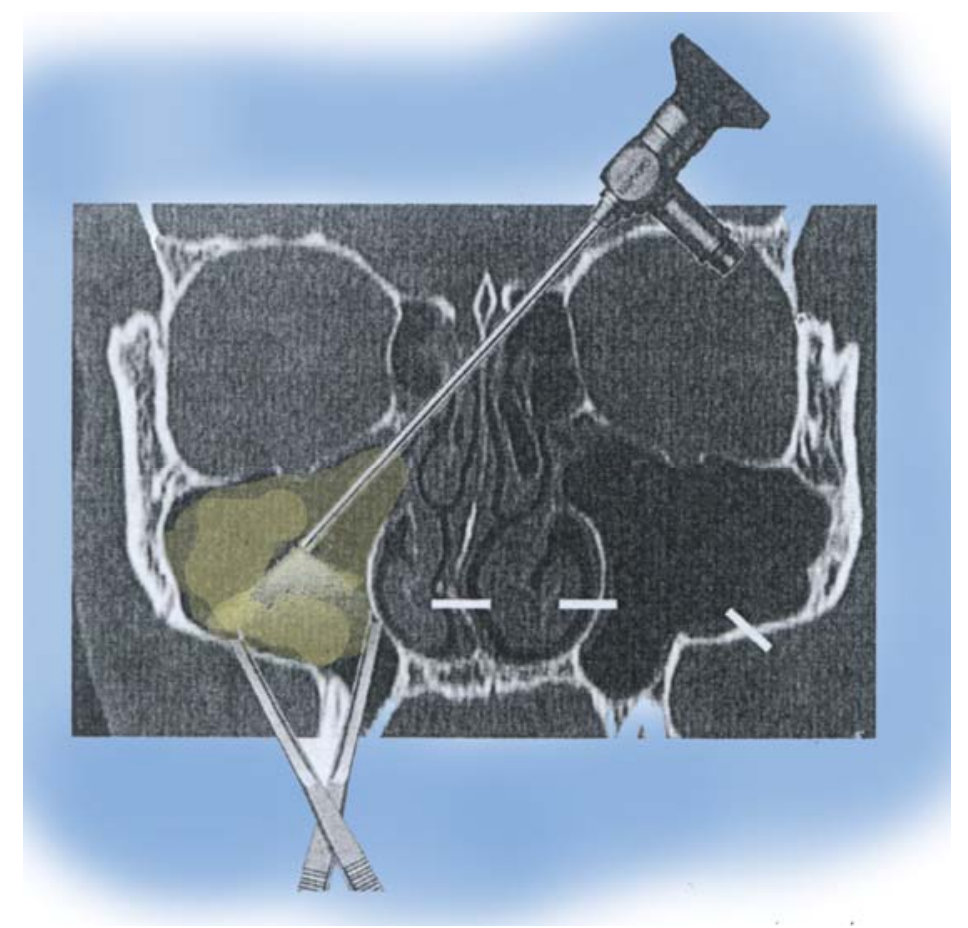

Figura 2.9 - Exemplo da técnica utilizando-se de endoscópio para a realização das osteotomias maxilares.

WOLFORD, RIECHE-FISCHEL \& MEHRA ${ }^{78}$, em 2002, avaliaram 311 pacientes submetidos à cirurgia maxilar, onde foi utilizada a incisão para-sagital da mucosa palatina para realização de osteotomia no palato a fim de se facilitar a expansão maxilar. Estes autores utilizavam blocos de hidroxiapatita nos locais onde o "gap" formado pela osteotomia era muito grande. Dos 311 pacientes avaliados, somente 18 tiveram algum tipo de complicação associada a esta incisão. 9 pacientes tiveram problemas com os blocos de hidroxiapatita, sendo que em 3, após antibioticoterapia, houve remissão do quadro e 6 tiveram que ser removidos 
cirurgicamente. 8 pacientes tiveram comunicação buco-nasal, onde 4 tiveram que ser submetidos a nova cirurgia para fechamento desta comunicação e 1 paciente teve complicação com um fio de aço fixado ao palato, que necessitou de remoção cirúrgica. Segundo estes autores, a incisão parasagital mediana é um procedimento seguro que deve ser utilizado com associação de blocos de hidroxiapatita nas técnicas de expansão maxilar.

YOKOO e cols ${ }^{81}$, em 2002, avaliaram as indicações de osteotomias segmentares da maxila para a resolução de várias deformidades dentofaciais. Os autores recomendam estas osteotomias em casos onde o paciente não possua recursos financeiros para o tratamento ortodôntico prévio à cirurgia ortognática. Para a resolução de deficiências transversais maxilares, os autores recomendam a osteotomia segmentada posterior a fim de se expandir os cotos osteotomizados, desde que a quantidade de expansão seja inferior a $5 \mathrm{~mm}$.

ANTTILA e cols ${ }^{4}$, em 2004, utilizaram a técnica de GLASSMAN ${ }^{31}$, em 20 pacientes realizando controle pós-operatório após o término da expansão e após a finalização do tratamento ortodôntico. Apesar de conseguirem expansão adequada em todos os pacientes, foi notada recidiva acima do normal, de até $9 \%$ segundo BAYS \& GRECO ${ }^{9}$, na distância intercanina e intermolar quando comparados os modelos de gesso 
dos pacientes ao final da expansão e ao final do tratamento ortodôntico (em alguns casos de mais de 40\%). Porém, esta recidiva não foi suficiente para comprometer o tratamento dos pacientes, pois, estas distâncias eram muito superiores se comparados com os valores pré-operatórios.

$$
\text { RACHMIEL, ALZENBUD e PELED }{ }^{62} \text {, em 2005, }
$$
utilizaram um dispositivo, colocado no trans-operatório após a confecção de uma osteotomia Le Fort I, em 12 pacientes. Neste trabalho, os autores utilizaram a distração osteogênica para realizar o avanço da maxila, mas consideram possível uma adaptação deste procedimento para o tratamento de deficiências transversais, concomitante ao avanço maxilar. Após 2 anos da realização da cirurgia os autores controlaram seus pacientes clínica e radiograficamente, mostrando resultados estáveis neste período.

RAMIERI e cols ${ }^{63}$, em 2005, descreveram uma técnica onde um disjuntor palatino ancorado esqueleticamente foi utilizado em 29 pacientes. Os pacientes foram submetidos a este procedimento sob anestesia geral, e após a realização da osteotomia Le Fort I e clivagem da sutura palatina mediana com o uso de um cinzel, o dispositivo era colocado no palato do paciente, preso por 4 parafusos de $7 \mathrm{~mm}$. Uma semana após a cirurgia o dispositivo era ativado $0,33 \mathrm{~mm}$ por dia durante 2 dias, 
aumentando para $0,66 \mathrm{~mm}$ a partir do $3^{\circ}$ dia até a obtenção da expansão desejada.

CHUAH \& MEHRA ${ }^{21}$, em 2005, descrevem uma complicação pós-operatória incomum relacionada à ERMAC. Um paciente desenvolveu parestesia bilateral do nervo lingual após a realização da ERMAC. Uma das causas associadas a esta complicação se deve, provavelmente, ao fato do paciente possuir alguma variação anatômica do percurso do nervo lingual passando pela fossa pterigomaxilar, que foi comprimida pela formação de um hematoma pós-operatório, já que houve uma hemorragia nesta região no trans-operatório. A hipótese de ter ocorrido devido à entubação naso-oro-traqueal foi descartada pelo fato de que a parestesia ocorreu 3 dias após o início da ativação do aparelho expansor. Após 87 dias o quadro de parestesia desapareceu. 


\section{3 - Escalas Analíticas de Dor.}

HUSKISSON ${ }^{38}$, em 1974, considera que a escala visual análoga de intensidade de dor é o meio que possui maior sensibilidade quando comparado com os outros métodos de análise de intensidade de dor dos pacientes.

GRACELY e cols ${ }^{32}$, em 1978, as escalas de medida de dor se dividem em dois grandes grupos: as de intensidade ou de desconforto. Ao utilizar-se de modalidades cruzadas, a escala numérica pode refletir tanto um tipo quanto outro, sendo para estes autores a escala numérica a mais confiável.

KREMER, ATKINSON \& IGNELZI ${ }^{45}$, em 1981, aplicaram em seus pacientes portadores de dores crônicas 3 métodos de aferição de intensidade dor: a escala visual análoga, a visual numérica e a adjetiva. Em seguida as escalas foram ranqueadas conforme as que melhores expressavam a intensidade de dor do paciente. Houve correlação significantemente estatística nas 3 escalas aplicadas aos pacientes. Os 
autores concluíram que a preferência de adoção por alguma destas escalas de intensidade de dor não influencia o relato do paciente, embora, acreditem que em alguns casos a escala numérica possa medir melhor a intensidade da dor do paciente. 


\section{3 - PROPOSIÇÃO}

O presente trabalho tem como finalidade avaliar, sob os mesmos parâmetros, as técnicas de expansão rápida da maxila assistida cirurgicamente descritas por BELL ${ }^{12}$ e GLASSMAN ${ }^{31}$ quanto:

1. A eficácia da técnica cirúrgica bem como a incidência de fraturas simétricas e assimétricas na crista alveolar entre os incisivos centrais superiores.

2. Dor trans e pós-operatória, causada pela cirurgia.

3. Dor causada pela ativação do aparelho expansor.

4. Edema causado pela cirurgia. 


\section{4-MATERIAL E MÉTODOS}




\section{4 - MATERIAL E MÉTODOS}

\section{1 - MATERIAL}

\subsection{1 - Amostra}

A amostra utilizada neste trabalho foi de 24 pacientes adultos, portadores de deficiência transversal maxilar com indicação para expansão rápida da maxila assistida cirurgicamente.

\subsection{2 - Radiografias oclusais de maxila}

As radiografias oclusais foram realizadas com filmes radiográficos oclusais Insight ${ }^{\circledR}$ da $\operatorname{Kodak}^{\circledR}$, do grupo $\mathrm{E} / \mathrm{F}$ de sensibilidade, utilizando-se aparelho de raios X odontológico de $10 \mathrm{~mA}$ e 70 kV, fabricado pela General Eletric ${ }^{\circledR}$ (USA). 
Estas radiografias foram realizadas de acordo com a técnica oclusal total de maxila, por um mesmo operador, estando o filme posicionado com seu longo eixo perpendicularmente ao plano sagital mediano e paralelo ao solo, estando a maxila centralizada na área do filme. O filme foi mantido em posição pela própria oclusão do paciente. Os ângulos verticais e horizontais para a realização da tomada radiográfica serão de $65^{\circ}$ e $0^{\circ}$, respectivamente, com o ponto de incidência dos raios X na glabela. O tempo de exposição foi de 0,5 segundos, de acordo com as especificações relativas ao aparelho e filmes utilizados.

O processamento dos filmes foi realizado manualmente em câmara escura equipada com filtro de segurança GBX-2® da $\operatorname{Kodak}^{\circledR}$, pelo método temperatura/tempo, sendo o tempo de revelação determinado após verificação da temperatura das soluções com um termômetro de imersão, graduado na escala Celsius. Para o processamento químico dos filmes foram utilizadas soluções reveladoras e fixadoras GBX® da $\operatorname{Kodak}^{\circledR}$, trocadas com periodicidade de 7 dias. Este processamento também foi feito por apenas um operador.

Após o processamento os filmes foram colocados em uma secadora até que estivessem completamente secos para o seu correto arquivamento. Estas radiografias foram, em todos os casos, processadas na 
clínica de Radiologia da FOB-USP, seguindo-se as normas de biossegurança e radioproteção preconizadas por esta disciplina.

\subsection{3 - Fichas dos pacientes}

Para esta pesquisa, uma ficha de acompanhamento formulada pela disciplina de Cirurgia da FOB-USP foi utilizada para acompanhamento destes pacientes, sendo que apenas o item correspondente ao tipo de fratura da crista alveolar foi utilizado (Anexo 1).

Foi elaborado, apenas para esta pesquisa, um questionário simples (Anexo 2) de escala numérica de avaliação de dor ${ }^{32,38 \text { e }}$ ${ }^{45}$, com a avaliação do paciente variando de 0 a 10 , sendo adotados os seguintes parâmetros:

- 0 a 2,5 - Procedimento confortável, sem dor ou com ausência de edema.

- 2,6 a 5,0 - Procedimento sem dor, tolerável, ou com pouco edema.

- 5,1 a 7,5 - Procedimento desconfortável, dolorido ou com edema moderado.

- 7,6 a 10 - Procedimento insuportável, muita dor ou muito edema. 
Estes parâmetros eram explicados ao paciente antes da realização das perguntas.

O questionário constava de 4 perguntas, sendo que a primeira pergunta era repetida ao primeiro controle pós-operatório.

As perguntas do questionário são as seguintes:

1. Como você classificaria o desconforto de sua cirurgia?

2. Como você classificaria o desconforto durante a ativação do aparelho?

3. Como você classificaria a sua dor no pósoperatório?

4. Como você classificaria seu edema no pósoperatório?

\subsection{4-Material para cirurgia}

Para a realização da cirurgia, foi utilizado o seguinte material (Figura 4.1 A e B):

4.1.4.1 - Equipamento:

- 1 caneta cirúrgica multiplicadora.

- 1 micromotor com irrigação própria. 
4.1.4.2 - Instrumental:

- Seringa carpulle

- Um cabo de bisturi n. 3

- Um descolador de Molt

- Uma espátula n. 7

- Broca n. 702 para peça reta.

- 1 Cinzel reto de Wagner

- 1 afastador de Obwegeser para rama

- 2 afastadores de Minessota

- 1 martelo cirúrgico

- 2 pinças hemostáticas tipo mosquito.

- 1 porta agulha Mayo-Hegar $14 \mathrm{~cm}$

- 1 tesoura de ponta fina

- 1 pinça Dietritch de $18 \mathrm{~cm}$

- 1 pinça tipo Allis

4.1.4.3 - Material de Consumo:

- Agulha curta para anestesia 
- 7 tubetes de Cloridrato de articaína 4\% 1:100.000.

- 2 lâminas de bisturi 15 ou 15-C

- 1 bisnaga de $500 \mathrm{~mL}$ de soro fisiológico.

- 20 gazes estéreis

- 1 fio de sutura Vicryl ${ }^{\circledR}$ 4-0 de $70 \mathrm{~cm}$

- Um sugador cirúrgico descartável
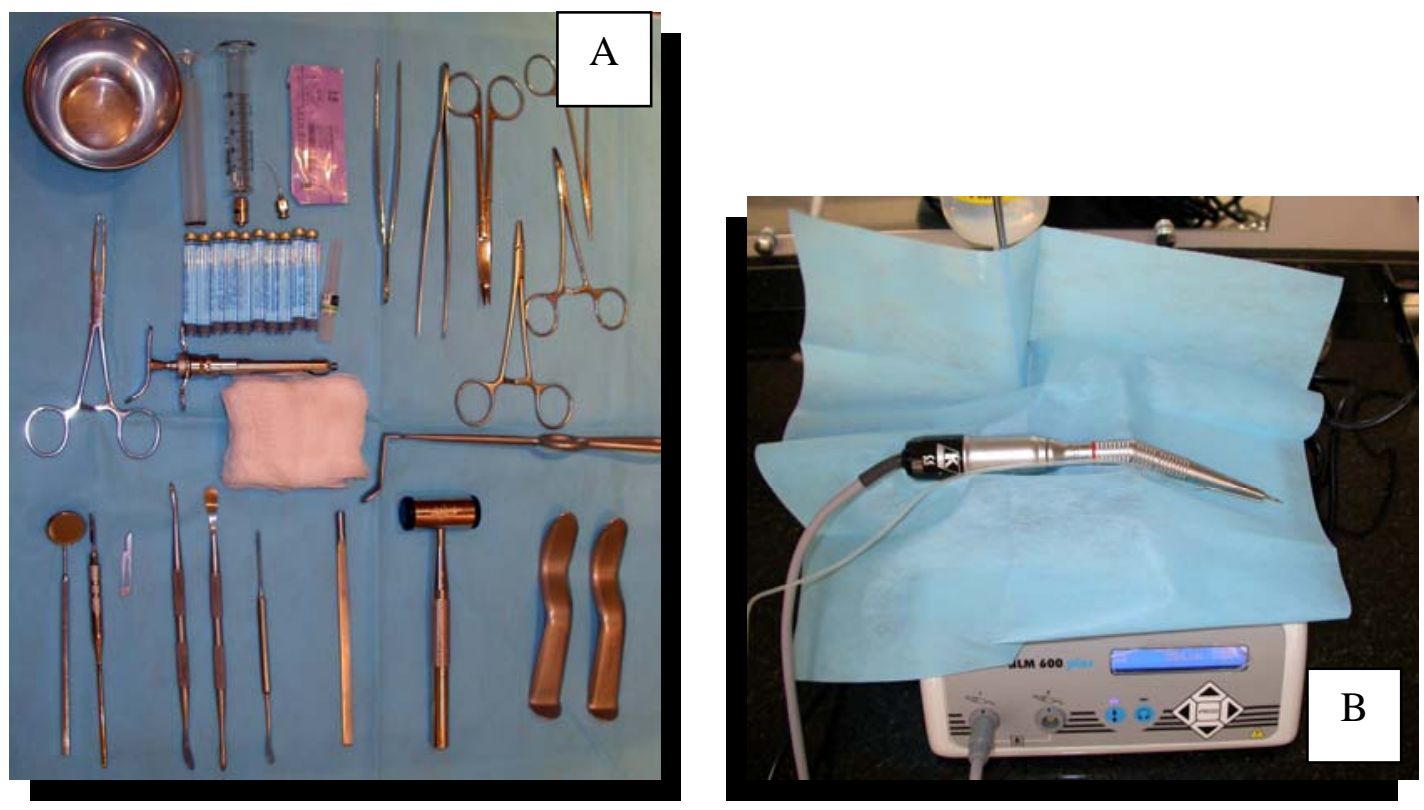

Figura 4.1 A e B - Material utilizado na cirurgia (A). Ponta cirúrgica e motor elétrico utilizado para a realização das osteotomias (B). 


\section{2 - MÉTODOS}

\subsection{1 - Exame e seleção dos pacientes}

Os 24 pacientes adultos com indicação para expansão rápida da maxila cirurgicamente assistida, foram divididos, aleatoriamente, em dois grupos (I e II), sendo que, os pacientes do grupo I, composto por 14 pacientes, foram submetidos à técnica cirúrgica proposta por BELL ${ }^{12}$, e o grupo II, composto por 10 pacientes, pela técnica proposta por GLASSMAN ${ }^{31}$, ambos sob analgesia local. Este número da amostra ,bem como a divisão desigual entre os grupos, será justificado na discussão do presente trabalho.

Ao exame clínico o paciente trouxe a documentação ortodôntica inicial, composta de radiografias, fotos e um par de modelos de gesso.

Durante o exame radiográfico, avaliou-se o grau das discrepâncias esqueléticas nas telerradiografias P.A e perfil, sendo complementada por meio dos modelos de gesso e de manipulação mandibular a fim de se obter oclusão de relação cêntrica.

Os pacientes selecionados são aqueles que se enquadram nas três possibilidade abaixo descritas: 
- Possuem exclusivamente deficiência

transversal maxilar e a expansão maxilar cirurgicamente assistida é suficiente para a correção do caso.

- Possuem deficiência transversal maxilar superior a $7 \mathrm{~mm}$, e que necessite de expansão rápida da maxila assistida cirurgicamente, antecedendo às outras correções de deformidades dentofaciais.

Os pacientes selecionados fizeram a leitura da CARTA DE INFORMAÇÃO AO PACIENTE (Anexo 3) e assinaram o TERMO DE CONSENTIMENTO LIVRE E ESCLARECIDO (Anexo 4), obedecendo as normas da Comissão de Ética em Pesquisa da FOB-USP.

Em seguida foi feita uma carta ao ortodontista responsável pelo caso, solicitando a instalação de um aparelho expansor do tipo Hyrax. O paciente também recebeu uma requisição para exames laboratoriais (hemograma completo, coagulograma completo e glicemia em jejum), e para uma avaliação cardiológica.

Os pacientes portadores de alterações nestes exames tiveram suas cirurgias reagendadas após tratamento médico e estado geral de saúde favorável. 


\subsection{2 - Instalação do aparelho expansor}

Para esta pesquisa, foram utilizados aparelhos expansores dentossuportados do tipo Hyrax, com capacidade para $7 \mathrm{~mm}$ de expansão, confeccionados e instalados de acordo com as especificações contidas em um protocolo estabelecido pela Disciplina de Cirurgia da FOBUSP (Anexo 5). Este protocolo foi adotado de forma a favorecer a padronização da amostra, sendo que, este protocolo fora encaminhado previamente a todos os profissionais interessados em encaminhar à FOBUSP os seus pacientes com indicação de expansão rápida da maxila assistida cirurgicamente. Este protocolo contém a descrição dos critérios de confecção e instalação dos aparelhos expansores. A cimentação destes aparelhos foi realizada pelos ortodontistas, sendo que previamente à cirurgia é feita uma verificação da efetividade desta cimentação (Figura 4.2).

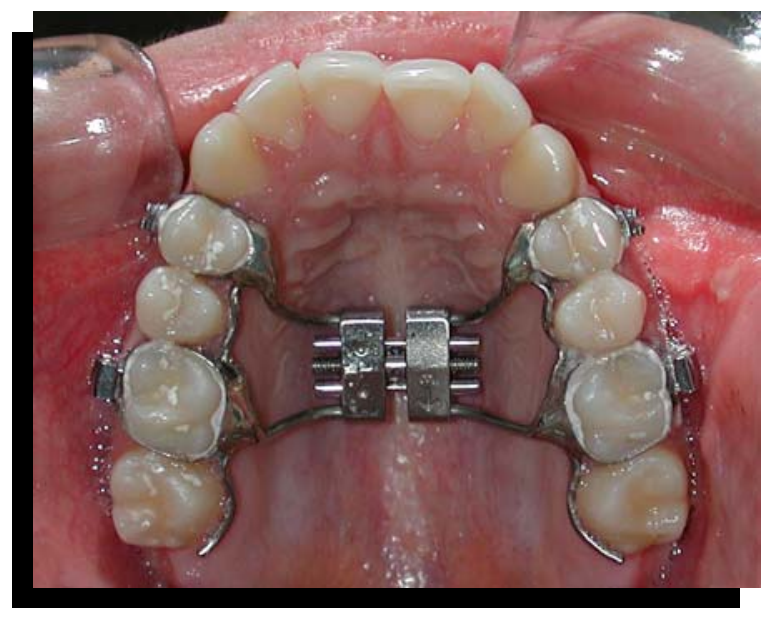

Figura 4.2 - Aparelho Expansor tipo Hyrax instalado antes da realização da cirurgia. 


\section{$\underline{4.2 .3 \text { - Procedimento cirúrgico }}$}

As cirurgias foram realizadas por 2 cirurgiões calibrados, sob a supervisão de um professor da Disciplina de Cirurgia da FOB-USP, seguindo-se os preceitos de biossegurança propostos para procedimentos críticos.

\subsubsection{1 - Grupo I (técnica de BELL ${ }^{12}$ ):}

Após a montagem da mesa cirúrgica, foi realizada a anti-sepsia do paciente com solução tópica de clorexidina e colocação dos campos cirúrgicos sobre o paciente.

Na seqüência foram realizados todos os bloqueios regionais maxilares, bilateralmente, utilizando-se Cloridrato de Articaína 4\% com adrenalina 1:100.000. Em seguida, anestesias infiltrativas terminais subperiósticas eram realizadas na região que compreende a parede anterior do seio maxilar, linha média e processo zigomático da maxila.

Após a analgesia, foi feita a primeira incisão em fundo de sulco vestibular, estendendo-se da região de primeiro molar a incisivo lateral (Figura 4.3 A). Em seguida foi feito o rebatimento do retalho e colocação do afastador de Obwegeser para rama na tuberosidade maxilar, possibilitando o acesso cirúrgico e proteção dos tecidos adjacentes à região. Este retalho foi rebatido de tal forma que fosse possível visualizar a 
chanfradura piriforme, onde, uma espátula n.7 é colocada entre o osso e a mucosa nasal a fim de proteger esta última no momento da osteotomia. (Figuras 4.3 B, C e D)



Figuras 4.3 A, B, C e D - Incisão, rebatimento do retalho e exposição da área a ser osteotomizada.

Após a exposição da área a ser osteotomizada, com a utilização de uma broca n. 702 sob baixa rotação e intensa irrigação de soro fisiológico, foi feita a osteotomia sub-total tipo Le Fort I, 
compreendendo desde a tuberosidade da maxila até a chanfradura piriforme, a uma altura de $5 \mathrm{~mm}$ do ápice dos dentes (Figura 4.4).

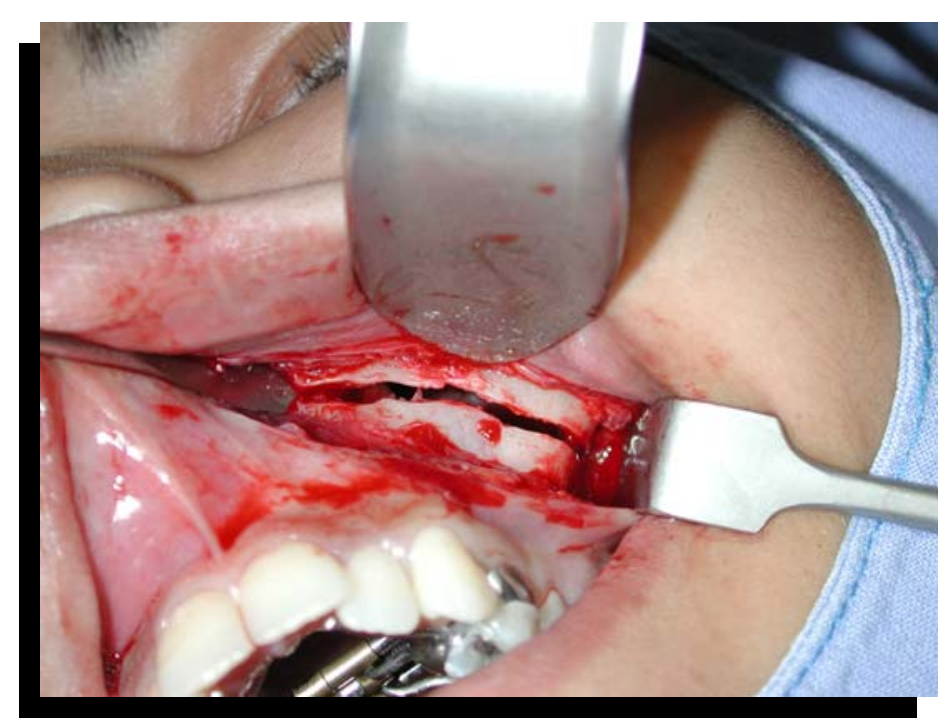

Figura 4.4 - Osteotomia Sub-Total Le Fort I realizada.

Após a realização desta osteotomia, uma gaze embebida em soro fisiológico foi colocada no local, sendo todo o procedimento realizado da mesma forma do lado oposto (Figura 4.5).

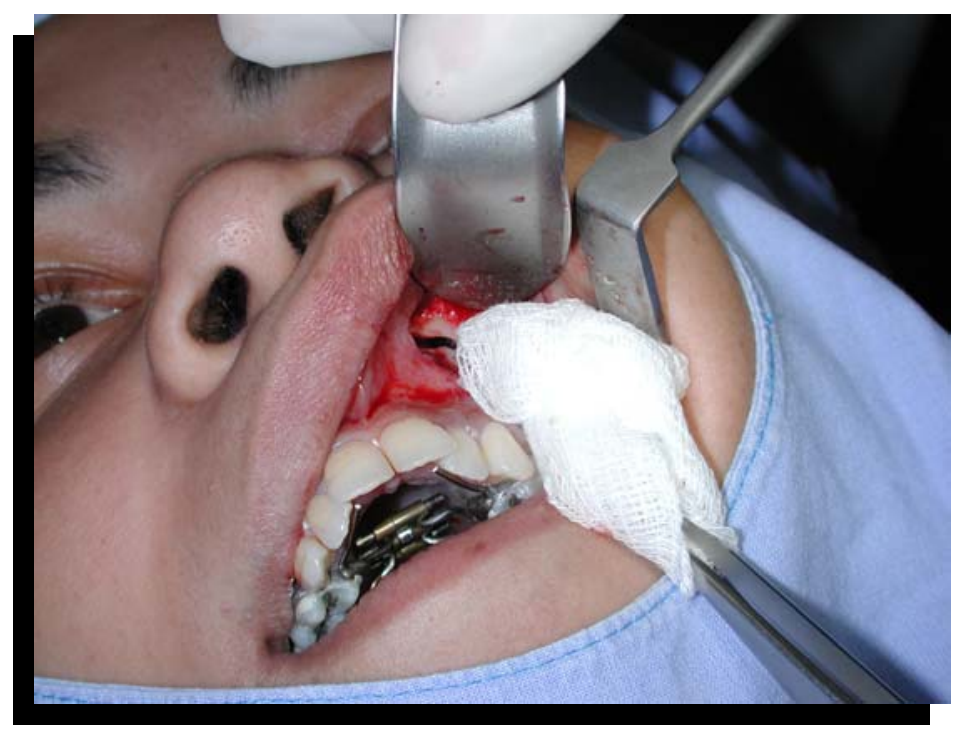

Figura 4.5 - Gaze colocada sobre a osteotomia. 
Após as osteotomias, uma incisão em "V" foi feita em região de freio labial e, após o rebatimento retalho muco-periostal, a sutura intermaxilar foi exposta. Em seguida, uma pequena osteotomia foi feita, com broca n. 702 sob baixa rotação e intensa irrigação com soro fisiológico, na sutura intermaxilar com a finalidade de apoio do cinzel reto de Wagner (Figuras 4.6 A, B, C e D).
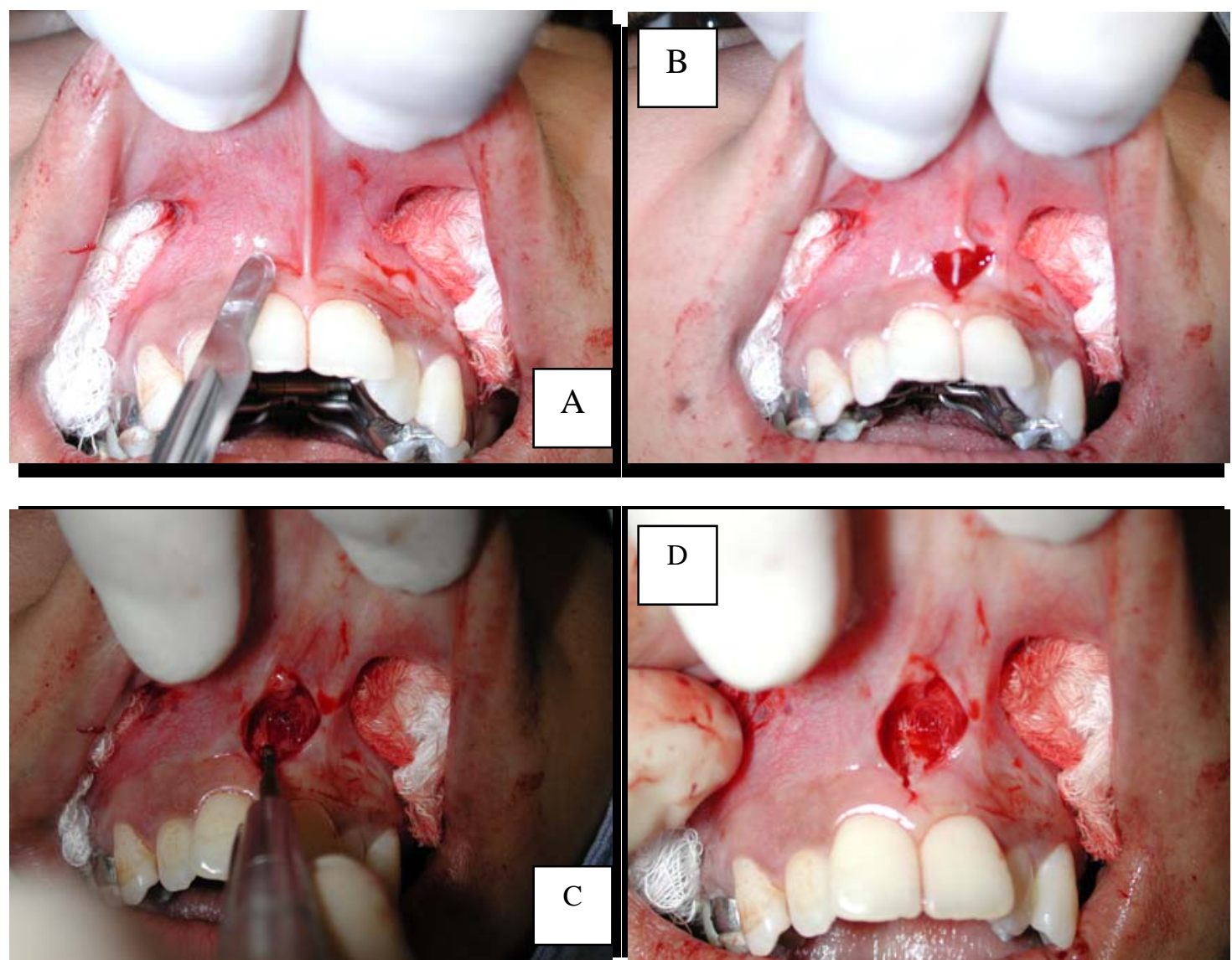

Figuras 4.6 A, B, C e D - Incisão (A e B), rebatimento do retalho e osteotomia da sutura intermaxilar (C e D). 
O cinzel reto de Wagner foi utilizado em duas inclinações distintas, sendo uma voltada para a sutura palatina e outra para a crista alveolar e a clivagem foi feita com o uso do martelo cirúrgico agindo sobre o cinzel. (Figuras 4.7 A e B).

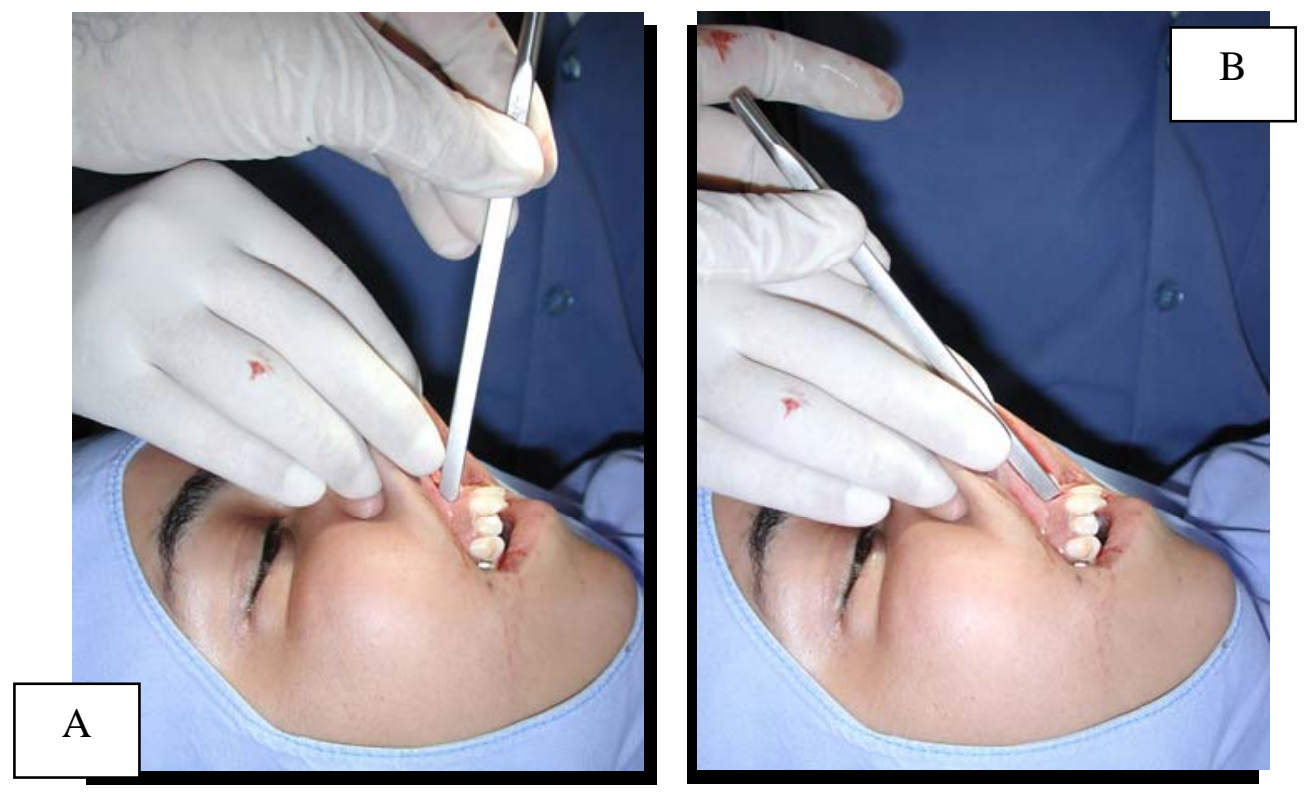

Figuras 4.7 A e B - Inclinações do cinzel de Wagner, sendo a primeira inclinação para a sutura palatina mediana (A) e a segunda para a crista alveolar (B).

Após a constatação da fratura maxilar, evidenciada clinicamente pela abertura de diastema entre os incisivos centrais superiores, realizou-se a ativação do aparelho expansor com 2 voltas completas (8 ativações) mantendo-se assim até o início das ativações pós-operatórias. (Figuras 4.8 A, B, C e D) 

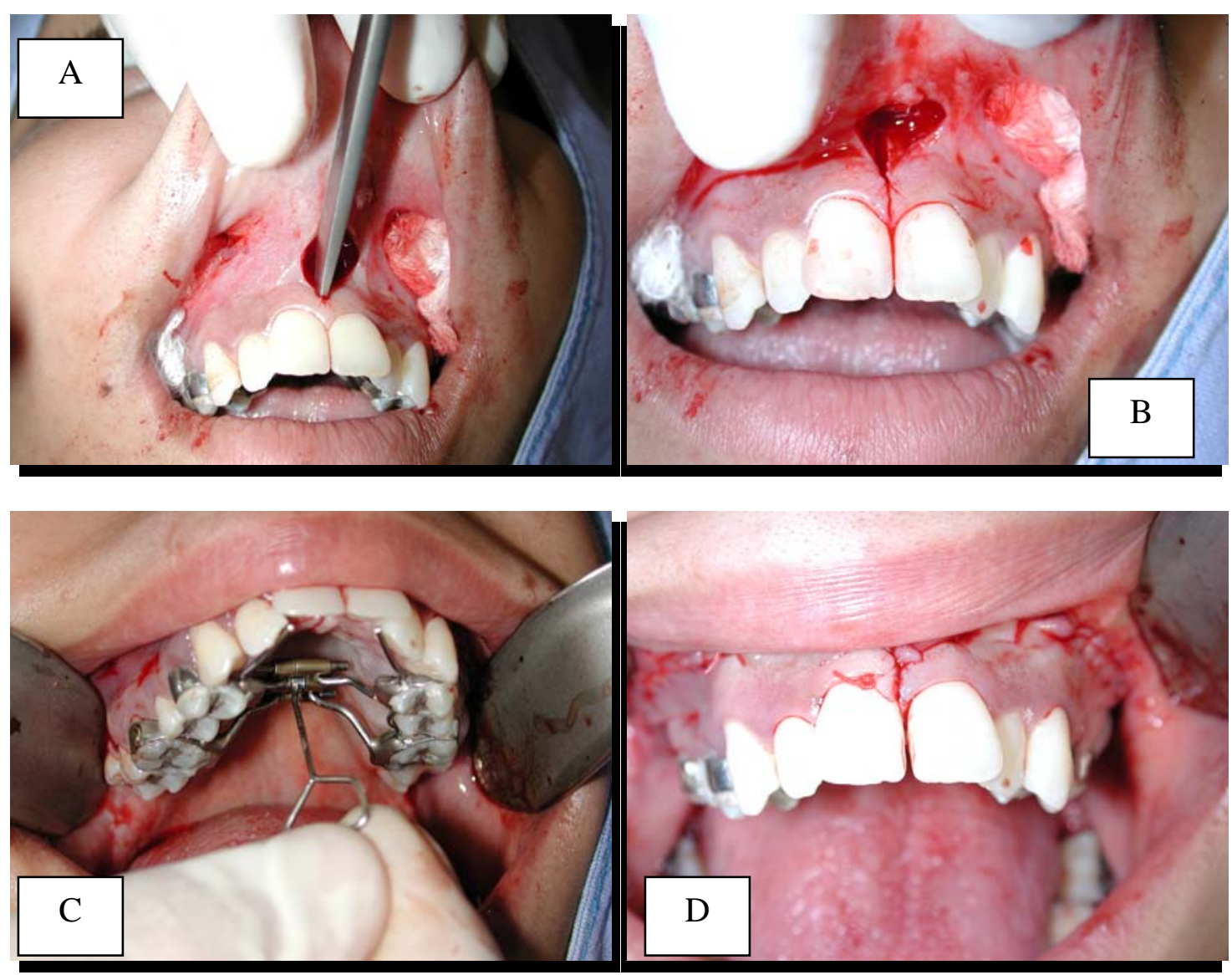

Figuras 4.8 A, B, C e D - Clivagem da maxila (A e B), ativação do aparelho expansor (C) e evidenciação clínica do diastema (D).

Em seguida a sutura dos tecidos foi realizada com a utilização de fios Vicryl ${ }^{\circledR}$ 4-0. (Figura 4.9)



Figura 4.9 - Sutura final. 


\subsubsection{2 - Grupo II (técnica de GLASSMAN ${ }^{31}$ ):}

Todos os passos descritos para o grupo I, até o final da osteotomia sub-total Le Fort I, se aplicam a este grupo.

Os pacientes do grupo II, conforme a técnica de GLASSMAN $^{31}$, não sofrem a osteotomia da sutura intermaxilar, bem como a clivagem trans-cirúrgica com o uso do cinzel e martelo.

Após a realização da osteotomia sub-total tipo Le Fort I, foi feita imediatamente a ativação de uma volta completa (4 ativações) do aparelho expansor. Em seguida, a sutura com fio Vicryl® 4-0 foi realizada (Figuras 4.10 A, B, C, D, E, F, G, H e I).
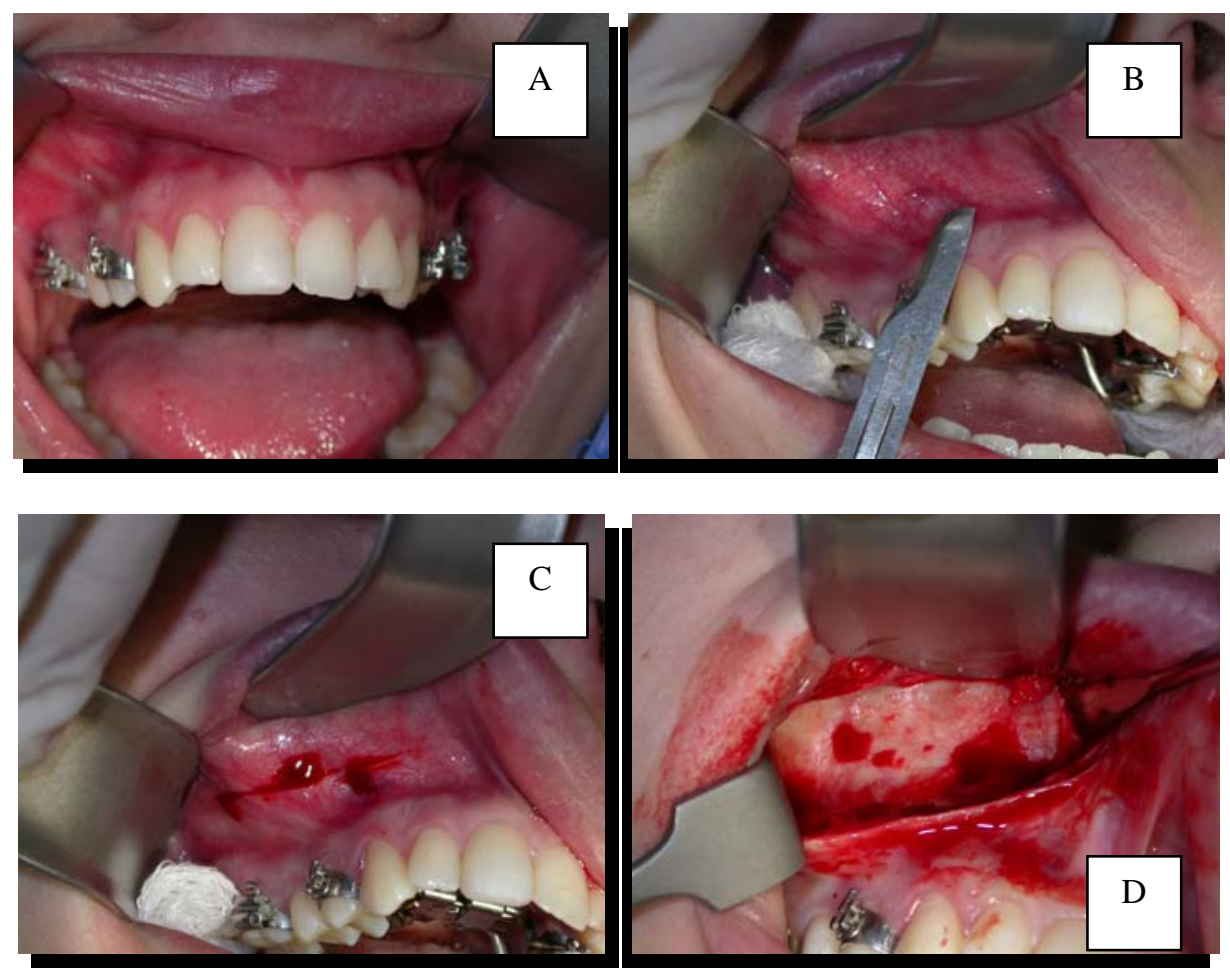

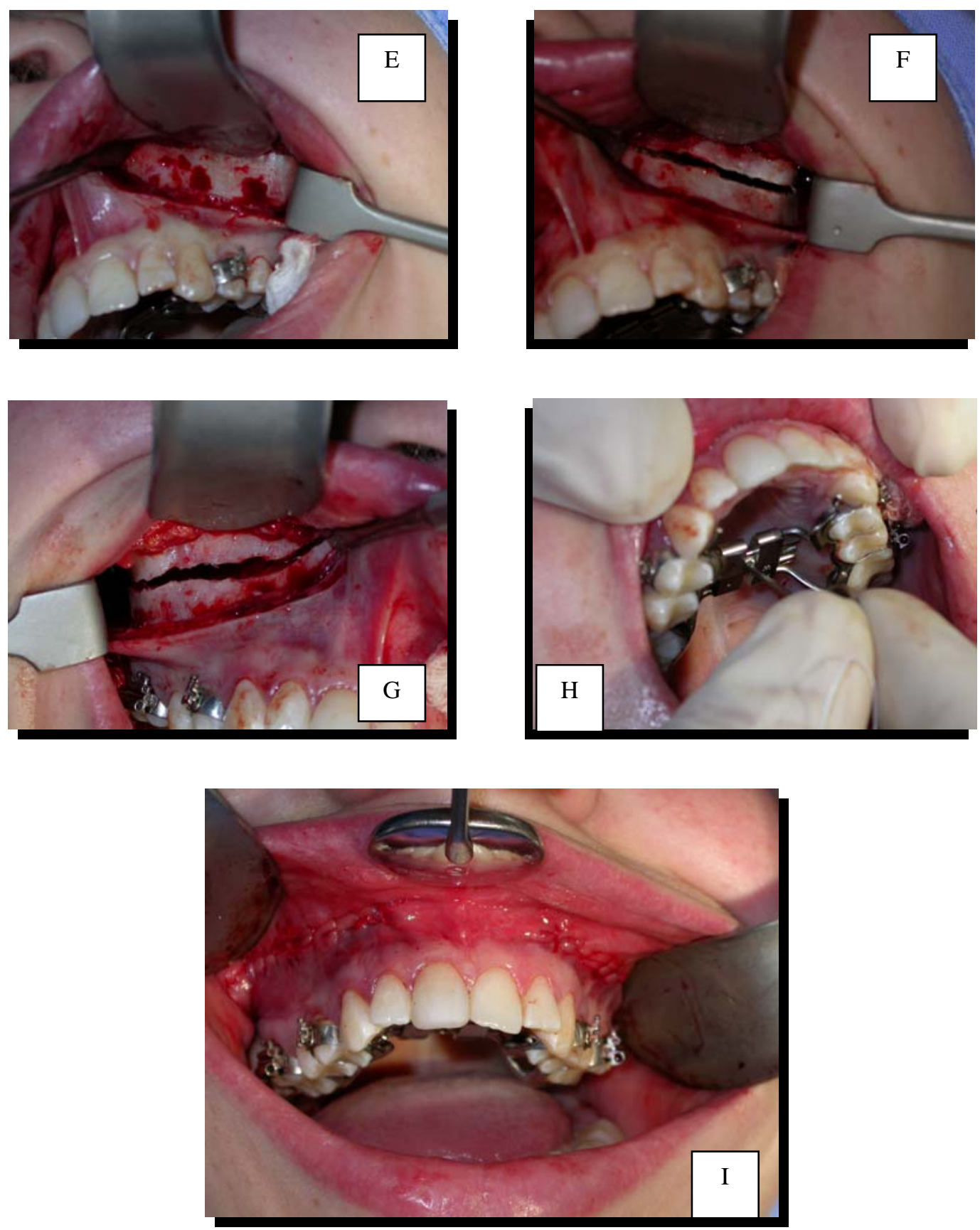

Figuras 4.10 A, B, C, D, E, F, G, H, I - Técnica cirúrgica proposta por Glassman ${ }^{31}$.

Notar a ausência da clivagem da maxila com cinzel, bem como, ausência de diastema ao final da cirurgia. 


\subsection{4 - Radiografia pós-operatória imediata}

Imediatamente após a cirurgia, uma radiografia oclusal total de maxila foi realizada com a finalidade de se determinar o tipo de fratura ocorrido na crista alveolar (Figuras 4.11 A e B, 4.12 A e B). Este passo no atendimento é de fundamental importância, pois, o tipo de ativação do aparelho expansor a ser feita no paciente, dependerá do tipo de fratura ocorrida na crista alveolar.


Figuras 4.11 A e B - Fratura simétrica entre os incisivos centrais superiores (A), (B).

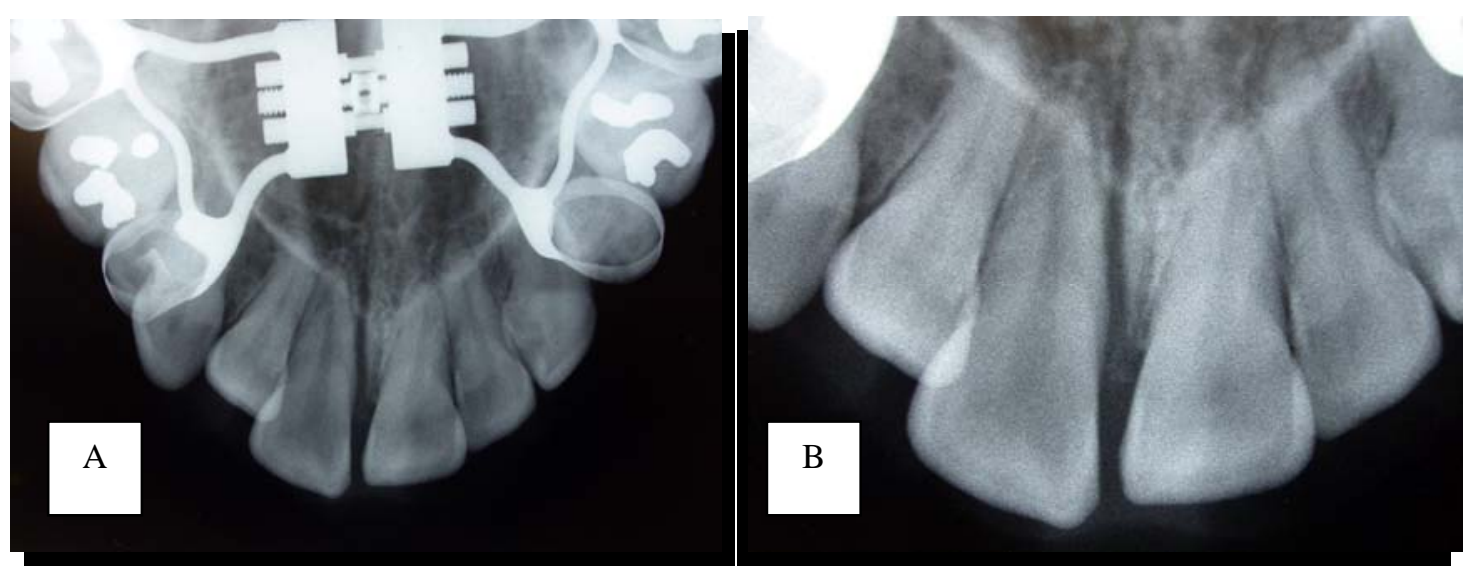

Figuras 4.12 A e B - Fratura assimétrica entre os incisivos centrais superiores (A) (B).

Notar perda de continuidade da lâmina dura na face mesial da raiz do 11 


\subsection{5 - Instruções pós-operatórias e medicação}

Os pacientes receberam como prescrição medicamentosa a indicação de 3 injeções intramusculares de Dexametasona 4 mg ( 1 a cada 24 h), 1 cápsula de amoxicilina 500 mg a cada 8 h por 7 dias, 1 cápsula de Nimesulida $100 \mathrm{mg}$ a cada 12 h por 5 dias e 45 gotas de Paracetamol em caso de dor.

Os pacientes foram instruídos quanto à colocação de gelo sobre a face, com a proteção de uma toalha, principalmente nos dois primeiros dias de pós-operatório e a necessidade de uma alimentação líquida e/ou pastosa fria e/ou gelada também nestes dois primeiros dias. As instruções quanto a repouso, higiene e condutas foram explicadas uma a uma e a folha impressa com os cuidados pós-operatórios foi fornecida ao paciente.

Com relação às ativações do aparelho expansor, uma carta foi feita ao ortodontista do paciente, explicando ao profissional qual regime de ativação seu paciente deveria ser submetido. 
A ativação do aparelho expansor foi dependente do grupo em que o paciente estava inserido.

\subsubsection{1 - Grupo I}

Os pacientes do Grupo I realizaram a ativação do aparelho conforme o tipo de fratura ocorrida na crista alveolar, seguindo-se os preceitos propostos por CURETON \& CUENIN ${ }^{25}$. Com a finalidade de evitarmos transtornos periodontais e estéticos futuros aos pacientes, o protocolo de ativação seguia-se da seguinte maneira:

Nos casos em que a fratura foi diagnosticada como simétrica, o paciente começou a ativar o aparelho expansor no dia seguinte após a cirurgia, com 2 ativações pela manhã (2/4 de volta) e 2 ativações à noite (2/4 de volta), seguindo-se este protocolo até a obtenção da quantidade de expansão desejada.

Nos casos de fratura assimétrica, ou casos duvidosos (onde não se conseguiu estabelecer o diagnóstico seguro pela imagem da radiografia oclusal, o que ocorreu em um número expressivo de casos), aguardava-se uma semana após a cirurgia, e então foi realizada uma ativação pela manhã (1/4 de volta) e uma à noite (1/4 de volta). Aguardavase 48 horas e nova ativação era feita da mesma maneira. Nos caos de fratura duvidosa, este protocolo foi seguido por no máximo 7 dias, quando o 
paciente retornaria para controle e realização de nova radiografia oclusal total de maxila para estabelecimento de diagnóstico do tipo de fratura ocorrida na crista alveolar.

\subsubsection{2- Grupo II}

Os pacientes do Grupo II realizaram a ativação do aparelho expansor diariamente, seguindo os preceitos propostos por GLASSMAN $^{31}$, sendo que $1 / 4$ de volta foi feita pela manhã e $1 / 4$ de volta foi feita à noite até se obter a quantidade de expansão desejada.

\subsection{7 - Aplicação do questionário}

Logo em seguida à realização da radiografia oclusal total de maxila, à prescrição medicamentosa e instruções pósoperatórias, a primeira pergunta do questionário foi feita, com o intuito de se avaliar o grau de desconforto do paciente durante o trans-operatório.

Após a explicação dos parâmetros de valores, foi solicitado ao paciente que desse uma nota de zero a dez sobre o grau de desconforto sofrido durante a realização do procedimento.

Após o paciente dizer em voz alta o valor numérico a ser marcado na escala, este foi anotado na ficha em local apropriado sendo em seguida anexado ao seu prontuário. Em seguida o 
paciente foi dispensado, e o seu retorno agendado após 14 dias de pósoperatório.

\subsection{8 - Controle de 14 dias e reaplicação do questionário}

Aos 14 dias de pós-operatório, o primeiro controle dos pacientes do Grupo I, com fratura simétrica, e todos os pacientes do Grupo II foi realizado por meio de radiografia oclusal, avaliação clínica e aplicação do questionário.

Nos pacientes do Grupo I que tiveram como diagnóstico a fratura de crista alveolar duvidosa, este controle foi apenas clínico e radiográfico, sem a aplicação do questionário. Em seguida um novo controle era agendado, conforme o regime de expansão ao qual o paciente foi submetido, para a aplicação do questionário.

Para a aplicação do questionário era necessário que o paciente tivesse realizado 28 ativações do aparelho expansor $(7 \mathrm{~mm})$. Portanto, a adoção deste tempo de controle pós-operatório se deu pelo fato de que este era um período suficiente para que a quantidade de expansão desejada fosse obtida. Esta quantidade mínima de ativações do aparelho expansor é importante, devido à avaliação da sintomatologia do paciente durante a ativação do mesmo. 
Após a verificação clínica da região onde o procedimento foi realizado, uma nova radiografia oclusal total de maxila foi feita com a finalidade de se avaliar a quantidade de expansão obtida. Esta radiografia também serviu como parâmetro inicial para os futuros controles radiográficos do processo de reparo ósseo na região da sutura palatina mediana.

Após a realização da radiografia oclusal, o questionário foi aplicado ao paciente.

A primeira pergunta foi repetida com o intuito de se fazer uma comparação da impressão imediata após a cirurgia, e se houve ou não mudança.

Em seguida, foi perguntado sobre o grau de desconforto sofrido durante a ativação do aparelho expansor. Depois foi perguntado sobre a dor e sobre o edema pós-operatório, levando-se em conta os parâmetros de avaliação de zero a dez já descritos.

Após as anotações dos valores na ficha, foi agendado novo retorno para 60 dias de pós-operatório. 
4.2.8.1 - Pacientes com insucesso na abertura da

sutura palatina mediana

Para os pacientes do Grupo II, onde houve insucesso da cirurgia, ou seja, sem a expansão maxilar ter ocorrido, evidenciado clinicamente pela ausência do diastema entre os incisivos centrais superiores, e radiograficamente pela radiografia oclusal total de maxila, novo procedimento cirúrgico ao $14^{\circ}$ dia de controle pós-operatório foi realizado.

Após a desinfecção das superfícies, anti-sepsia intrabucal e colocação dos campos cirúrgicos, os bloqueios anestésicos infra-orbitários (direito e esquerdo), naso-palatino e palatino maiores (direito e esquerdo) foram realizados.

Uma incisão em forma de "V" foi realizada, na região de freio labial, expondo-se a sutura intermaxilar. Realizou-se a osteotomia na sutura intermaxilar com broca n. 702 em baixa rotação sob intensa irrigação com soro fisiológico, com a finalidade de se colocar o cinzel de Wagner reto para a clivagem maxilar. Em seguida, com o uso de um martelo cirúrgico agindo sobre o cinzel de Wagner, a clivagem da sutura palatina mediana foi feita, seguindo-se as inclinações propostas por BELL \& EPKER $^{10}$ (1979). 
Neste caso, nenhuma ativação após a cirurgia foi feita, pois o aparelho expansor estava ativado. Clinicamente observou-se a abertura de um diastema entre os incisivos centrais superiores, e, a sutura na região do freio labial foi feita utilizando-se fio Vicryl ${ }^{\circledR}$ 4-0.

Em seguida, a prescrição medicamentosa seguiu os mesmos parâmetros propostos pelo protocolo de atendimento de pacientes a serem submetidos à expansão rápida da maxila assistida cirurgicamente, e, as instruções pós-operatórias foram novamente dadas ao paciente.

Uma nova radiografia oclusal total de maxila foi feita a fim de se determinar o tipo de fratura da crista alveolar e uma vez diagnosticada, uma carta ao ortodontista foi feita com a finalidade de se determinar o regime de expansão a ser adotado para este paciente.

\subsection{9 - Controle de 28 dias.}

Este controle se aplica aos pacientes do grupo I, onde foi diagnosticada a fratura assimétrica ou duvidosa. Este tempo foi necessário, pois esta expansão é mais lenta, e, como a avaliação do desconforto durante o procedimento de expansão é feita com pelo menos 7 mm de expansão, um tempo maior de expansão era dado ao paciente. 
Este controle seguiu os mesmos parâmetros de procedimentos feitos aos 14 dias para os pacientes do grupo I com fratura simétrica e do grupo II.

\subsubsection{0 - Controle de 90,120 e 150 dias.}

Estes controles objetivavam o acompanhamento clínico dos pacientes submetidos à expansão rápida da maxila assistida cirurgicamente, avaliando-se principalmente se houve recidiva de mordida cruzada posterior. Nestes controles radiografias oclusais totais de maxila foram realizadas a fim de se observar o processo de reparo da crista alveolar e da abertura da sutura palatina mediana, além de se verificar possíveis recidivas de mordida cruzada posterior durante o período de contenção.

A partir dos 120 dias, começou-se a cogitar a hipótese da remoção do aparelho expansor, que estava nesta fase fazendo a contenção da maxila expandida, evitando recidiva. Esta hipótese foi confirmada se, aos 120 dias, a radiografia oclusal total de maxila apresentou indícios de mineralização do "gap" formado entre as hemi-maxilas. Caso contrário outro controle radiográfico, aos 150 dias, foi realizado para a mesma finalidade. 


\subsubsection{2 - Controle de 180 dias}

Este foi o período do controle final da pesquisa, onde o paciente retornou à clínica de pós-graduação de Estomatologia da FOB-USP para a realização das radiografias finais, sem o uso do aparelho expansor.

O paciente trouxe um modelo de gesso final de maxila e mandíbula para arquivamento na Disciplina de Cirurgia da FOBUSP.

Nesse dia nova radiografia oclusal total de maxila foi realizada com a finalidade de documentação final de tratamento, além de uma telerradiografia P.A, uma telerradiografia de perfil, uma radiografia panorâmica e fotos finais.

Em seguida, o paciente foi dispensado para a continuação de seu tratamento ortodôntico e/ou cirúrgico com seu ortodontista e cirurgião de escolha (terminando aqui a atuação da Faculdade de Odontologia de Bauru - Universidade de São Paulo, no tratamento destas deformidades dento-faciais).

Em síntese, o protocolo de controle dos pacientes submetidos à ERMAC foi o seguinte (Tabela 4.1): 
Tabela 4.1 - Protocolo de controle pós-operatório dos pacientes submetidos

à ERMAC neste trabalho.

\begin{tabular}{c|c|c|c|c} 
& \multicolumn{3}{|c|}{ GRUPO I } & GRUPO II \\
\cline { 2 - 5 } & Fratura Simétrica & Fratura duvidosa & Fratura Assimétrica & \\
\hline 14 dias & Sim & Sim & & Sim \\
\hline 28 dias & & Sim & Sim & $\begin{array}{c}\text { Sim (insucesso } \\
\text { cirurgia pos op } \\
14 \text { dias) }\end{array}$ \\
\hline 60 dias & Sim & & Sim & Sim \\
\hline 120 dias & Sim & & Sim & Sim \\
\hline 150 dias & Sim & & Sim & Sim \\
\hline 180 dias & Sim & & Sim & Sim \\
\hline
\end{tabular}

Tabela 4.1 - Controles de pacientes que se submeteram à ERMAC. Notar, na coluna do grupo II, que aos 28 dias se realiza um controle de 14 dias de pós-operatório dos pacientes que não obtiveram sucesso com a técnica cirúrgica de GLASSMAN ${ }^{31}$.

\subsubsection{3 - Critérios para estabelecimento de sucesso de cirurgia}

Para este trabalho o principal critério para o sucesso da cirurgia foi a constatação clínica e radiográfica da abertura da sutura palatina mediana. Clinicamente, a avaliação se deu pela presença de um diastema entre os incisivos centrais superiores, e, radiograficamente, pela presença de uma área radiolúcida correspondente à separação da sutura palatina mediana e crista alveolar, ambos devendo ser visualizados no primeiro controle pós-operatório. 
O sucesso da cirurgia é considerado como obtido através da observação destes dois fatores. 


\section{5 - RESULTADOS}

\section{$\underline{5.1-N^{o} \text { de pacientes }}$}

Para a realização deste trabalho, 24 pacientes foram submetidos à expansão rápida da maxila assistida cirurgicamente, sendo 14 pacientes pertencentes ao Grupo I e 10 pacientes pertencentes ao Grupo II.

Deste total, 17 pacientes são do sexo feminino e 7 pacientes do sexo masculino, com idade média de 26,8 anos $( \pm 1,42)$.

\section{2 - Eficácia das diferentes técnicas cirúrqicas.}

Em todos os pacientes do Grupo I, houve a evidencia clínica e radiográfica do sucesso da cirurgia, ou seja, eficácia da técnica de 100\% (Figura 5.1). 
Em contrapartida, dos 10 pacientes submetidos à expansão cirúrgica da maxila pela técnica proposta por GLASSMAN ${ }^{31}$ (Grupo II), houve sucesso em apenas 3 casos (Gráfico 5.1). Nos outros 7 casos foi necessária a realização de cirurgia complementar aos 14 dias de pós-operatório. Ou seja, eficácia da técnica de 30\%.

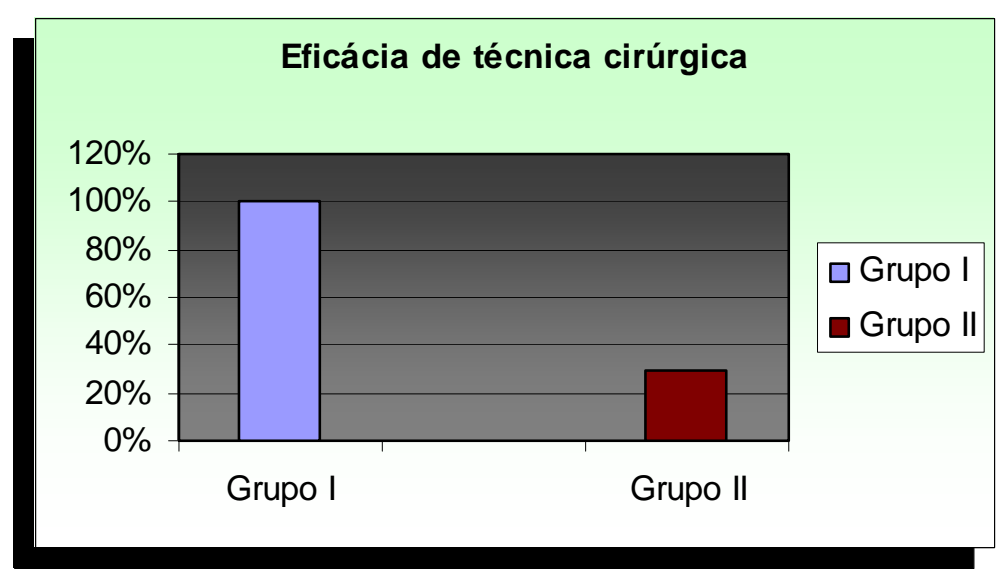

Gráfico 5.1 - Grau de eficácia da técnica cirúrgica adotada, separado por grupos.

\section{3 - Tipos de fratura}

Com relação aos tipos de fratura da crista alveolar, 5 pacientes do Grupo I (35,71\%) mostraram radiograficamente a ocorrência de fratura simétrica, enquanto que, em todos os 10 pacientes do Grupo II (100\%), este tipo de fratura foi diagnosticada. Com relação ao Grupo II, é interessante ressaltar que, mesmo nos casos onde houve o insucesso da técnica cirúrgica proposta por GLASSMAN ${ }^{31}$, ao realizarmos o segundo procedimento cirúrgico, as fraturas ocorreram simetricamente. 
Com relação às fraturas assimétricas, estas ocorreram em $4(28,57 \%)$ pacientes do Grupo I e as fraturas diagnosticadas como duvidosas em 5 pacientes (37,71\%) do mesmo grupo. Destas 5 fraturas consideradas duvidosas, uma foi posteriormente diagnosticada como simétrica e 4 como assimétricas (Tabela 5.1).

Tabela 5.1 - Tipos de fratura de crista alveolar ocorrida nos pacientes de ambos grupos.

\begin{tabular}{c|c|c|c|c}
\hline \multirow{2}{*}{ FRATURA } & \multicolumn{2}{|c|}{ G-I } & G-II & Total \\
\hline Simétrica & $5(35,71 \%)$ & & $10(100 \%)$ & $15+1$ \\
& & & & $\mathbf{1 6}(\mathbf{6 6 , 5 \% )}$ \\
\hline Assimétrica & $4(21,44 \%)$ & & & $4+4$ \\
& & & & $\mathbf{8}(33,5 \%)$ \\
\hline Duvidosa & $5(35,71 \%)$ & 1 Simétrica & & \\
\hline
\end{tabular}

Tabela 5.1 - Tipos de fratura de crista alveolar diagnosticadas em ambos os grupos.

Evidenciando as fraturas duvidosas após o seu diagnóstico final.

Este trabalho obteve um resultado total, incluindo os dois grupos de 16 (66,5\%) fraturas simétricas da crista alveolar, e 8 fraturas assimétricas (33,5\%). 


\section{4-Questionário dos pacientes}

A avaliação dos pacientes foi feita utilizando-se de uma escala numérica, sendo que os valores obtidos foram os seguintes (Tabela 5.2 e 5.3):

Tabela 5.2 - Resultados obtidos com os pacientes do Grupo I

\section{G-I}

\begin{tabular}{c|c|c|c|c|c}
\hline & Q.1 - Pós Op. Im. & Q.1 - $\mathbf{1}^{\mathbf{0}}$ Pós Op & $\mathbf{Q . 2}$ & $\mathbf{Q . 3}$ & $\mathbf{Q . 4}$ \\
\hline P01 & 4 & 2,5 & 3 & 1,5 & 2,5 \\
\hline P02 & 3,5 & 3 & 5 & 2 & 2 \\
\hline P03 & 2 & 2 & 0 & 0 & 3,5 \\
\hline P04 & 4 & 3 & 1 & 3 & 1 \\
\hline P05 & 3 & 3 & 3 & 3 & 3 \\
\hline P06 & 3 & 3 & 5 & 0 & 0 \\
\hline P07 & 5 & 5 & 4 & 0 & 3 \\
\hline P08 & 1 & 0 & 0 & 0 & 2 \\
\hline P09 & 2 & 0 & 0 & 0 & 2 \\
\hline P10 & 2 & 1 & 1 & 1 & 2 \\
\hline P11 & 3 & 1,5 & 1,5 & 1 & 1,5 \\
\hline P12 & 2,5 & 1,5 & 1 & 0 & 2 \\
\hline P13 & 2 & 1,5 & 0,5 & 0,5 & 2 \\
\hline P14 & 3 & 2 & 0 & 3 & 3 \\
\hline
\end{tabular}

Tabela 5.2 - Resultados obtidos após a aplicação do questionário nos pacientes do Grupo 
Tabela 5.3 - Resultados obtidos com os pacientes do Grupo II

\begin{tabular}{c|c|c|c|c|c}
\multicolumn{7}{c}{ G-II } \\
\hline & Q.1 - Pós Op. Im. & Q.1 - 1 ${ }^{\circ}$ Pós Op & Q.2 & Q.3 & Q.4 \\
\hline P15 & 2,5 & 2 & 5 & 3 & 3 \\
\hline P16 & 1 & 1 & 4 & 1 & 0 \\
\hline P17 & 1,5 & 0,5 & 5 & 3 & 2 \\
\hline P18 & 2 & 1,5 & 4,5 & 1,5 & 2 \\
\hline P19 & 1,5 & 1,5 & 4 & 2 & 2,5 \\
\hline P20 & 2 & 1 & 5,5 & 3 & 2 \\
\hline P21 & 3 & 2 & 5 & 3 & 1 \\
\hline P22 & 3 & 1,5 & 5,5 & 2 & 2 \\
\hline P23 & 3 & 2 & 5 & 2 & 1,5 \\
\hline P24 & 2,5 & 2 & 5 & 1,5 & 1 \\
\hline
\end{tabular}

Tabela 5.3 - Resultados obtidos após a aplicação do questionário nos pacientes do Grupo

II. Em destaque estão os pacientes que obtiveram sucesso com esta técnica cirúrgica.

\subsection{1 - Questão n.1 Pós-Operatório imediato.}

Imediatamente após a cirurgia, utilizando-se de uma escala visual numérica para dor e desconforto, o paciente era questionado sobre o que sentiu durante a cirurgia ao qual fora submetido. Obtivemos os seguintes resultados (Tabela 5.4): 
Tabela 5.4 - Resultados obtidos pela Q.1 no pós-operatório imediato.

\begin{tabular}{c|c} 
& G-I \\
\hline & Q.1 - Pós Op. Im. \\
\hline P01 & 4 \\
\hline P02 & 3,5 \\
\hline P03 & 2 \\
\hline P04 & 4 \\
\hline P05 & 3 \\
\hline P06 & 3 \\
\hline P07 & 5 \\
\hline P08 & 1 \\
\hline P09 & 2 \\
\hline P10 & 2 \\
\hline P11 & 3 \\
\hline P12 & 2,5 \\
\hline P13 & 2 \\
\hline P14 & 3 \\
\hline
\end{tabular}

\begin{tabular}{c|c}
\multicolumn{1}{c}{ G-II } \\
\hline & Q.1 - Pós Op. Im. \\
\hline P15 & 2,5 \\
\hline P16 & 1 \\
\hline P17 & 1,5 \\
\hline P18 & 2 \\
\hline P19 & 1,5 \\
\hline P20 & 2 \\
\hline P21 & 3 \\
\hline P22 & 3 \\
\hline P23 & 3 \\
\hline P24 & 2,5 \\
\hline
\end{tabular}

Tabela 5.4 - Resultados obtidos após a aplicação da Q.1 ao pós-operatório imediato.

Como se pode observar, 6 pacientes do Grupo I (43\%) estão na faixa de 0 a 2,5, o que corresponde ao procedimento confortável ou sem dor, enquanto que 7 pacientes do Grupo II (70\%) estão na mesma faixa. Também se observa que 8 pacientes do Grupo I (57\%) estão na faixa de 2,6 à 5,0, o que corresponde a um procedimento tolerável, onde 3 pacientes do Grupo II (30\%) também se encontram.

Para os pacientes do Grupo I, a mediana da avaliação da sintomatologia pós-operatória imediata foi de 3,0 enquanto que para pacientes do Grupo II foi de 2,25 (Gráfico 5.2). 




Gráfico 5.2- Avaliação média dos pacientes referentes à questão n.1 ao pós-operatório imediato

Aplicando o teste estatístico de Mann Whitney para grupos não pareados, obtivemos um valor de $p=0,112$, ou seja, não existe diferença estatisticamente significante entre a avaliação dos pacientes submetidos à técnica de BELL ${ }^{12}$ (Grupo I) e dos pacientes submetidos à técnica de GLASSMAN ${ }^{31}$ (Grupo II) (Tabela 5.5).

Tabela 5.5 - Teste não paramétrico de Mann Whitney para Q.1 entre os pacientes do Grupo I e II

\begin{tabular}{c|c|c|c|c|c|c}
\hline Grupo & $\begin{array}{c}\text { Soma de } \\
\text { Postos }\end{array}$ & $\begin{array}{c}\mathrm{N}^{\text {o. de }} \\
\text { Valores }\end{array}$ & Posto médio & $\mathrm{U}$ & $\begin{array}{c}\text { Aproximação } \\
\text { Normal Z }\end{array}$ & $\mathrm{p}$ \\
\hline I & 201,5 & 14 & 14,39 & 43,5 & 1,58 & $0,112^{*}$ \\
\hline II & 98,5 & 10 & 9,85 & & & \\
\hline
\end{tabular}

*Não existe diferença estatisticamente significante entre os dois grupos 


\subsection{2 - Repetição da questão n.1 ao $1^{\circ}$ controle}

Pós-Operatório.

Ao primeiro controle pós-operatório do paciente, independente do grupo em que foi inserido, a questão n.1 foi novamente aplicada, obtendo-se os seguintes resultados (Tabela 5.6):

Tabela 5.6 - Resultados obtidos à Q.1 no primeiro controle pós-operatório.

\begin{tabular}{c|c} 
& G-I \\
\hline & Q.1 - $\mathbf{1}^{\text {P }}$ ós Op \\
\hline P01 & 2,5 \\
\hline P02 & 3 \\
\hline P03 & 2 \\
\hline P04 & 3 \\
\hline P05 & 3 \\
\hline P06 & 3 \\
\hline P07 & 5 \\
\hline P08 & 0 \\
\hline P09 & 0 \\
\hline P10 & 1 \\
\hline P11 & 1,5 \\
\hline P12 & 1,5 \\
\hline P13 & 1,5 \\
\hline P14 & 2 \\
\hline
\end{tabular}

G-II

\begin{tabular}{c|c}
\hline & Q.1 - 1 Pós Op \\
\hline P15 & 2 \\
\hline P16 & 1 \\
\hline P17 & 0,5 \\
\hline P18 & 1,5 \\
\hline P19 & 1,5 \\
\hline P20 & 1 \\
\hline P21 & 2 \\
\hline P22 & 1,5 \\
\hline P23 & 2 \\
\hline P24 & 2 \\
\hline
\end{tabular}

Tabela 5.6 - Valores obtidos pela avaliação dos pacientes à repetição da Q.1 no primeiro controle pós-operatório.

Aqui observamos uma diferença quanto a quantidade pacientes em cada faixa de avaliação. Temos agora 9 pacientes do Grupo I (64\%) na faixa de 0 a 2,5, o que corresponde ao procedimento confortável ou sem dor, e todos os 10 pacientes do Grupo II (100\%) estão na mesma faixa. Também se observa que 5 pacientes do Grupo I (36\%) estão 
na faixa de 2,6 à 5,0, o que corresponde a um procedimento tolerável. Ou seja, 3 pacientes de cada grupo, após nova avaliação da sintomatologia causada pela cirurgia, mudou de tipo de dor referida conforme os critérios estabelecidos por esta pesquisa.

Para os pacientes do Grupo I, a mediana da avaliação da sintomatologia pós-operatória imediata foi de 2,0 enquanto que para pacientes do Grupo II foi de 1,5 (Gráfico 5.3).

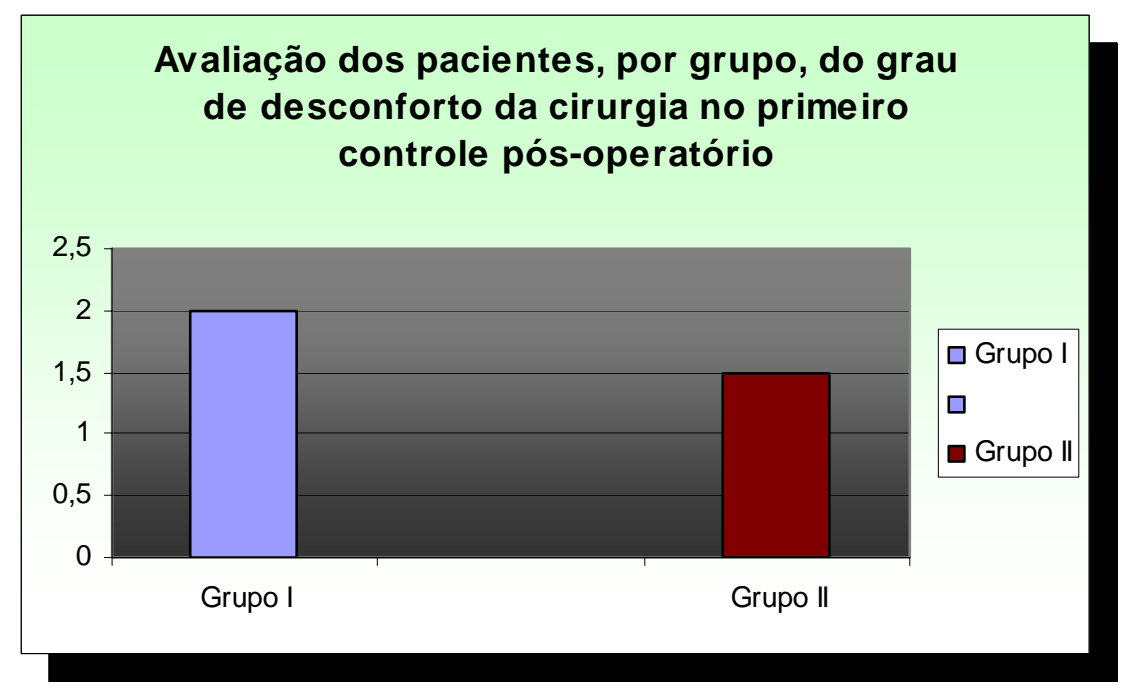

Gráfico 5.3 - Avaliação média dos pacientes referentes à questão n.1 no primeiro controle pós-operatório.

Aplicando o teste estatístico de Mann Whitney para grupos não pareados, obtivemos um valor de $\mathrm{p}=0,199$, ou seja, não existe diferença estatisticamente significante entre a avaliação dos pacientes 
submetidos à técnica de BELL ${ }^{12}$ (Grupo I) e dos pacientes submetidos à técnica de GLASSMAN ${ }^{31}$ (Grupo II) (Tabela 5.7).

Tabela 5.7 - Teste não paramétrico de Mann Whitney para Q.1 entre os pacientes do Grupo I e II

\begin{tabular}{c|c|c|c|c|c|c}
\hline Grupo & $\begin{array}{c}\text { Soma de } \\
\text { Postos }\end{array}$ & $\begin{array}{c}\mathrm{N}^{\text {o. de }} \\
\text { Valores }\end{array}$ & Posto médio & $\mathrm{U}$ & $\begin{array}{c}\text { Aproximação } \\
\text { Normal Z }\end{array}$ & $\mathrm{p}$ \\
\hline I & 196,5 & 14 & 14,03 & 48,5 & 1,28 & $0,199^{*}$ \\
\hline II & 103,5 & 10 & 10,35 & & & \\
\hline
\end{tabular}

*Não existe diferença estatisticamente significante entre os dois grupos

Neste momento torna-se importante a avaliação da existência de algum grau de relação entre as avaliações feitas pelo próprio paciente e se sempre haverá diferença entre o grau de sintomatologia do mesmo, imediatamente ao fim da cirurgia e do $1^{\circ}$ controle pós-operatório aos 14 ou 28 dias.

Para isto, o teste não paramétrico de Wilcoxon foi utilizado, com a hipótese de que as avaliações dos pacientes sempre serão diferentes ao fim da cirurgia em comparação com o $1^{\circ}$ controle pósoperatório (Tabelas 5.8 e 5.9). 
Tabela 5.8 - Teste não paramétrico de Wilcoxon para Questão 1 no Grupo I

\begin{tabular}{l|l|ll|l|c}
\hline $\begin{array}{l}\text { Q.1 - Pós-Op Imediato } \\
\text { Mediana }\end{array}$ & $\begin{array}{l}\text { Q.1 - Controle Pós-Op. } \\
\text { Mediana }\end{array}$ & $\mathrm{T}^{+}$ & $\mathrm{T}^{-}$ & $\begin{array}{c}\text { Apr. } \\
\text { Normal Z }\end{array}$ & $\mathrm{P}$ \\
\hline 3,0 & 2,0 & 55,0 &, 000 & 2,84 & $0,004^{*}$ \\
\hline
\end{tabular}

* diferença estatisticamente significante

Tabela 5.9 - Teste não paramétrico de Wilcoxon para Questão 1 no Grupo II

\begin{tabular}{l|l|ll|c|c}
\hline $\begin{array}{l}\text { Q.1 - Pós-Op Imediato } \\
\text { Mediana }\end{array}$ & $\begin{array}{l}\text { Q.1 - Controle Pós-Op. } \\
\text { Mediana }\end{array}$ & $\mathrm{T}^{+}$ & $\mathrm{T}^{-}$ & $\begin{array}{c}\text { Apr. } \\
\text { Normal Z }\end{array}$ & $\mathrm{p}$ \\
\hline 2,25 & 1,5 & 36,0 &, 000 & 2,56 & $0,01^{*}$ \\
\hline
\end{tabular}

* diferença estatisticamente significante

O nível de significância adotado foi de 5\%, ou seja, ocorre quando o valor de $\mathrm{p}<0,05$, logo, ambos os valores mostraram que existe uma grande probabilidade de que exista variação na avaliação do paciente ao pós-operatório imediato e no $1^{\circ}$ controle pós-operatório.

Quando examinamos o quadro comparativo das duas técnicas, obtemos o seguinte gráfico (Gráfico 5.4) 


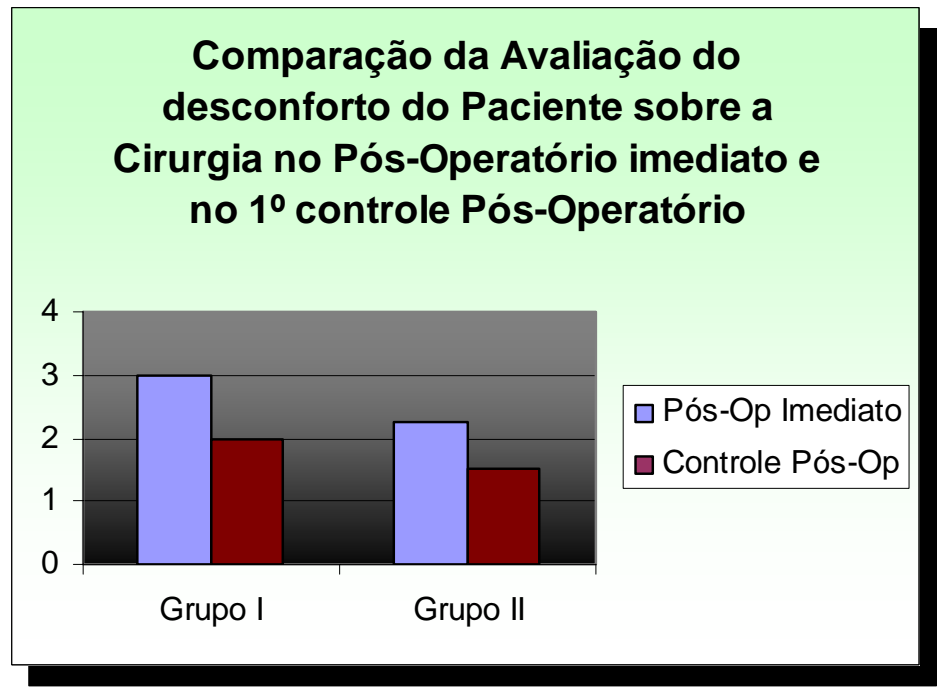

Gráfico 5.4 - Comparação dos valores obtidos na Questão 1 no pós-operatório imediato e no primeiro controle pós-operatório dos Grupos I e II, visualizando a melhora no relato dos pacientes.

Foi notada uma tendência, entre os pacientes dos dois grupos, de que as avaliações da sintomatologia do procedimento cirúrgico realizado ao primeiro controle pós-operatório possuíam valores maiores, ou seja, notou-se uma tendência dos pacientes em análise posterior à cirurgia, de que o procedimento é menos desconfortável do que avaliado imediatamente após a cirurgia. Para tal confirmação, o teste de correlação de Pearson foi realizado entre as avaliações de pós-operatório e do primeiro controle pós-operatório, para cada um dos grupos.

Ao aplicarmos o teste no Grupo I obtivemos um coeficiente de correlação de 0,88 e o seguinte gráfico (Gráfico 5.5): 




Gráfico 5.5 - Tela do programa Pacotico®, mostrando o gráfico de correlação positiva entre as avaliações dos pacientes do Grupo I, para a percepção do desconforto da cirurgia no pós-operatório imediato e no primeiro controle pós-operatório.

Aplicando o teste no Grupo II, obtivemos um coeficiente de correlação de 0,73 e o seguinte gráfico (Gráfico 5.6):

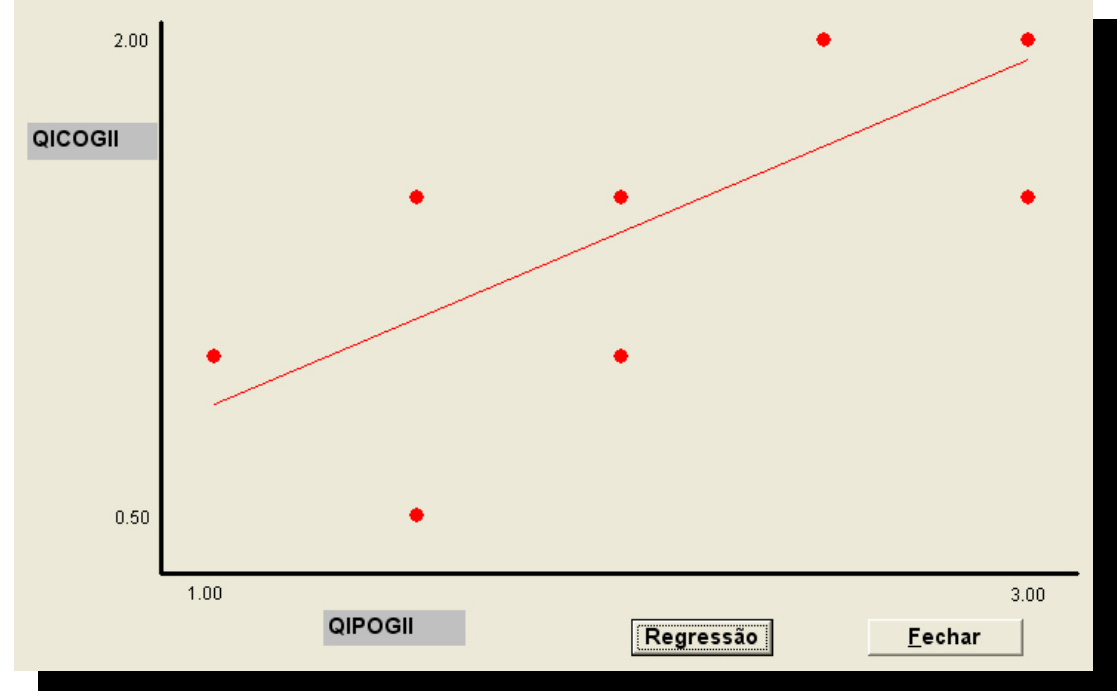

Gráfico 5.6 - Tela do programa Pacotico®, mostrando o gráfico de correlação positiva entre as avaliações dos pacientes do Grupo II, para a percepção do desconforto da cirurgia no pós-operatório imediato e no primeiro controle pós-operatório. 


\subsection{3 - Questão n.2.}

Esta questão refere-se à sintomatologia do paciente, quanto ao grau de desconforto durante as ativações do aparelho expansor no pós-operatório (Tabela 5.10).

Tabela 5.10 - Valores obtidos pela avaliação dos pacientes do Grupo I e II com relação à Q.2.

\begin{tabular}{c|c} 
& G-I \\
\hline & Q.2 \\
\hline P01 & 3 \\
\hline P02 & 5 \\
\hline P03 & 0 \\
\hline P04 & 1 \\
\hline P05 & 3 \\
\hline P06 & 5 \\
\hline P07 & 4 \\
\hline P08 & 0 \\
\hline P09 & 0 \\
\hline P10 & 1 \\
\hline P11 & 1,5 \\
\hline P12 & 1 \\
\hline P13 & 0,5 \\
\hline P14 & 0 \\
\hline
\end{tabular}

\begin{tabular}{c|c} 
& G-II \\
\hline & Q.2 \\
\hline P15 & 5 \\
\hline P16 & 4 \\
\hline P17 & 5 \\
\hline P18 & 4,5 \\
\hline P19 & 4 \\
\hline P20 & 5,5 \\
\hline P21 & 5 \\
\hline P22 & 5,5 \\
\hline P23 & 5 \\
\hline P24 & 5 \\
\hline
\end{tabular}

Após a observação dos resultados referentes à questão $\mathrm{n}^{\circ} .2$, no Grupo I existem 9 pacientes (64\%) situados na faixa de 0 a 2,5, e 5 pacientes (36\%) na faixa de 2,6 à 5,0. Com relação aos pacientes do Grupo II, nenhum se encontra na faixa de 0 à 2,5, 8 pacientes (80\%) se 
encontram na faixa de 2,6 à 5,0, correspondente à um procedimento tolerável, e 2 pacientes (20\%) na faixa de 5,1 à 7,5, correspondente à um procedimento dolorido ou desconfortável.

Para os pacientes do Grupo I, a mediana da avaliação da sintomatologia causada pela ativação do aparelho expansor foi de 1,0 enquanto que para pacientes do Grupo II foi de 5,0 (Gráfico 5.7).

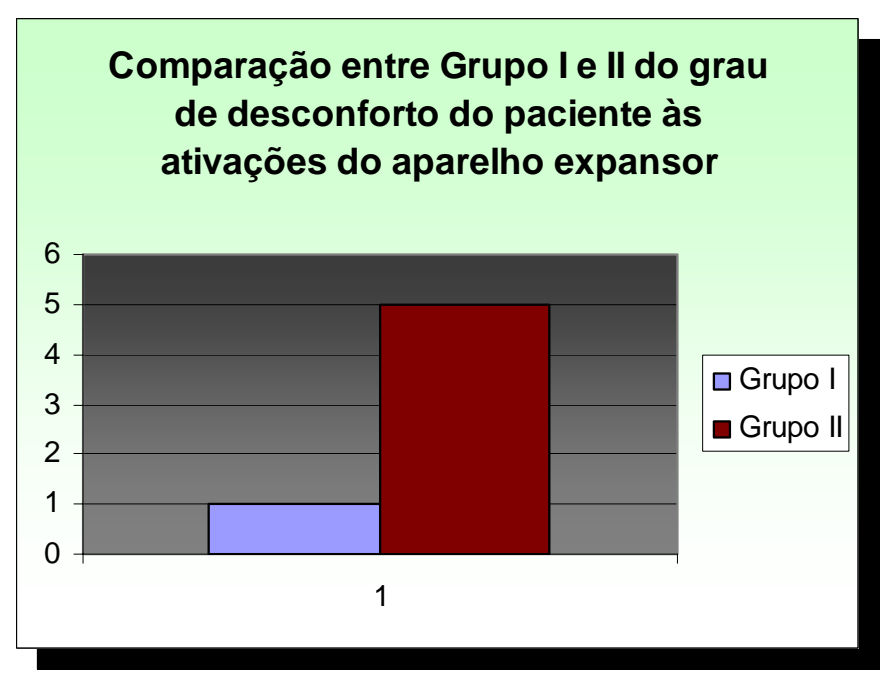

Gráfico 5.7 - Comparação da sintomatologia do paciente às ativações do aparelho expansor por grupo.

Nesta questão, também se aplica o teste não paramétrico de Mann-Whitney, a fim de se confirmar a hipótese de que as respostas dos Grupos I e II serão diferentes (Tabela 5.11). 
Tabela 5.11 - Teste não paramétrico de Mann-Whitney para Grupo I e II referente à Questão n.2

\begin{tabular}{c|c|c|c|c|c|c}
\hline Grupo & $\begin{array}{c}\text { Soma de } \\
\text { Postos }\end{array}$ & $\begin{array}{c}\mathrm{N}^{\text {o. de }} \\
\text { Valores }\end{array}$ & Posto médio & $\mathrm{U}$ & $\begin{array}{c}\text { Aproximação } \\
\text { Normal Z }\end{array}$ & $\mathrm{p}$ \\
\hline I & 117,0 & 14 & 8,35 & 12,0 & $-3,45$ & $0,005^{*}$ \\
\hline II & 183,0 & 10 & 18,30 & & & \\
\hline \multicolumn{7}{c}{ * diferença estatisticamente significante }
\end{tabular}

Estes testes mostram uma clara diferença no grau de desconforto ao longo dos dias de ativação do aparelho expansor, permitindo-nos afirmar que as ativações feitas pelos pacientes do Grupo II são mais dolorosas e/ou desconfortáveis àquelas feitas pelos pacientes do Grupo I.

5.4.4 - Questão n.3.

Esta questão refere-se à sintomatologia dolorosa do paciente no pós-operatório, lembrando que para todos os pacientes do Grupo I e II a medicação prescrita para o pós-operatório foi padronizada (Tabela 5.12). 
Tabela 5.12 - Valores obtidos pela avaliação dos pacientes do Grupo I e II com relação à Q.3.

\begin{tabular}{c|c} 
& G-I \\
\hline & Q.3 \\
\hline P01 & 1,5 \\
\hline P02 & 2 \\
\hline P03 & 0 \\
\hline P04 & 3 \\
\hline P05 & 3 \\
\hline P06 & 0 \\
\hline P07 & 0 \\
\hline P08 & 0 \\
\hline P09 & 0 \\
\hline P10 & 1 \\
\hline P11 & 1 \\
\hline P12 & 0 \\
\hline P13 & 0,5 \\
\hline P14 & 3 \\
\hline
\end{tabular}

\begin{tabular}{c|c} 
& G-II \\
\hline & Q.3 \\
\hline P15 & 3 \\
\hline P16 & 1 \\
\hline P17 & 3 \\
\hline P18 & 1,5 \\
\hline P19 & 2 \\
\hline P20 & 3 \\
\hline P21 & 3 \\
\hline P22 & 2 \\
\hline P23 & 2 \\
\hline P24 & 1,5 \\
\hline
\end{tabular}

Com relação à questão $n^{0}$. 3 , podemos afirmar que existem 11 pacientes do Grupo I (79\%) estão situados na faixa de 0 a 2,5, e 3 pacientes (21\%) na faixa de 2,6 à 5,0. Com relação aos pacientes do Grupo II, 6 pacientes (60\%) se encontram na faixa de 0 à 2,5, e 4 pacientes (40\%) se encontram na faixa de 2,6 à 5,0.

Para os pacientes do Grupo I, a mediana da avaliação da sintomatologia do período pós-operatório foi de 0,75 enquanto que para pacientes do Grupo II foi de 2,0 (Gráfico 5.8). 




Gráfico 5.8 - Comparação das notas dos pacientes do Grupo I e II sobre a dor pósoperatória.

Para esta questão, também se aplicou o teste não paramétrico de Mann-Whitney, com a finalidade de confirmação da hipótese de que pacientes do Grupo II possuem maior sintomatologia dolorosa durante os 14 ou 28 dias de pós-operatório (Tabela 5.13).

Tabela 5.13 - Teste não paramétrico de MannWhitney para Grupo I e II referente à Questão n.3.

\begin{tabular}{|c|c|c|c|c|c|c|}
\hline Grupo & $\begin{array}{c}\text { Soma de } \\
\text { Postos }\end{array}$ & $\begin{array}{c}\mathrm{N}^{\mathrm{o}} \text {. de } \\
\text { Valores }\end{array}$ & Posto médio & $\mathrm{U}$ & $\begin{array}{c}\text { Aproximação } \\
\text { Normal Z }\end{array}$ & $\mathrm{p}$ \\
\hline $\mathrm{I}$ & 136,5 & 14 & 9,75 & \multirow[t]{2}{*}{31,5} & \multirow[t]{2}{*}{$-2,30$} & \multirow[t]{2}{*}{$0,020 *$} \\
\hline II & 163,5 & 10 & 16,35 & & & \\
\hline
\end{tabular}


Estes valores nos permitem dizer que os pacientes submetidos à técnica proposta por GLASSMAN ${ }^{31}$ (Grupo II) têm maior sintomatologia dolorosa no pós-operatório do que àqueles submetidos à técnica cirúrgica proposta por BELL ${ }^{12}$ (Grupo I). Isto também pode ser reflexo da maior sintomatologia destes pacientes durante as ativações do aparelho expansor, observado na Q.2, sendo que, os períodos de ativação do aparelho expansor e recuperação pós-operatória são coincidentes.

\subsection{5 - Questão n. 4}

Esta questão refere-se à percepção do paciente quanto ao edema pós-operatório. Pelo fato dos pacientes dos dois grupos receberem medicação padronizada no pós-operatório, chegamos aos seguintes resultados (Tabela 5.14 e Gráfico 5.9): 
Tabela 5.14 - Valores obtidos pela avaliação dos pacientes do Grupo I e II com relação à Q.4.

\begin{tabular}{c|c} 
& G-I \\
\hline & Q.4 \\
\hline P01 & 2,5 \\
\hline P02 & 2 \\
\hline P03 & 3,5 \\
\hline P04 & 1 \\
\hline P05 & 3 \\
\hline P06 & 0 \\
\hline P07 & 3 \\
\hline P08 & 2 \\
\hline P09 & 2 \\
\hline P10 & 2 \\
\hline P11 & 1,5 \\
\hline P12 & 2 \\
\hline P13 & 2 \\
\hline P14 & 3 \\
\hline
\end{tabular}

\begin{tabular}{c|c} 
& G-II \\
\hline & Q.4 \\
\hline P15 & 3 \\
\hline P16 & 0 \\
\hline P17 & 2 \\
\hline P18 & 2 \\
\hline P19 & 2,5 \\
\hline P20 & 2 \\
\hline P21 & 1 \\
\hline P22 & 2 \\
\hline P23 & 1,5 \\
\hline P24 & 1 \\
\hline
\end{tabular}

Avaliação da percepção do paciente quanto ao edema formado no pósoperatório




Gráfico 5.9 - Avaliação da percepção do paciente quanto ao edema formado no pósoperatório.

Com relação à questão $n^{0}$. 4, podemos afirmar que existem 10 pacientes do Grupo I (71\%) estão situados na faixa de 0 a 2,5, e 4 pacientes (29\%) na faixa de 2,6 à 5,0. Com relação aos pacientes do Grupo II, 9 pacientes (90\%) se encontram na faixa de 0 à 2,5, e 1 pacientes (10\%) se encontram na faixa de 2,6 à 5,0.

Ao aplicarmos o teste não paramétrico de MannWhitney sobre a avaliação da percepção do paciente na questão n.4, obtivemos os seguintes resultados (Tabela 5.15):

Tabela 5.15- Teste não paramétrico de Mann-Whitney para Grupo I e II referente à Questão n.4

\begin{tabular}{|c|c|c|c|c|c|c|}
\hline Grupo & $\begin{array}{c}\text { Soma de } \\
\text { Postos }\end{array}$ & $\begin{array}{c}\mathrm{N}^{\mathrm{o}} \text {. de } \\
\text { Valores }\end{array}$ & Posto médio & U & $\begin{array}{c}\text { Aproximação } \\
\text { Normal Z }\end{array}$ & $\mathrm{p}$ \\
\hline I & 194,0 & 14 & 13,85 & \multirow[t]{2}{*}{51,0} & \multirow[t]{2}{*}{1,15} & \multirow[t]{2}{*}{$0,246^{*}$} \\
\hline II & 106,0 & 10 & 10,60 & & & \\
\hline
\end{tabular}

Tabela 5.15 - Teste não paramétrico de Mann-Whitney aplicado sobre a avaliação do edema pós-operatório em pacientes do Grupo I e II. 


\section{6 - DISCUSSÃO}

A expansão rápida da maxila assistida cirurgicamente é um procedimento que visa a correção das deficiências transversais maxilares em pacientes adultos. O presente trabalho avaliou duas formas de tratamento desta deformidade dentofacial sob anestesia local, com enfoque principal à percepção dos pacientes à sintomatologia trans e pós-operatória, uma vez que a literatura é inexpressiva sob este ponto de vista.

O grande desafio deste trabalho foi a obtenção de uma padronização do modo de atendimento, prescrição medicamentosa e controles radiográficos, pois, na literatura não existe tal sugestão de acompanhamento destes pacientes. Como forma de resolver este tipo de problema, a Disciplina de Cirurgia da Faculdade de Odontologia de Bauru, 
da Universidade de São Paulo, criou um protocolo de atendimento e controle pós-operatório destes pacientes.

Como visto anteriormente na revisão de literatura, cada autor cria uma metodologia específica de avaliação de pacientes e afirmam que a técnica utilizada é eficiente e alcança a estabilidade necessária para o tratamento destes pacientes.

Com isto em mente, o presente trabalho lança o seguinte questionamento, que quando respondido, guiará cirurgiões e ortodontistas à melhor forma de tratamento destes pacientes:

“Qual a melhor forma de se tratar um paciente adulto, portador de uma deficiência transversal maxilar?”.

Ao analisarmos a revisão de literatura, cada autor mostra em seu trabalho uma forma de tratamento apenas. Um determinado autor, por exemplo, utiliza-se da técnica de BELL ${ }^{12}$ sob anestesia local, outro autor utiliza a variação da técnica STAINHAUSER ${ }^{69}$ sob anestesia geral, WILFTANG \& KESSLER ${ }^{77}$ criam uma técnica com uso de endoscópio, outros trabalhos tratam pacientes com a técnica de BASDRA, ZÖELLER \& $\mathrm{KOMPOSCH}^{8}$ sob anestesia geral. Os regimes de ativação dos aparelhos expansores são diferentes quando comparamos autores que utilizam a mesma técnica cirúrgica. A medicação utilizada é diferente de 
trabalho para trabalho. O aparelho expansor utilizado por um autor é de um tipo e no trabalho de outro autor, utilizando a mesma técnica cirúrgica, é de outro. Ou seja, através da revisão de literatura é impossível confrontarmos dados para a eleição de um tipo de tratamento que atinja de forma mais rápida e estável os resultados que desejamos aos nossos pacientes.

Em contrapartida, os autores destes trabalhos relatam aumento de qualidade de vida do paciente e estabilidade destes resultados a longo prazo, recomendando que a técnica utilizada em seu trabalho seja empregada na correção das deficiências transversais maxilares.

Mas outro fator a ser levado em consideração é que apesar da variada gama de técnicas e dos resultados obtidos como duradouros e estáveis, em nenhum caso existe na metodologia, uma avaliação da sintomatologia do paciente referente ao tratamento recebido. As impressões observadas na literatura quanto ao procedimento ser ou não agressivo e/ou traumático ao paciente são observações empíricas dos autores, sem uma metodologia científica associada às mesmas.

Exemplo disto está na técnica proposta por WILTFANG \& KESSLER ${ }^{77}$ para a realização da ERMAC com a utilização de um endoscópio. A alegação destes autores, de que esta seja uma técnica menos traumática ao paciente, possui algumas controvérsias. Em primeiro 
lugar, como avaliar se a cirurgia é traumatizante ao paciente se ele está sob anestesia geral? Em segundo lugar, estes autores utilizam a clivagem da sutura palatina mediana com cinzel e martelo como a maioria das técnicas já descritas, sendo este, o passo considerado mais traumático das técnicas cirúrgicas de expansão rápida da maxila assistida cirurgicamente.

Segundo a maioria dos autores que se utilizam da separação do processo pterigóide da maxila e clivagem da sutura palatina mediana com a utilização de cinzel e martelo, estes são os procedimentos onde podem ocorrer as maiores complicações durante o trans-operatório ${ }^{6,10 \text {, }}$ $11,31,47,53,54,69$

Outro ponto a ser considerado é que o tempo cirúrgico dos pacientes desta pesquisa foi de cerca de 40 minutos, enquanto que a técnica descrita por WILTFANG \& KESSLER ${ }^{77}$ possui 90 minutos de cirurgia. Portanto, não se vê grandes vantagens nesta técnica. Fato este comprovado após novo levantamento bibliográfico por parte deste trabalho, e que não foi encontrada qualquer seqüência desta linha de pesquisa.

Outro exemplo é dado por WOLFORD, RIECHEFISCHEL \& MEHRA ${ }^{78}$, em seu trabalho de 2002, em que não mostram qual o número de pacientes onde os blocos de hidroxiapatita são utilizados entre os cotos maxilares. Sabe-se que biomateriais devem possuir 
estabilidade para que suas propriedades osteocondutoras, osteoindutoras, osteoestimuladoras ou osteogenéticas sejam alcançadas. A ERMAC, bem como as osteotomias segmentares da maxila são procedimentos dinâmicos, com alteração de posição dos cotos seccionados bem como de alterações faciais ao longo de um ano 4, 9, 13, 14, 26, 46, 57, 59, 61, 76. Este tipo de processo de reparo é, de certa forma, incompatível com a utilização deste biomaterial que é, segundo CARVALHO, BASSI \& PEREIRA ${ }^{20}$ osteocondutor. Provavelmente, apenas o enxerto ósseo autógeno, que é osteogênico, poderia ser utilizado para este propósito.

Sendo assim, o presente trabalho não recomenda o uso destas técnicas.

O que não foi observado na literatura, é a adoção de uma comparação entre duas ou mais formas de tratamento cirúrgico da deficiência transversal maxilar em pacientes adultos, sob um mesmo padrão de controle pós-operatório, para que a pergunta: “Qual a melhor forma de se tratar um paciente adulto, portador de uma deficiência transversal maxilar?”, comece a ser respondida.

À partir desta proposta, este trabalho tem por finalidade começar a responder esta questão, levando em consideração os resultados obtidos por duas técnicas cirúrgicas para a correção da deficiência 
transversal maxilar, observados por um mesmo parâmetro de atendimento, controle radiográfico pós-operatório e principalmente, através de um método, como o paciente percebe o procedimento cirúrgico ao qual foi submetido e, como este reage durante os primeiros dias do pós-operatório. 


\section{$\underline{6.1 \text { - Eficácia das técnicas cirúrgicas }}$}

$$
\text { GLASSMAN }{ }^{31} \text {, em 1984, ao descrever sua }
$$

técnica, aponta como principal vantagem a pouca sintomatologia pósoperatória, quando em comparação ao uso do cinzel ou osteotomia da sutura palatina mediana. Porém, ao analisar o trabalho, nota-se que esta é uma observação do próprio autor, pois não há referências sobre esta afirmação. Acreditamos que devido à época em questão do desenvolvimento do trabalho e à própria medicação analgésica existente à época, que também não é descrita no trabalho com clareza suficiente, esta comparação foi feita. Mas ao confrontarmos os dados obtidos no presente trabalho com os dados obtidos por GLASSMAN ${ }^{31}$ vemos algumas diferenças.

Em primeiro lugar, a diferença de índice de sucesso. Alcançamos um índice de sucesso das cirurgias em 30\% dos casos, em comparação aos 100\% de GLASSMAN ${ }^{31}$. Este fato, na opinião do autor deste trabalho, já suficiente para contra-indicar a adoção de referida técnica.

Em segundo lugar, concordamos que exista um relativo menor grau de desconforto ao paciente no trans-operatório e que, prováveis transtornos trans e pós-operatórios, como hemorragia oriunda do canal incisivo, possui menor probabilidade de ocorrer, já que não existe manipulação cirúrgica da área em questão. Porém os resultados obtidos nesta 
pesquisa mostram que não existe diferença estatisticamente significante entre os dois grupos para afirmar com precisão a observação do desconforto trans-operatório.

Em terceiro lugar, os resultados obtidos de pacientes submetidos à técnica proposta por GLASSMAN ${ }^{31}$ (Grupo II) mostram um desempenho pós-operatório pior do que os pacientes submetidos à expansão rápida da maxila assistida cirurgicamente, utilizando a técnica de BELL ${ }^{12}$ (Grupo I). Vale ressaltar que o tempo de transoperatório é de cerca de 40 minutos para ambos os grupos e que o período compreendido de pós-operatório pode variar de 14 a 28 dias.

Ao observarmos os valores de avaliação dos pacientes do Grupo I, em que apesar de possuírem inexpressivo grau de sintomatologia maior do que o Grupo II durante o trans-operatório, tiveram um período de 14 ou 28 dias com menor sintomatologia, neste ponto, com significância estatística, sendo fatos a serem discutidos mais adiante.

O presente trabalho, ao contrário do trabalho de GLASSMAN ${ }^{31}$, controlou todos os aspectos envolvidos no pós-operatório como a medicação analgésica padronizada.

Portanto acreditamos que as principais vantagens desta técnica, defendida por seus autores, não sejam realistas. Outro fator a 
ser considerado é que 7 dos 10 pacientes submetidos à técnica de GLASSMAN $^{31}$ tiveram que se submeter a um novo procedimento cirúrgico, o que nos leva a questionar a afirmação destes autores sobre o procedimento, descrito por eles, ser pouco traumático.

Outro trabalho que mostra eficiência desta técnica cirúrgica é o artigo de SCHIMMING e cols ${ }^{66}$ em que as cirurgias foram realizadas sob anestesia geral e ,apesar dos autores chamarem de técnica de GLASSMAN ${ }^{31}$, houve uma importante modificação da técnica. Estes autores faziam 12 ativações do aparelho expansor após a realização das osteotomias e mantinham esta ativação por 5 minutos, então voltavam 8 ativações totalizando 4 ativações. GLASSMAN ${ }^{31}$, em seu artigo em 1984, descreve sua técnica com apenas 4 ativações após a realização das osteotomias.

Provavelmente este foi o motivo do alto índice de sucesso destes autores utilizando esta técnica, sendo o único trabalho, além de GLASSMAN e cols ${ }^{31}$, que mostrou tal eficácia. O presente trabalho utilizou a técnica de GLASSMAN ${ }^{31}$ descrita em seu artigo sem aplicar qualquer modificação, pois acreditamos que o paciente sob anestesia local não suportaria o desconforto causado pelas 12 ativações e mantendo-as por 5 minutos, mas esta também é uma observação sem mensuração científica. 
O trabalho de LEHMAN \& HAAS ${ }^{49}$, mostra um índice de sucesso da técnica proposta por GLASSMAN ${ }^{31}$ de 70\%. Acreditamos que estes autores tenham tido um índice de sucesso maior do que o obtido pelo presente trabalho pela simples mudança do aparelho expansor. O aparelho dento-muco suportado, utilizado neste artigo, força mais as estruturas ósseas do que os dentes, ao contrário do aparelho dento suportado, utilizado no presente trabalho, onde todas as forças ortopédicas incidem nos dentes onde a ancoragem é feita.

Porém em um dos pacientes excluído da amostra, tratado pelo autor do presente trabalho, em que o ortodontista erroneamente cimentou um aparelho dento-muco suportado, ao invés do dento suportado como pedido pelo nosso protocolo de atendimento, também não obtivemos sucesso de cirurgia, sendo que as observações referentes a este paciente serão discutidas mais adiante. Este paciente não foi inserido no contexto desta pesquisa, porém devido às curiosidades de seus resultados pósoperatórios, relacionando-os com os trabalhos supracitados, será alvo de discussão, uma vez que o questionário também fora aplicado ao paciente, além de ilustrar o segundo procedimento cirúrgico ao qual os pacientes do Grupo II foram submetidos em casos de insucesso de cirurgia. 
De acordo com SHETTY e cols ${ }^{67}$, baseados em observação fotoelástica, concluem que apenas as osteotomias laterais maxilares são inadequadas para a expansão maxilar em adultos. Concordamos com estes autores quando afirmam que as forças exercidas pelo aparelho expansor de Hyrax produzem grandes efeitos anatômicos, e que, a ativação deste aparelho expansor nas condições descritas acima causa grande dor e desconforto ao paciente, fato este observado pelos resultados do Grupo II quanto a sintomatologia das ativações do aparelho expansor e dor pós-operatória.

Ao levarmos em consideração as afirmações de SHETTY e cols ${ }^{67}$, comparando os dados obtidos entre os dois grupos quanto à dor e desconforto pós-operatório e ativação do aparelho expansor, a diferença cirúrgica entre os grupos é a clivagem da sutura palatina nos pacientes do Grupo I e a não clivagem da sutura palatina nos pacientes do Grupo II. Os pacientes do Grupo I obtiveram melhor resposta pós-operatória concordando com as afirmações destes autores ${ }^{67}$.

BELL \& JACOBS ${ }^{11}$, em 1979, já afirmavam que pacientes submetidos às expansões maxilares cirurgicamente assistidas possuíam pouco desconforto pós-operatório e mínimo desconforto às ativações. Estes autores realizavam a osteotomia palatina e separação do 
processo pterigóide. Este mesmo autor, em 1992, mostra que a separação do processo pterigóide é um passo desnecessário na grande maioria dos casos ${ }^{12}$. Os dados levantados por estes autores são corroborados por este trabalho ao analisarmos os pacientes do Grupo I, submetidos à técnica descrita por BELL em $1992^{12}$.

Segundo CHUNG \& GOLDMAN ${ }^{23}$, mesmo após a realização das osteotomias laterais e palatina, existe um certo grau de movimentação dentária (rotação e inclinação) associada à ativação do aparelho expansor em seus pacientes adultos, fato este confirmado pelo trabalho de ZIMRING \& ISAACSON ${ }^{83}$, onde demonstram que com o avançar da idade as forças necessárias para realizar a ERM são maiores.

Acreditamos que as suturas zigomaticomaxilares, zigomáticotemporais e frontomaxilar são as estruturas mais importantes no que se referem à resistência ao movimento de expansão maxilar, mas também acreditamos que a sutura palatina mediana deva ser considerada como uma área de resistência à expansão e que deve ser manipulada cirurgicamente. Fato este mostrado nos pacientes do Grupo II que tiveram como principal complicação pós-operatória, além da dor, a excessiva inclinação dos primeiros pré-molares e dos primeiros molares (locais onde as bandas do aparelho expansor estavam cimentadas) (Figuras 6.1 A e B). 
Acreditamos que se a sutura palatina mediana não interferisse na movimentação maxilar durante a expansão, os resultados do Grupo II seriam diferentes, alcançando um melhor índice de sucesso.

Ainda em relação à resistência da sutura palatina mediana, LANIGAN \& MINTZ ${ }^{48}$ reportam em seu trabalho, a fratura de parte do corpo do esfenóide causado pelo estresse das ativações do aparelho expansor, justificando este achado pelos trabalhos de ISAACSON ${ }^{40} \mathrm{e}$ SHEETY ${ }^{67}$, que mostram as áreas de dissipação de forças durante a expansão maxilar e que estas forças podem ser dirigidas à base do crânio. Acreditamos existir uma hipótese para o caso em questão. Durante a cirurgia, não houve a completa separação dos cotos maxilares na confecção das osteotomias, sendo que, ao invés destas realizarem a fratura maxilar, a ativação do aparelho expansor a fez. Isso vem corroborar com os achados deste trabalho, já que a sutura palatina veio mostrar-se como uma área de intensa resistência à expansão maxilar.

ISAACSON $^{40}$ e SHEETY ${ }^{67}$ recomendam uma ativação trans-cirúrgica não superior a $1 \mathrm{~mm}$, assim como GLASSMAN ${ }^{31}$. Em todos os nossos pacientes submetidos à clivagem da sutura palatina mediana, foram realizadas 8 ativações imediatamente ao fim da cirurgia e 
em nenhum caso houve qualquer tipo de complicação ou sensação de desconforto ao paciente.

O trabalho de MOSSAS, BYLOFF \& RICHTER 56, mostram as alterações anatômicas causadas pela ERMAC, porém a amostra do trabalho (4 pacientes divididos em 2 grupos) é muito pequena para alcançar as conclusões obtidas. Acreditamos que as conclusões sejam realistas e verdadeiras apesar da pequena amostra utilizada, pois as inclinações dentárias também foram vistas em nossos pacientes, principalmente com relação aos pacientes do Grupo II, onde as forças exercidas pelo aparelho expansor eram aplicadas sobre os dentes em que a ancoragem do aparelho era feita, sem a separação da sutura palatina mediana. Esta foi uma observação clínica feita durante o controle pósoperatório, não sendo objetivo de investigação do presente trabalho.

As implicações clínicas destas alterações anatômicas podem ser sintetizadas com a evolução clínica da paciente referida anteriormente, sexo feminino, 28 anos de idade. Após a realização da cirurgia desta paciente, seguindo a técnica de GLASSMAN ${ }^{31}$, observamos ao controle pós-operatório uma extensa vestibularização dos dentes onde a banda do aparelho dento-muco suportado estava cimentado. O fato da utilização deste aparelho, por este paciente apenas (erro do 
ortodontista), pode comprometer os argumentos de que os pacientes do Grupo II obtiveram insucesso de técnica cirúrgica, devido ao uso de um aparelho expansor do tipo dento suportado e não de um aparelho dento-muco suportado. Lembrando que GLASSMAN ${ }^{31}$ descreveu sua técnica utilizando-se de aparelhos expansores do tipo Hyrax (dento suportado) (Figuras 6.1 A e B).

Segundo GURGEL e cols ${ }^{33}$, a telerradiografia P.A. é um meio confiável de se avaliar as expansões maxilares e avaliação de inclinações dentárias, desde que a radiografia seja realizada dentro de um mesmo protocolo. Em todos os pacientes desta pesquisa, as telerradiografias P.A. foram realizadas com o uso de um cefalostato e a colocação do plano de Camper do paciente paralelo ao solo. Esta padronização nos permite avaliar o grau de vestibularização dos dentes utilizados como suporte para os aparelhos expansores. Apesar de este não ser um dos parâmetros de avaliação deste trabalho, o efeito foi mais percebido em pacientes do Grupo II em comparação aos pacientes do Grupo I, porém não foram mensurados porque este é objetivo de outro trabalho em desenvolvimento na Faculdade de Odontologia de Bauru.

Este fator foi trazido ao momento apenas para ratificar o observado na revisão de literatura, pois nesta paciente observamos 
radiograficamente ao compararmos a telerradiografia P.A. realizada no préoperatório (exame do paciente) com a telerradiografia P.A. do primeiro controle pós-operatório, as inclinações dentárias e a ausência de disjunção maxilar (Figuras 6.2 A e B).
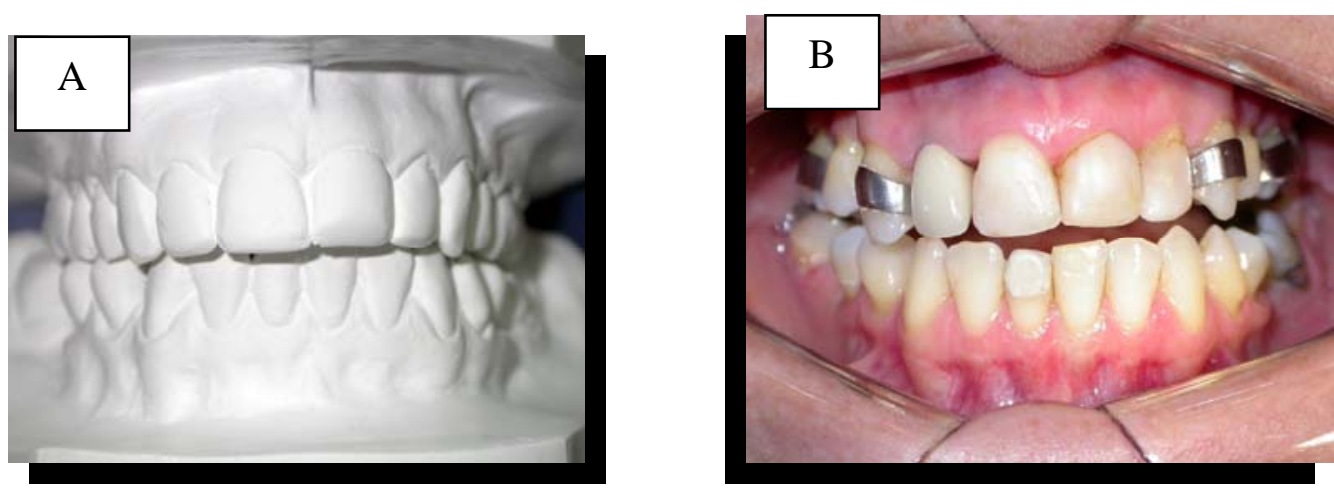

Figuras 6.1 A e B - Modelo de gesso com a oclusão inicial da paciente (A). Oclusão da paciente no primeiro controle pós-operatório, onde se nota a ausência do diastema entre incisivos centrais superiores e a formação de uma mordida aberta anterior devido a inclinação dos molares (B).


Figuras 6.2 A e B. Telerradiografia P.A. feita no pré-operatório (A), aplicando um dos traçados descritos por GURGEL e cols ${ }^{33}$. Telerradiografia P.A. feita ao controle pósoperatório utilizando o mesmo traçado feito na radiografia pré-operatória, evidenciando a maior inclinação dos molares. 
Esta paciente também avaliou que as ativações do aparelho expansor foram dolorosas (o menor valor obtido em todos os casos da pesquisa) (Tabela 6.1).

Tabela 6.1 - Resultados obtidos com os pacientes do Grupo II

\section{G-II}

\begin{tabular}{l|c|c|c|c|c}
\hline & Q.1 - Pós Op. Im. & Q.1 - 1 ${ }^{\circ}$ Pós Op & Q.2 & Q.3 & Q.4 \\
\hline P15 & 7,5 & 8 & 5 & 7 & 7 \\
\hline P16 & 9 & 9 & 6 & 9 & 10 \\
\hline P17 & 8,5 & 9,5 & 5 & 7 & 8 \\
\hline P18 & 8 & 8,5 & 5,5 & 8,5 & 8 \\
\hline P19 & 8,5 & 8,5 & 6 & 8 & 7,5 \\
\hline P20 & 8 & 9 & 4,5 & 7 & 8 \\
\hline P21 & 7 & 8 & 5 & 7 & 9 \\
\hline P22 & 7 & 8,5 & 4,5 & 8 & 8 \\
\hline P23 & 7 & 8 & 5 & 8 & 8,5 \\
\hline P24 & 7,5 & 8 & 5 & 8,5 & 9 \\
\hline
\end{tabular}

Neste momento, também, faremos a análise da evolução de outro paciente excluído da amostra do Grupo II, onde obtivemos sucesso de técnica cirúrgica. Assim como a paciente n. 22, a avaliação do desconforto às ativações do aparelho expansor obteve o mesmo escore (Tabela 6.1). A grande diferença é que esta paciente fez, por conta própria, uma ativação excessiva do aparelho expansor fugindo do protocolo de ativação proposto por GLASSMAN ${ }^{31}$, sendo esta a justificativa de sua exclusão. Esta paciente fazia 4 ativações diárias do aparelho ao invés de 2. 
Neste caso, assim como foi visto no trabalho de SCHIMMING e cols ${ }^{66}$, acreditamos que uma maior força aplicada ao aparelho expansor, associada à técnica proposta por GLASSMAN ${ }^{31}$, possa então trazer benefícios clínicos aos pacientes, em termos de eficácia de cirurgia apenas.

Porém, fica claro, a partir dos resultados do presente trabalho, que o período de recuperação pós-operatória e ativação do aparelho expansor é mais doloroso para estes pacientes.

Acreditamos que a evolução destes pacientes sejam uma síntese de todos os fatores abordados pelos autores, da revisão de literatura, no que diz respeito à áreas de reforço maxilar, quantidade de osteotomia e chances de recidiva, bem como, experiências dolorosas ao pósoperatório, a resistência da sutura palatina mediana à expansão maxilar e chance de insucesso.

Os pacientes P-15 a 19, P-21 e P-22 após a avaliação pós-operatória, foram submetidos a nova cirurgia da seguinte maneira (Figuras 6.3 A, B. C e D):

Realização de analgesia maxilar com os bloqueios regionais infra-orbitários bilateralmente, bloqueio regional dos nervos palatinos maiores e bloqueio regional nasopalatino. 
Incisão em "V” na região de freio labial e clivagem da maxila seguindo-se os parâmetros cirúrgicos propostos pela técnica de BELL $^{12}$.
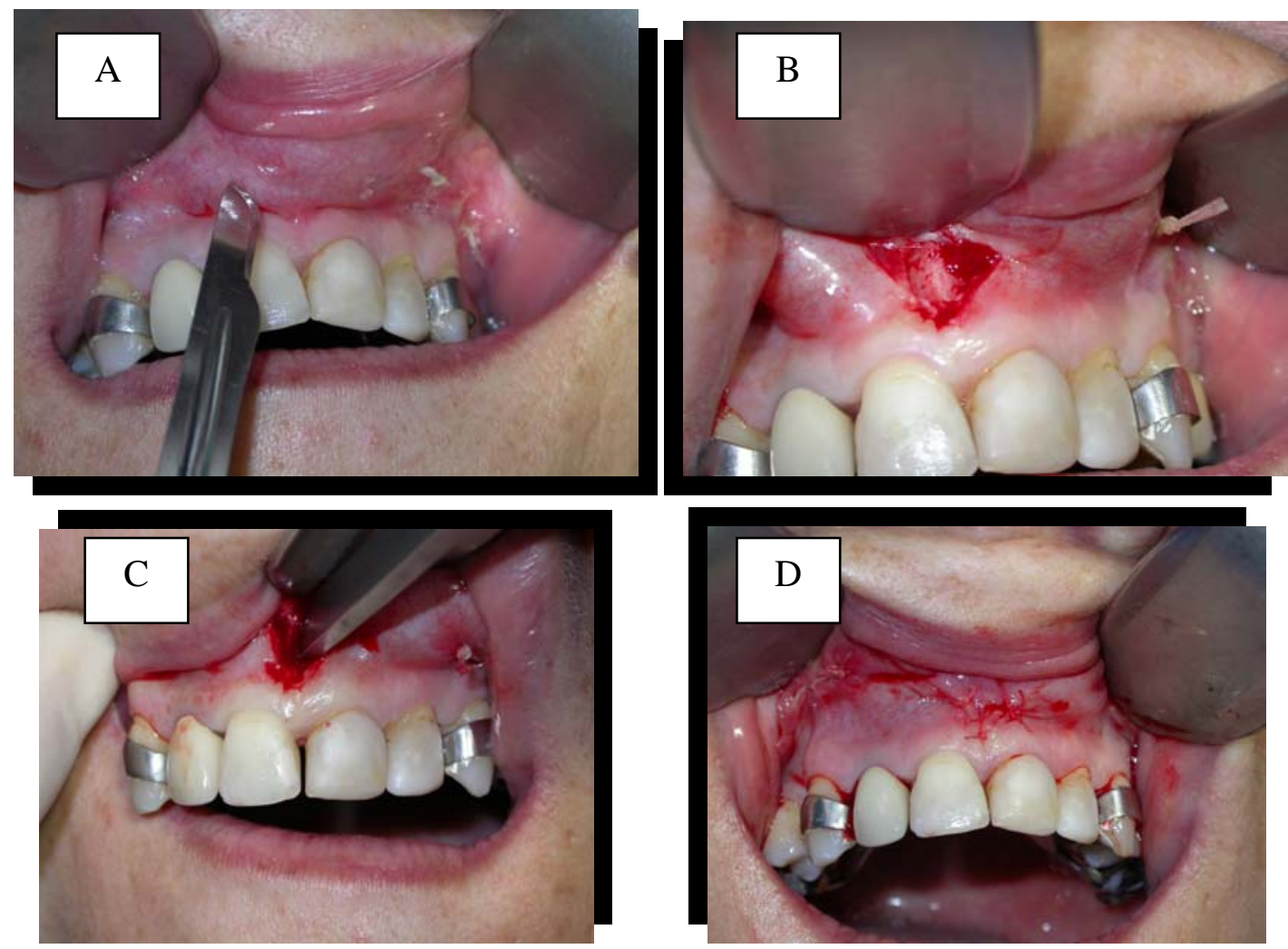

Figuras 6.3 A, B, C e D - Após os bloqueios anestésicos, incisão em "V” realizada em região de freio labial (A). Rebatimento do retalho e visualização da sutura intermaxilar (B). Clivagem da sutura palatina mediana com cinzel e imediata abertura do diastema (C). Sutura final (notar a presença ainda dos fios de sutura utilizados na primeira cirurgia) (D).

BASDRA, ZÖLLER \& KOMPOSCH ${ }^{8}$ afirmam que quanto menos osteotomia é realizada durante a cirurgia, maiores são as taxas de recidiva de mordida cruzada posterior e maior o desconforto do 
paciente durante as ativações do aparelho expansor. Estes autores são os primeiros que citam a falta de padronização dos tempos de contenção pósoperatória e que isto é reflexo de falta de um protocolo definido para atendimento destes pacientes. Estas afirmações vão de encontro aos resultados obtidos por este trabalho, onde pacientes submetidos à cirurgias, consideradas pela literatura como conservadoras, tiveram mais desconforto durante o período pós-operatório e às ativações do aparelho expansor do que àqueles que se submeteram às cirurgias mais “completas”.

Com relação à falta de um protocolo definido para o atendimento destes pacientes, a questão levantada no início deste capítulo se faz evidente: "Qual a melhor forma de se tratar um paciente adulto portador de uma deficiência transversal maxilar?”. Questão esta, levantada de forma semelhante por POGREL, KABAN e VARGERVIK ${ }^{59}$ e que atende as expectativas de cirurgiões, ortodontistas e pacientes: "Qual é o procedimento mínimo necessário para produzir uma expansão maxilar em adultos consistente e estável?”.

Questão, que se respondida, irá guiar cirurgiões e ortodontistas para um tratamento previsível com mínima morbidade aos pacientes. 
Existem os autores que consideram a sutura intermaxilar como essencial na resistência do movimento lateral maxilar, recomendando inclusive a osteotomia no palato ${ }^{10,72,73}$. Outros mostram que a sutura zigomatigomaxilar, com seu forte osso cortical, é mais decisiva como região de resistência da movimentação maxilar ${ }^{31,} 49$ e, por conseqüência, se deve osteotomizar estas áreas apenas. Muitos autores são favoráveis ao uso da osteotomia palatina combinada com a osteotomia lateral da maxila 9, 10, 15, 50, 57, 59. É evidente a falta de consenso entre os autores sobre a quantidade mínima de osteotomia necessária para facilitar a expansão maxilar, e a questão lançada por POGREL, KABAN e VARGERVIK $^{59}$ ainda não foi bem respondida.

Apesar da pergunta ter sido lançada em $1992^{59}$, acreditamos que TIMMS \& VERO ${ }^{73}$, em 1981, tenham dado a melhor resposta até o momento à questão, pois os autores relacionaram o aumento de procedimentos cirúrgicos necessários à expansão maxilar com a idade do paciente. Ou seja, quanto mais velho é o paciente, maior a probabilidade de realização de maiores procedimentos cirúrgicos.

Em outras palavras, existe a probabilidade de que após uma série de estudos controlados, onde, conforme o tipo de deficiência 
transversal maxilar, idade do paciente e sexo, exista uma técnica cirúrgica que melhor atenda a estas necessidades.

Neste momento, após todas estas considerações sobre a eficácia da técnica cirúrgica, cabe a discussão sobre a amostragem e a divisão entre os grupos de forma desigual.

O projeto inicial desta pesquisa era de 12 pacientes por grupo, dando um total de 24 pacientes. Porém era necessário que durante a fase de execução da pesquisa, resultados parciais fossem obtidos de tal forma que se confirmasse que o número da amostra era suficiente.

Após a realização de 20 cirurgias (10 dos pacientes do Grupo I e 10 do Grupo II), uma análise estatística prévia foi utilizada, onde já se mostrava uma clara discrepância de insucesso de técnica cirúrgica dos pacientes do Grupo II (30\% em comparação com os 100\% do Grupo I). Uma consulta com representantes do Comitê de Ética em Pesquisa da FOBUSP foi feita. Nesta consulta, foi levantada a questão sobre a real necessidade de continuar a submeter os pacientes a este tipo de tratamento, uma vez que a análise estatística feita com 20 pacientes era suficiente para as conclusões deste trabalho. Optou-se então em concluir a amostra do Grupo I e submeter os outros dois pacientes do Grupo II à técnica proposta por BELL ${ }^{12}$. Desta forma, mantivemos a amostra original do projeto de 
pesquisa, dando o atendimento que os pacientes necessitavam colhendo os dados científicos que nos interessavam.

\section{2 - Tipos de fraturas da crista alveolar}

O trabalho de CURETON \& CUENIN ${ }^{25}$ é um dos mais importantes, na opinião do autor da presente pesquisa, relacionados à expansão rápida da maxila assistida cirurgicamente.

Pela primeira vez, através de uma metodologia de controle radiográfico pós-operatório, se começa a levar em consideração diferentes tipos de regime de ativação do aparelho expansor conforme o tipo de fratura ocorrida na crista alveolar entre os incisivos centrais superiores.

É importante salientar também que estes autores foram os que descreveram os critérios para adoção dos termos fratura simétrica e assimétrica.

A grande contribuição deste trabalho é a de apresentar aos cirurgiões e ortodontistas uma maneira de se contornar um dos mais desagradáveis “efeitos colaterais” da expansão rápida da maxila assistida cirurgicamente: o defeito ósseo, recessão gengival e formação de 
bolsa periodontal entre os incisivos centrais superiores 1, 9, 17, 25, 26, 40, 42, 46, 48, $53,63,79,81,83$

O trabalho de BELL \& EPKER ${ }^{10}$ de 1976 mostra uma evolução da técnica de STAINHAUSER ${ }^{69}$ de 1972, onde não se faz mais necessário o uso das osteotomias palatinas. As ativações feitas por estes autores não respeitavam o tipo de fratura ocorrida na crista, sendo este um dos principais pontos criticados desta técnica. A revisão de literatura aponta os defeitos estéticos na região de incisivos superiores uma das principais desvantagens desta técnica ${ }^{1,9,17,25,26,40,42,46,48,53,63,79,81,83}$.

\section{Assim como MORGAN \& FRIDRICH ${ }^{55}$, em} 2001, a técnica de clivagem da sutura palatina mediana com o uso de cinzéis e martelo segue os princípios descritos por estes autores para a realização das osteotomias verticais na realização da osteotomia Le Fort I multissegmentar da maxila, onde conseguiram praticamente anular os efeitos sobre o periodonto do paciente, nas regiões de fratura. $\mathrm{O}$ fato de o presente trabalho seguir técnica semelhante, respeitando os princípios de análise de fratura descritos por CURETON \& CUEENIN ${ }^{25}$, para somente então definir o regime de expansão a ser adotado, explica a ausência de recessões gengivais e outros problemas periodontais em nossos pacientes, principalmente nos casos de fraturas assimétricas (Figuras 6.4 A, B, C, e D). 

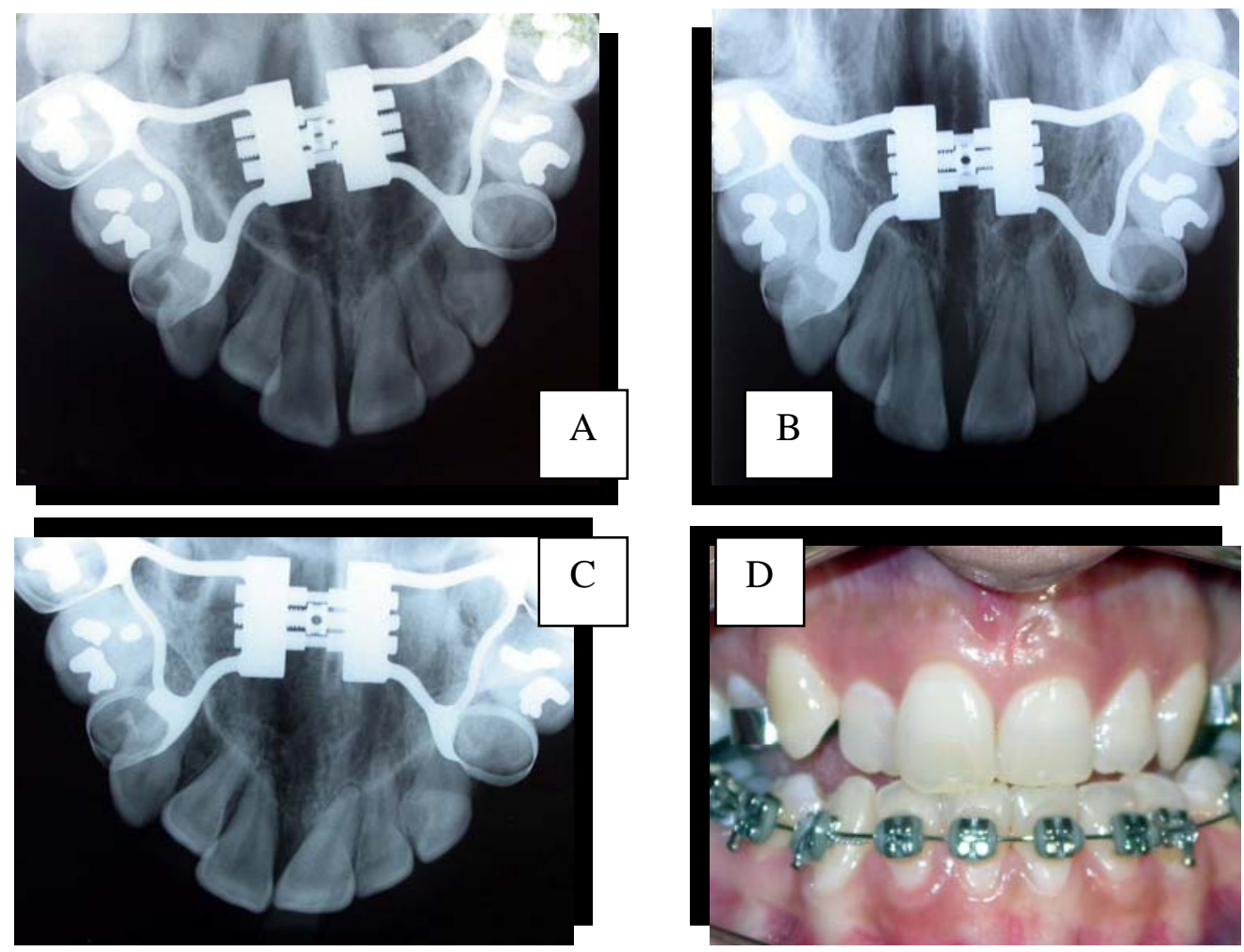

Figura 6.4 A, B, C, e D - Radiografia oclusal realizada ao pós-operatório imediato diagnosticando uma fratura assimétrica (A). Controle radiográfico pós-operatório de 4 meses (B). Controle radiográfico pós-operatório de 6 meses (C). Último controle clínico antes da remoção do aparelho expansor (D). Notar a excelente saúde gengival e ausência de defeitos estéticos entre os incisivos centrais superiores.

Ao analisarmos os trabalhos da revisão de literatura após a publicação do estudo de CURETON \& CUENIN ${ }^{25}$, fica evidente o grande problema das metodologias científicas para análise de ERMAC. Uma vez que estes fatores descritos são praticamente ignorados pela maioria dos autores, adotando um único regime de expansão aos pacientes, resultados ruins como os de RAMIERI e cols ${ }^{63}$ podem ser vistos. 
Acreditamos que se RAMIERI e cols ${ }^{63}$ tivessem realizado uma radiografia periapical ou oclusal de maxila do pós-operatório imediato, adotando os princípios de CURETON \& CUENIN ${ }^{25}$, onde se realiza menos expansão, com intervalo de 2 dias, entre as ativações nos casos de fraturas duvidosas e assimétricas, estes efeitos periodontais teriam sido evitados, assim como foram nos pacientes da presente pesquisa.

Um fato interessante notado nos pacientes do Grupo II é que independentemente do sucesso ou insucesso da cirurgia (após a segunda cirurgia, é claro), todos seguiram o mesmo padrão de fratura de crista alveolar do tipo simétrica. A fratura simétrica, segundo CURETON \& CUENIN $^{25}$, é o tipo de fratura ideal de crista alveolar, pois estas protegem o periodonto de sustentação dos incisivos centrais superiores e fornece arquitetura favorável à neoformação óssea evitando defeitos periodontais e estéticos nesta região.

Porém, apesar da relativa alta incidência de fraturas assimétricas nos pacientes do Grupo I (21,44\%), ao seguir o regime de expansão adequado a cada paciente conforme o tipo de fratura de crista alveolar, esta aparente vantagem dos pacientes do Grupo II perde a importância. Acreditamos que a importância do diagnóstico se dá nos casos de fraturas duvidosas, onde no Grupo I ocorreu em praticamente 1/3 dos 
pacientes. Dentre as fraturas consideradas como duvidosas, no pósoperatório imediato, $80 \%$ foram posteriormente diagnosticadas como assimétricas (4 fraturas assimétricas de 5 diagnosticadas como duvidosas). Ou seja, segundo nossos resultados, existe uma tendência de que uma fratura diagnosticada como duvidosa ser na realidade assimétrica, daí a importância da adoção de um regime de expansão adequado.

\section{3 - Sintomatologia relatada referente ao trans-operatório}

Como já mostrado pela revisão de literatura, a gama de variações de técnicas cirúrgicas para correção da deficiência transversal maxilar em pacientes adultos é grande. Como já discutido anteriormente, todos os autores afirmam que a técnica usada em seu trabalho causa pouco, ou nenhum desconforto ao paciente.

Trabalhos mostram que este procedimento, na maioria das vezes, pode ser realizado nos consultórios odontológicos, sob anestesia local. Segundo estes autores, estas cirurgias são pouco traumatizantes e bem aceitas pelos pacientes ${ }^{10,11,12,31}$.

Entretanto, outros trabalhos afirmam que este procedimento é extremamente agressivo e traumatizante ao paciente, sendo 
que recomendam a realização desta cirurgia sob anestesia geral em ambiente hospitalar ${ }^{6,8,47,56}$.

Concordamos que, quando se faz necessária a realização da separação do processo pterigóide da maxila, em casos de atresia severa maxilar posterior, esta cirurgia deva ser feita sob anestesia geral, sendo este o único ponto de convergência entre todos os autores.

O interessante é que em nenhum dos dois casos supra citados um autor fez, através de uma metodologia, científica uma avaliação do paciente que recebera o tratamento proposto, o que nos leva a por em dúvida a real validade científica de tais afirmações.

Dentre uma das finalidades deste trabalho, a de se tentar responder à questão feita por POGREL, KABAN e VARGERVIK ${ }^{59}$ é fundamental: “Qual é o procedimento mínimo necessário para produzir uma expansão maxilar, em adultos, consistente e estável?’.

Uma das variáveis a ser levada em consideração na escolha deste procedimento é o conforto que devemos propiciar aos nossos pacientes. Portanto, a avaliação da sintomatologia do paciente sobre as diferentes formas de correção cirúrgica da deficiência transversal maxilar passa a ser fundamental. Assim, se a avaliação dos pacientes mostrar que o 
procedimento é agressivo e intolerável ao paciente, as cirurgias sob anestesia local não devem ser mais indicadas.

Os nossos resultados são encorajadores na realização deste procedimento sob anestesia local, com a grande diferença de que nossa afirmação é feita com base de sustentação estatística.

Nos dois grupos deste trabalho obtivemos um grau de avaliação muito bom por parte dos pacientes, sendo que a avaliação mediana dos pacientes submetidos à técnica do Grupo I foi de 3,0 e dos pacientes do Grupo II foi de 2,25.

Um dado interessante, e que causou surpresa aos pesquisadores do presente trabalho, foi a não significância estatística quando comparado os valores obtidos, com a questão referente ao desconforto transoperatório, entre os pacientes do Grupo I com os pacientes do Grupo II. Este fato pode servir de base para que a técnica proposta por GLASSMAN ${ }^{31}$ deixe de ser utilizada devido aos seguintes fatores:

1. Clinicamente, é visível, imediatamente após a realização da clivagem da sutura palatina mediana, a formação do diastema entre incisivos centrais superiores. Isto nos dá a certeza de que a cirurgia foi completada com êxito. Portanto o paciente deixa a sala de cirurgia com a disjunção palatina realizada. O fato de não se observar a formação de um 
diastema imediatamente em nenhum caso dos pacientes do grupo II, coloca em dúvida ao final da cirurgia se a disjunção palatina ocorreu, ou ainda se ocorrerá no período pós-operatório. Uma vez não ocorrendo a disjunção maxilar, o paciente deverá ser submetido a um novo procedimento cirúrgico.

2. A não significância do grau de sintomatologia devido à técnica cirúrgica entre os pacientes do Grupo I em comparação aos pacientes do Grupo II. Em outras palavras, na percepção do paciente, tanto faz realizarmos a clivagem da sutura palatina mediana com o uso de cinzel e martelo, ou não realizarmos este passo.

Assim, se de um lado temos uma técnica eficaz, do outro temos uma técnica de resultado duvidoso, e a sintomatologia relatada pelos pacientes no trans-operatório não mostra diferença do procedimento que está sendo usado. Portanto, acreditamos que a utilização da técnica proposta por GLASSMAN ${ }^{31}$, deixe de ser considerada como uma das formas de tratamento cirúrgico das deficiências transversais maxilares. 


\section{4 - Sintomatologia relatada durante a ativação do aparelho expansor}

Todas as técnicas cirúrgicas aplicadas, para o tratamento da deficiência transversal maxilar, têm como finalidade principal o enfraquecimento das áreas que oferecem resistência às movimentações ortopédicas laterais da maxila.

$$
\text { ISAACSON }{ }^{40} \text {, em } 1964 \text { já mostrava que a }
$$

resistência do esqueleto facial às movimentações ortopédicas aumenta conforme a idade do paciente avança, sendo que em 1965 ZIMRING \& ISAACSON $^{83}$, com o uso de medidores de força, mostraram numericamente o aumento desta resistência. Pela lógica, os pacientes cirúrgicos são mais velhos, portanto espera-se um grau de resistência maior às forças ortopédicas exercidas pelo aparelho expansor.

LINES e cols ${ }^{50}$ já apontavam que falhas ocorridas durante a expansão maxilar em adultos era devido ao grau de fusão das suturas faciais, sendo que para estes autores as suturas do complexo zigomático era a região de maior resistência às forças ortopédicas, sendo esta a explicação do alto índice de insucesso de expansão rápida da maxila em adultos. Este fato foi comprovado posteriormente por KENNEDY e cols 43, onde concluem que o movimento lateral da maxila deve ser feito reduzindo a esta resistência, através de osteotomias. 
Pela lógica, é esperado que quanto menos osteotomias fizermos em nossos pacientes cirúrgicos, maior vai ser a resistência da maxila às movimentações ortopédicas ao ativarmos o aparelho expansor. Fato este já descrito por BASDRA, ZÖLLER \& KOMPOSCH ${ }^{8}$. Por conseqüência, é de se esperar que haja maior grau de desconforto e dor durante a ativação dos aparelhos expansores nestes casos.

Afirmação esta, corroborada pelo trabalho de CAPELOZZA FILHO e cols ${ }^{19}$, onde foi realizada a expansão não cirúrgica de 38 pacientes adultos. Apesar do resultado considerado satisfatório, onde somente em 5 pacientes foi necessária à realização de cirurgia, foi relatado que os pacientes tiveram uma experiência de dor intensa durante a ativação do aparelho expansor. Fato este sustentado por SILVERSTEIN \& QUINN ${ }^{68}$, onde os autores afirmam que a ativação de aparelhos expansores contra suturas fechadas e/ou fusionadas pode levar o paciente à sensação de dor ou pressão.

Os resultados obtidos com os pacientes do Grupo II, em relação ao desconforto durante a ativação do aparelho expansor, corroboram as afirmações destes autores.

O trabalho de JAFARI, SHEETTY \& KUMAR ${ }^{42}$, vem de encontro às queixas durante o pós-operatório dos pacientes do Grupo 
II, que sentiram um grande desconforto durante a ativação do aparelho expansor. Segundo o relato destes pacientes, a sensação de pressão se dava por toda a cabeça e não somente à região palatina, fato este também observado nos controles pós-operatórios em nossos pacientes, mas sem relevância científica, pois estes dados não foram obtidos de forma metodológica e padronizados, mas achamos interessante a mesma observação feita por outros pacientes de diferentes trabalhos.

Foi notado pela avaliação e relato destes pacientes, história de muita dor e sensação de pressão durante a ativação do aparelho expansor (Grupo II mediana $=5,0)$.

BELL \& JACOBS ${ }^{11}$ relatam que após a realização de osteotomias maxilares, a expansão é feita com o mínimo desconforto ou sensação de pressão nas articulações maxilares.

Este fato foi também observado nos pacientes do Grupo I, submetidos à técnica de BELL ${ }^{12}$, onde não foi relatado pelos pacientes sensações dolorosas ou desconfortáveis durante a ativação do aparelho expansor (Grupo I mediana $=1,0)$.

Um fator a ser abordado é o de como a sutura palatina mediana influenciou esta sintomatologia. A diferença técnica entre BELL ${ }^{12}$ e GLASSMAN ${ }^{31}$ é a clivagem da sutura palatina mediana. Se a 
sutura palatina mediana não é uma área de reforço e resistência às movimentações ortopédicas da maxila, por que os pacientes do Grupo II, submetidos à cirurgia pela técnica de GLASSMAN ${ }^{31}$, tiveram alto índice de insucesso na cirurgia e uma maior sintomatologia dolorosa do que os pacientes submetidos à técnica de BELL ${ }^{12}$ ?

Na opinião do autor do presente trabalho, a razão é muito simples. A sutura palatina mediana, em pacientes adultos, é uma área de resistência ao movimento lateral da maxila.

Acreditamos que as afirmações de GLASSMAN ${ }^{31}$, e KENNEDY \& cols ${ }^{43}$, de que a sutura palatina mediana não é a principal área de resistência às movimentações ortopédicas sejam verdadeiras. Mas discordamos quanto ao ponto de vista de que esta região não deva sofrer disjunção e/ou osteotomia, devido aos resultados obtidos por esta pesquisa. 


\section{$\underline{6.5 \text { - Sintomatologia dolorosa relatada no pós-operatório }}$}

Os resultados deste trabalho mostram que os pacientes submetidos à cirurgia pela técnica de BELL ${ }^{12}$ (Grupo I) tiveram menor sintomatologia dolorosa no período de controle pós-operatório, do que os pacientes submetidos à técnica de GLASSMAN ${ }^{31}$ (Grupo II).

Pelo fato dos pacientes de ambos os grupos possuírem uma medicação padronizada, para controle de dor e infecção no pós-operatório, acreditamos que esta sintomatologia esteja também associada à uma sobreposição de sintomatologia da ativação do aparelho expansor, do que somente a dor causada pelo trauma cirúrgico da região.

De certa forma, este resultado também surpreendeu os pesquisadores, já que era esperado, com a padronização da medicação, um resultado uniforme entre os dois grupos.

Apesar disto, consideramos estes resultados encorajadores à realização destes procedimentos, pois apesar de existir diferenças significantes entre a percepção de dor dos dois grupos, ambos possuíram boa avaliação quanto à dor pós-operatória (Grupo I mediana = 0,75 e Grupo II mediana = 2,0). 


\section{$\underline{6.6 \text { - Percepção dos pacientes ao edema pós-operatório }}$}

Acreditamos que devido ao fato de usarmos uma medicação padronizada para controle de edema pós-operatório (Dexametasona 4mg, injetável, 1 aplicação diária I.M. por 3 dias), e que apesar da diferença de técnica cirúrgica envolvida entre os grupos I e II, a manipulação tecidual em ambos os grupos é muito semelhante.

Este fator é responsável pela não significância, da diferença de valores obtidos pela avaliação dos pacientes, quanto ao edema formado no pós-operatório. Mesmo assim, observamos que, segundo os pacientes, não existe grande quantidade de edema formado durante o período de pós-operatório quando seguimos os protocolos de atendimento de pacientes que necessitem de correção cirúrgica da deficiência transversal maxilar, estabelecidos pela Disciplina de Cirurgia da Faculdade de Odontologia de Bauru (Grupo I mediana = 2,0 e Grupo II mediana = 2,0).

Sabemos que este tipo de avaliação é subjetivo, porém, a partir desta avaliação poderemos futuramente medir a quantidade de edema sabendo que esta quantidade é tolerável ao paciente. Não realizamos a medida do edema, nesta pesquisa, pela dificuldade financeira da maioria dos pacientes que teriam que se deslocar de outras cidades 
durante, no mínimo, uma semana todos os dias para avaliação, prevista no projeto, porém deixada de lado na execução da pesquisa. 


\section{7 - CONCLUSÕES}

Após a análise dos resultados obtidos por este trabalho, podemos concluir que:

1. A técnica cirúrgica proposta por BELL ${ }^{12}$ foi mais eficiente no tratamento cirúrgico das deficiências transversais maxilares do que a técnica proposta por GLASSMAN ${ }^{31}$. Houve maior incidência de fraturas simétricas nos pacientes submetidos à técnica de GLASSMAN ${ }^{31}$.

2. Ambas técnicas mostraram-se toleráveis aos pacientes para a realização deste procedimento sob anestesia local, sendo que o edema formado também é tolerável segundo a percepção dos pacientes.

3. A técnica proposta por GLASSMAN obteve piores resultados pós-operatórios quanto à sintomatologia pós-operatória

4. A técnica proposta por GLASSMAN obteve piores resultados pós-operatórios quanto à ativação do aparelho expansor. 


\section{FICHA DE PACIENTES PARA EXPANSÃO MAXILAR}

NOME

NOME ORTODONTISTA
TELEFONE

TELEFONE

EXAME INICIAL

MORDIDA CRUZADA POSTERIOR

$\square$ UNILATERAL

BILATERAL

MORDIDA CRUZADA POSTERIOR EM RC

UNILATERAL

BILATERAL

NECESSIDADE DE EXP. MAXILAR CIR.

$\square$ SIM

NÃO

NECESSIDADE DE OUTRAS CIRURGIAS

(ORTOGNÁTICAS)

PROFUNDIDADE DE SONDAGEM INCISIVOS SUPERIORES

CONTROLE RADIOGRÁFICO

INICIAL

DATA:

TELE P.A.

PANORÂMICA

OCLUSAL MAXILA

PERIAPICAL INC.

\begin{tabular}{|l|l}
\hline & CI MARC. \\
SIM \\
CI MARC.
\end{tabular}

DATA:

PÓS OPERATÓRIO IMEDIATO PERIAPICAL INC.

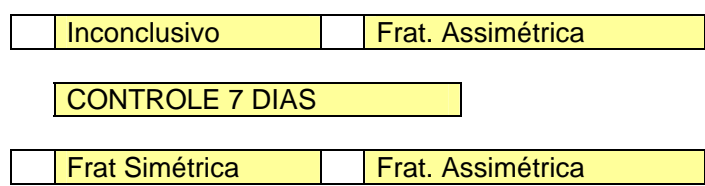

ESQUEMA DE ATIVAÇÃO DO APARLEHO $\square$ Ativações / dia $\square$ Intervalo

\begin{tabular}{|l|l|l|l|l|}
\hline ESQUEMA DE ATIVAÇÃO DO APARELHO & Ativações / dia & & Intervalo \\
\hline
\end{tabular}

CONTROLE 14 DIAS APÓS 7 ATIVAÇÕES COMPLETAS

PERIAPICAL INC.

mm de abertura na crista.

TELE P.A.

C/ MARC.

$\square$ S/ MARC.

CONTROLE 60 DIAS

TELE P.A.

DATA:

OCLUSAL MAXILA

C/ MARC.

C/ MARC.

S/ MARC

S/ MARC

\section{CONTROLE 120 DIAS \\ TELE P.A. \\ DATA: \\ OCLUSAL MAXILA $\quad$ C/MARC.}

REMOÇÃO APARELHO INDICADA



NÃO

\begin{tabular}{|c|c|}
\hline CONTROLE 150 DIAS & DATA: \\
\hline TELE P.A. & C/ MARC. \\
\hline OCLUSAL MAXILA & C/ MARC. \\
\hline
\end{tabular}

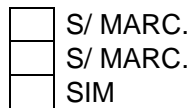

\begin{tabular}{|c|c|}
\hline CONTROLE 180 DIAS & DATA: \\
\hline TELE P.A. & C/ MARC. \\
\hline OCLUSAL MAXILA & C/ MARC. \\
\hline
\end{tabular}

REMOÇÃO APARELHO INDICADA

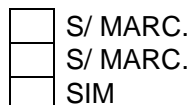

NÃO

Anexo 1 - Ficha do paciente 


\section{CONTROLE DE PACI ENTES SUBMETI DOS À EXPANSÃO MAXI LAR CI RURGI CAMENTE ASSI STI DA}

\section{Nome do Paciente:}

Grupo I

Data da Cirurgia:

Grupo II

\section{Parte I}

1- Como você classificaria o desconforto da cirurgia a qual acabou de ser submetido?

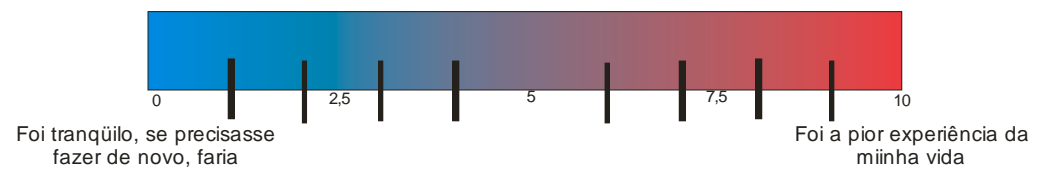

\section{Parte I I}

1- Como você classificaria o desconforto da cirurgia a qual foi submetido?

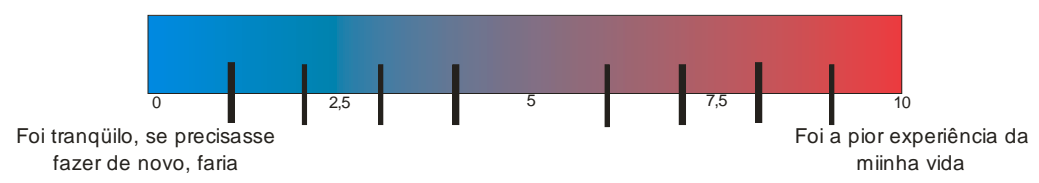

2- Como você classificaria o desconforto durante a ativação do expansor?

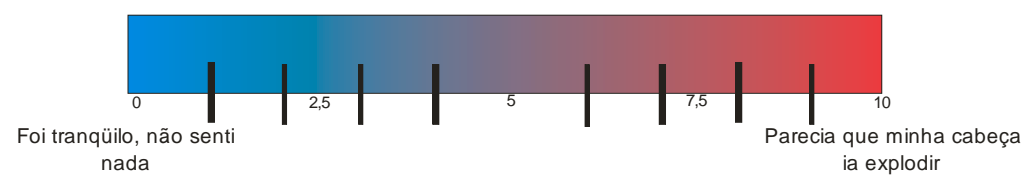

3- Como você classificaria a sua dor pós-operatória?

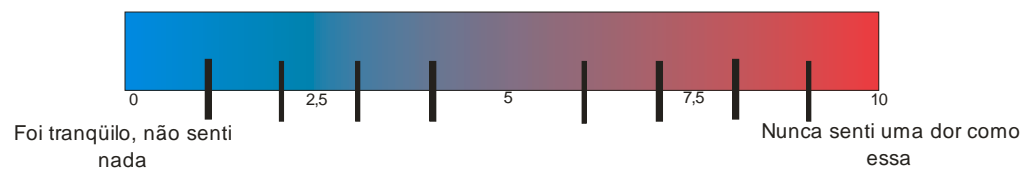

4- Como você classificaria o seu inchaço no pós- operatória?

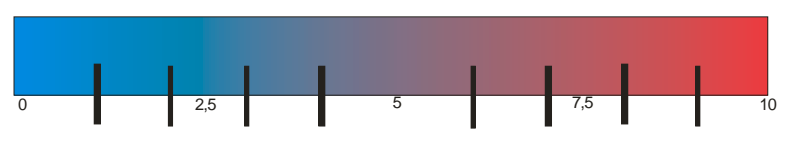

Anexo 2 - Questionário dos pacientes. 


\section{Carta de Informação do Paciente}

Senhor Paciente:

A nossa pesquisa vai avaliar duas diferentes formas de tratar a maxila estreita. Ambas formas são conhecidas e já usadas por outros profissionais. Perguntaremos a você sobre o desconforto durante a cirurgia, após a cirurgia e durante a ativação dos aparelhos expansores que estão colocados em sua boca. Também avaliaremos seus dentes incisivos centrais superiores e sua gengiva. Durante este tipo de tratamento, nos dentes em que o aparelho fica preso ocorrem inclinações, nós estaremos medindo estas inclinações. A cirurgia será indicada após exame clínico, análise de modelos de gesso e exames complementares.

Durante todo o período de tratamento, você fará várias radiografias (cerca de 15). Sendo que as primeiras serão feitas antes da cirurgia, outras logo após a cirurgia e outras com regularidade mensal. Estas radiografias serão monitoradas e feitas dentro de todos os critérios que diminuem a dose de exposição do paciente aos raios $\mathrm{X}$.

Os dados obtidos durante o ato cirúrgico e no pós-operatório serão usados em nossas pesquisas para publicações futuras.

Bauru, de de 2005.

Assinatura do paciente

C.D. Luís Fernando de Mello Sant'Ana Aluno de Pós-Graduação em Estomatologia

Anexo 3 - Carta de informação ao paciente 


\section{UNIVERSIDADE DE SÃO PAULO \\ FACULDADE DE ODONTOLOGIA DE BAURU \\ COMITÊ DE ÉTICA EM PESQUISA TERMO DE CONSENTIMENTO LIVRE E ESCLARECIDO}

Pelo presente instrumento que atende às exigências legais, o(a) senhor(a) , portador(a) da cédula de identidade $\mathrm{n}^{\mathrm{o}}$ após leitura minuciosa da CARTA DE INFORMAÇÃO AO PACIENTE, devidamente explicada pelos profissionais em seus mínimos detalhes, ciente dos serviços e procedimentos aos quais será submetido, não restando qualquer dúvida a respeito do lido e explicado, firma-se CONSENTIMENTO LIVRE E ESCLARECIDO em concordância em participar na pesquisa proposta no que lhe é cabível, conforme a CARTA DE INFORMAÇÃO AO PACIENTE.

Fica claro que o paciente ou seu representante legal, podem a qualquer momento retirar seu CONSENTIMENTO LIVRE E ESCLARECIDO e deixar de participar do estudo alvo da pesquisa e ciente de que todo o trabalho realizado torna-se informação confidencial guardada por força de sigilo profissional (Art. 9. do código de Ética Odontológica).

Por estarem entendidos e conformados, assinam o presente termo.

Bauru, de de 200 


\section{PROTOCOLO DE PROCEDIMENTOS PARA PACIENTES QUE SERÃO SUBMETIDOS À DISJUNÇÃO MAXILAR ASSISTIDA CIRURGICAMENTE, NA FACULDADE DE ODONTOLOGIA DE BAURU.}

\section{ETAPA PRÉ-CIRÚRGICA}

1. Realização dos seguintes exames radiográficos, a fim de serem enviados para os arquivos da Disciplina de Cirurgia, e não serão devolvidos:
a. Radiografia Panorâmica.
b. Radiografia Oclusal de Maxila.
c. Telerradiografia P.A.
d. Telerradiografia Perfil.

2. Modelos de estudo inicial.

3. Realização dos seguintes exames:
a. Hemograma completo.
b. Coagulograma completo.
c. Glicemia em jejum.
d. Avaliação do cardiologista.

4. Correção das angulações acentuadas dos incisivos centrais superiores.

5. Instalação do torno de Hyrax, com acessórios 022” x 028” ou 022” x 030” soldados firmemente às bandas.

6. Informações sobre o tamanho do parafuso expansor.

7. Envio da chave do torno de Hyrax antes do dia da cirurgia.

\section{ETAPA CIRÚRGICA}

1. Agendamento da $1^{\text {a }}$ consulta para exame clínico e instalação dos marcadores radiográficos. Nesta consulta serão realizadas as seguintes radiografias:
a. Telerradiografia P.A.
b. Oclusal total de maxila.

2. Agendamento da cirurgia.

3. Realização da cirurgia sob anestesia local.

4. Segue cronograma dos controles:

\begin{tabular}{|c|c|c|c|c|c|}
\hline Consulta Inicial & Cirurgia & $\begin{array}{c}\text { Controle } 14 \\
\text { dias. }\end{array}$ & $\begin{array}{c}\text { Controle } 90,120, \\
\text { 150, } 180 \text { dias. }\end{array}$ & Pós Contenção & Final \\
\hline $\begin{array}{l}\text { Colocação dos marcadores } \\
\text { Exame Clínico } \\
\text { Rx P.A. } \\
\text { Rx Oclusal } \\
\text { Modelos de Estudo. }\end{array}$ & Rx Oclusal & $\begin{array}{l}\text { Rx Oclusal } \\
\text { Rx P.A. }\end{array}$ & $\begin{array}{l}\text { Rx Oclusal } \\
\text { Rx P.A. }\end{array}$ & $\begin{array}{l}\text { Rx Oclusal } \\
\text { Rx P.A. } \\
\text { Modelos de Estudo }\end{array}$ & $\begin{array}{l}\text { Rx P.A. } \\
\text { Modelos de } \\
\text { Estudo. }\end{array}$ \\
\hline
\end{tabular}

5. Serão avaliados:
a. Inclinação de molares e pré-molares (inicial, pós-expansão,durante ossificação e final).
b. Quantidade de expansão em incisivos centrais superiores.
c. Quantidade de expansão na rafe mediana.
d. Tipo de fratura de crista alveolar.
e. Tempo de reparo ósseo.

Anexo 5 - Protocolo de atendimento dos pacientes na FOB-USP. 


\section{REFERÊNCIAS BIBLIOGRÁFICAS*¹}

1. ALPERN, M.C.; YUROSKO, J.J. Rapid palatal expansion in adults. Angle Orthod, v. 57, n. 3, p. 245-63, Jul, 1987.

2. AlVARES, L.C.; TAVANO, O. Curso de Radiologia em Odontologia. $3^{\text {a }}$. Edição, são Paulo, Ed. Santos, 1993.

3. ANGELL, E.C. Treatment of irregularities of the permanent or adult teeth. Dent Cosmos, v. 1, p. 540-44, 1860 apud HAAS, A.J. Rapid expansion of the maxillary dental arch and nasal cavity by opening the midpalatal suture. Angle Orthod, v. 31, n. 2, p. 7390, Apr, 1961.

\footnotetext{
* Normas recomendadas para o uso no âmbito da Universidade de São Paulo, com base no documento "Referências Bibliográficas", oferecido pelo Serviço de Biblioteca e Documentação da Faculdade de Odontologia de Bauru, de 2001.
} 
4. ANTTILA, A.; et al. Feasibility and long-term stability of surgically assisted rapid maxillary expansion with lateral osteotomy. Eur J Orthod, v. 26, n. 4, p. 391-95, Aug, 2004.

5. BAILEY, L.J.; et al. Segmental Le Fort I osteotomy for management of transverse maxillary deficiency. J Oral Maxillofac Surg,v. 55, n. 7, p. 728-31, Jul, 1997.

6. BANNING, L.M.; et al. Treatment of transverse maxillary deficiency with emphasis on surgically assisted-rapid maxillary expansion. Compend Contin Educ Dent, v. 17, n. 2, p. 170-78, Feb, 1996.

7. BASCIFTCI, F.A.; et al. Does timing end method of rapid maxillary expansion have an effect on the changes in nasal dimensions? Angle Orthod, v. 72, n. 2, p. 118-23, Apr, 2002.

8. BASDRA, E.K.; ZÖLLER, J.E.; KOMPOSCH, G. Surgical assisted rapid palatal expansion. J Clin Orthod, v. 29, n. 12, p. 762-66, Dec, 1995.

9. BAYS, R.A.; GRECO, J. Surgically assisted rapid palatal expansion: an outpatient technique with long-term stability. J Oral Maxillofac Surg, v. 50, n. 2, p. 110-15, Feb, 1992. 
10. BELL, W.H.; EPKER, B.N. Surgical-orthodontic expansion of the maxilla. Am J Orthod v. 70, n. 6, p. 517-28, Dec, 1976.

11. BELL, W.H.; JACOBS, J.D. Surgical-orthodontic correction of horizontal maxillary deficiency. J Oral Surg, v. 37, n. 12, p. 897-902, Dec, 1979.

12. BELL, W.H.; Modern practice in orthognathic and reconstructive surgery. Philadelphia: WB Saunders Co; 1992.

13. BERGER, J.L.; et al. Stability of orthopedic and surgically assisted rapid palatal expansion over time. Am J Orthod Dentofac Orthop, v. 114, n. 6, p. 638-45, Dec, 1998.

14. BERGER, J.L.; et al. Photographic analysis of facial changes associated with maxillary expansion. Am J Orthod Dentofac Orthop, v. 116, n. 5, p. 563-71, Nov, 1999.

15. BETTS, N.J.; STURTZ, D.H.; ALDRICH, D.A. Treatment of transverse (width) discrepancies in patients who require isolated mandibular surgery: The case for maxillary expansion. J Oral Maxillofac Surg v. 62, n. 3, p. 361-64, Mar, 2004.

16. BIEDERMAN, W. Rapid correction of class III malocclusion by midpalatal expansion. Am J Orthod v. 63, n.1, p. 47-55, Jan, 1973. 
17. BISHARA, S.E.; STALEY, R.N. Maxillary expansion: clinical implications. Am J Orthod Dentofac Orthop, v. 91, n. 1, p. 314, Jan, 1987.

18. CAPELOZZA FILHO, L.; et al. Expansão rápida da maxila cirurgicamente assistida. Ortodontia, v. 27, n. 1, p. 21-30, JanApr, 1994.

19. CAPEELOZZA FILHO, L.; et al. Non-surgically assisted rapid maxillary expansion in adults. Int $\mathbf{J}$ Adult Orthod Orthognath Surg, v. 11, n. 1, p. 57-66, 1996. apud STUART, D.A. Rapid palatal expansion in the young adult: Time for a paradigm shift? J Can Dent Assoc, v. 69, n. 6, p. 374-77, Jun, 2003.

20. CARVALHO, P.S.P.; BASSI, A.P.F.; PEREIRA, L.A.V.D. Revisão e proposta de nomenclatura para os biomateriais. Implant News, v. 1, n. 3, p. 255-60, Mai-Jun, 2004.

21. CHUAH, C.; MEHRA, P. Bilateral lingual anesthesia following surgically assisted rapid palatal expansion: Report of a case. J Oral Maxillofac Surg, v. 63, n. 3, p. 416-18, Mar, 2005.

22. CHUNG, C-H.; et al. Maxillary sagittal and vertical displacement induced by surgically assisted rapid palatal expansion. Am J Orthod Dentofac Orthop, v. 120, n. 2, p. 144-48, Aug, 2001. 
23. CHUNG, C-H.; GOLDMAN, A.M. Dental tipping and rotation immediately after surgically assisted rapid palatal expansion. Eur J Orthod v. 25, n. 4, p. 353-58, Aug, 2003.

24. CONLEY, R.S.; LEGAN, H.L. Correction of severe vertical maxillary excess with anterior open bite and transverse maxillary deficiency. Angle Orthodon v. 72, n. 3, p. 265-74, Jun, 2002.

25. CURETON, S.L.; CUENIN, M. Surgically assisted rapid palatal expansion: Orthodontic preparation for clinical success. Am J Orthod Dentofac Orthop, v. 116, n. 1, p. 46-59, Jul, 1999.

26. DAVIS, W.M.; KRONMAN, J.H. Anatomical changes induced by splitting of the midpalatal suture. Angle Orthod v. 31, n. 2,p. 7390, Apr, 1961.

27. EPKER, B.N.; FISH, L.C.; PAULUS, P.J. The surgical-orthodontic correction of maxillary deficiency. Oral Surg, v. 46, n. 2, p. 171205, Aug, 1978.

28. GARDNER, G.E.; KRONMAN, J.H. Cranioskeletal displacements caused by rapid palatal expansion in the rhesus monkeys. Am $\mathbf{J}$ Orthod v. 59, n.2, p. 146-55, Feb, 1971. 
29. GERLACH, K.L.; ZAHL, C. Surgically assisted rapid palatal expansion using a new distraction device: Report of a case with an epimucosal fixation. J Oral Maxillofac Surg, v. 63, n. 6, p. 711-13, Jun, 2005.

30. GILL, D.; et al. The management of transverse maxillary deficiency. Dent Update, v. 31, n. 9, p. 516-23, Nov, 2004.

31. GLASSMAN, A.S.; et al. Conservative surgical orthodontic adult rapid palatal expansion: Sixteen cases. Am J Orthod v. 86, n.3, p. 207-13, Sep. 1984.

32. GRACELY, R.H.; et al. New methods of pain measurement and their application to pain control. Int Dent J, v. 28, n. 1, p. 52-65, Mar, 1978.

33. GURGEL, J.A.; et al. Uso de marcadores para identificação de posicionamento dentário em telerradiografias frontais pósteroanteriores - Proposta de um método. Rev Dental Press Ortod Ortop Facial, v. 10, n. 6, p. 84-89, Dez, 2005.

34. HAAS, A.J. Rapid expansion of the maxillary dental arch and nasal cavity by opening the midpalatal suture. Angle Orthod, v. 31, n. 2, p. 73-90, Apr, 1961. 
35. HAAS, A.J. The treatment of maxillary deficiency by opening the midpalatal suture. Angle Orthod, v. 35, n. 3, p. 200-17, Jul, 1965.

36. HAAS, A.J. Palatal expansion: just the beginning of dentofacial orthopedics. Am J Orthod v. 57, n 3, p. 219-55, Mar, 1970.

37. HAAS, A.J. Long-term posttreatment evaluation of rapid palatal expansion. Angle Orthod,v. 50, n. 3, p. 189-217, Jul, 1980.

38. HUSKISSON, E.C. Measurement of pain. The Lancet, v. 304, n. 7889, p. 1127-31, Nov. 1974.

39. ISAACSON, R.J.; MURPHY, T.D. Some effects of rapid maxillary expansion in cleft lip and palate patients. Angle Orthod v.34, n. 3, p. 143-54, Jul, 1964.

40. ISAACSON, R.J. Forces produced by rapid maxillary expansion. Angle Orthod v. 34, n. 4, p. 256-69, Oct, 1964.

41. JACOBS, J.D.; et al. Control of the transverse dimension with surgery and orthodontics. Am J Orthod, v. 77, n. 3, p. 284-306, Mar, 1980. 
42. JAFARI, A.; SHETTY, K.S.; KUMAR, M. Study of stress distribution and displacement of various craniofacial structures following application of transverse orthopedic forces - a threedimensional FEM study. Angle Orthod, v. 73, n. 1, p. 12-20, Feb, 2003.

43. KENNEDY III, J.W.; et al. Osteotomy as an adjunct to rapid maxillary expansion. Am J Orthod v. 70, n. 2, p. 123-37, Aug, 1976.

44. KRAUT, R. Surgically assisted rapid maxillary expansion by opening the midpalatal suture. J Oral Maxillofac Surg, v. 42, n. 10, p. 651-55, Oct, 1984.

45. KREMER, E.; ATKINSON, J.H.; IGNELZI, R.J. Measurement of pain: Patient reference does not confound pain measurement. Pain, v. 10, n. 2, p. 241-48, Apr, 1981.

46. KOUDSTAAL, M.J.; et al. Surgically assisted rapid maxillary expansion (SARME): A review of the literature. Int $\mathbf{J}$ Oral Maxillofac Surg v. 34, n. 7, p. 709-14, Oct, 2005.

47. LANIGAN, D.T.; HEY, J.H.; WEST, R.A. Aseptic Necrosis following maxillary osteotomies: Report of 36 cases. J Oral Maxillofac Surg, v. 48, n. 2, p. 142-56, Feb, 1990. 
48. LANIGAN, D.T.; MINTZ, S.M. Complications of surgically assisted rapid palatal expansion: Review of the literature and report of a case. J Oral Maxillofac Surg, v. 60, n.1, p. 104-10, Jan, 2002.

49. LEHMAN JR., J.A.; HAAS, A.J. Surgical-othodontic correction of transverse maxillary deficiency. Dent Clin North Am, v. 34, n. 2, p. 385-95, Apr, 1990.

50. LINES, P.A.; et al. Adult rapid maxillary expansion with corticotomy. Am J Orthod v. 67, n. 1, p. 44-56, Jan, 1975.

51. MALMSTRÖM, M.F.V. Avaliação da neoformação óssea na sutura palatina mediana por meio de radiografia digitalizada após a expansão rápida da maxila assistida cirurgicamente. Bauru, 2005, 132p. Dissertação (Mestrado) - Faculdade de Odontologia de Bauru, Universidade de São Paulo.

52. MAO, J.J.; WANG, X.; KOPHER, R.A. Biomechanics of craniofacial sutures: Orthopedic implications. Angle Orthod, v. 73, n. 2, p. 128-35, Apr, 2003.

53. MEHRA, P.; et al. Life-threatening, delayed epistaxis after surgically assisted rapid palatal expansion: A case report. J Oral Maxillofac Surg, v. 57, n.2, p. 201-04, Feb, 1999. 
54. MESSER, E.J.; BOLLINGER, T.E.; KELLER, J.J. Surgicalmechanical maxillary expansion. Quintessence Int, v. 10, n. 8, p. 13-16, Aug, 1979.

55. MORGAN, T.A.; FRIDRICH, K.L. Effects of the multiple-piece maxillary osteotomy on the periodontium. Int $\mathbf{J}$ Adult Orthod Orthognath Surg v. 16, n.4, p. 255-65, Sep, 2001.

56. MOSSAS, C.F.; BYLOF, F.K.; RICHTER, M. Unilateral and bilateral corticotomies for correction of maxillary transverse discrepancies. Eur J Orthod, v. 14, n. 2, p. 110-16, Apr, 1992.

57. NORTHWAY, W.M.; MEADE JR, J.B. Surgically assisted rapid maxillary expansion: a comparison of technique, response and stability. Angle Orthod, v. 67, n. 4, p. 309-20, 4, 1997.

58. PERSSON, M.; THILANDER, B. Palatal suture closure in man from 15 to 35 years of age. Am J Orthod, v. 72, n. 1, p. 43-52, Jul, 1977.

59. POGREL, M.A.; KABAN, L.B.; VARGERVIK, K. Surgically assisted rapid maxillary expansion in adults. Int $\mathbf{J}$ Adult Orthod Orthognath Surg, v. 7, n. 1, p. 37-41, 1992. 
60. PROFFIT, W.R.; PHILLIPS, C., DANN, C. Who seeks surgicalorthodontic treatment? Int J Adult Orthod Orthognath Surg, v. 5, n. 2, p. 153, 1990.

61. PROFFIT, W.R.; TURVEY, T.A.; PHILLIPS, C. Orthognathic surgery: a hierarchy of stability. Int $\mathbf{J}$ Adult Orthod Orthognath Surg, v. 11, n. 3, p. 191-204, 1996.

62. RACHMIEL, A.; ALZENBUD, D.; PELED, M. Long-term results in maxillary deficiency using intraoral devices. Int $\mathbf{J}$ Oral Maxillofac Surg, v. 34, n. 5, p. 473-79, Jul 2005.

63. RAMIERI, G.A.; et al. Transverse maxillary distraction with a boneanchored applience: dento-periodontal effects and clinical and radiological results. Int J Oral Maxillofac Surg, v. 34, n. 4, p. 357-63, Jun 2005.

64. ROBIONY, M.; et al. Truncal anaesthesia of the maxillary nerve for outpatient surgically assisted rapid maxillary expansion. Br J Oral Maxillofac Surg, v. 36, n. 5, p. 389-91, Oct, 1998.

65. SCHWARZ, G.M.; et al. Tomographic assessment of nasal septal changes following surgical-orthodontic rapid maxillary expansion. Am J Orthod, v. 87, n. 1, p. 39-45, Jan, 1985. 
66. SCHIMMING, R.; et al. Surgical and orthodontic rapid palatal expansion in adults using Glassman's technique: Retrospective study. Br. J. Oral Maxillofac Surg. v. 38, n. 1, p. 66-69, Feb, 2000.

67. SHETTY, V. et al. Biomechanical rationale for surgical-orthodontic expansion of the adult maxilla. J Oral Maxillofac Surg, v. 52, n. 7, p. 742, 51, Jul., 1994.

68. SILVERSTEIN, K.; QUINN, P. Surgically-assisted rapid palatal expansion for management of transverse maxillary deficiency. $\mathbf{J}$ Oral Maxillofac Surg, v. 55, n. 7, p. 725-27, Jul, 1997.

69. STAINHAUSER, E.W. The midline-splitting of the maxilla for correction of malocclusion. J Oral Surg v. 30, p. 413-22, 1972. apud BELL, W.H.; EPKER, B.N. Surgical-orthodontic expansion of the maxilla. Am J Orthod v. 70, n. 6, p. 517-28, Dec, 1976.

70. STUART, D.A. Rapid palatal expansion in the young adult: Time for a paradigm shift? J Can Dent Assoc, v. 69, n. 6, p. 374-77, Jun, 2003. 
71. TAVARES, C.A.; SCHEFFER, M. Surgically assisted rapid palatal expansion (SARPE) prior to combined Le Fort I and sagittal osteotomias: a case report. Int J Adult Orthod Orthognath Surg, v. 16, n. 3, p. 200-6, Aug, 2001.

72. TENCATE, A.R.; FREEMAN, E.; DICKINSON, J.B. Sutural development: structural and its response to rapid expansion. Am J Orthod, v. 71, n. 6, p. 622-36, Jun, 1977.

73. TIMMS, D.J.; ORTH, D.; VERO, D. The relationship of rapid maxillary expansion to surgery with special reference to midpalatal synostosis. Br J Oral Surg v. 19, n. 3, p. 180-96, Sep, 1981.

74. VARDIMON, A.D.; et al. Rapid palatal expansion: Part 1. Mineralization pattern of the midpalatal suture in cats. Am $\mathbf{J}$ Orthod Dentofac Orthop, v. 113, n. 4, p. 371-78, Apr, 1998.

75. WARREN, D.W.; et al. The nasal airway following maxillary expansion. Am J Orthod Dentofac Orthop, v. 91, n. 2, p. 11116, Feb, 1987.

76. WERTZ, R.A. Skeletal and dental changes accompanying rapid maxillary expansion. 1. Forces present during treatment. Am $\mathbf{J}$ Orthod, v. 58, n. 1, p. 41-66, Jul, 1970. 
77. WILTFANG, J.; KESSLER, P. Endoscopically assisted Le Fort I osteotomy to correct transverse and sagittal discrepancies of the maxilla. J Oral Maxillofac Surg, v. 60, n. 10, p. 1142-46, Oct, 2002.

78. WOLFORD, L.M.; RIECHE-FISCHEL, O.; MEHRA, P. Soft tissue healing after parasagittal palatal incisions in segmental maxillary surgery: a review of 311 patients. J Oral Maxillofac Surg, v. 60, n. 1, p. 20-26, Jan, 2002.

79. WOODS, M.; WIESENFELD, D.; PROBERT, T. Surgicallyassisted maxilary expansion. Aust Dent J, v. 42, n. 1, p. 38-42, Feb, 1997.

80. WRIEDT, S.; et al. Surgically assisted rapid palatal expansion: An acoustic rhinometric, morphometric and sonographic investigation. J Orofac Orthop, v. 62, n. 2, p. 108-15, Mar, 2001.

81. YOKOO, S.; et al. Indications and procedures for segmental dentoalveolar osteotomy: A review of 13 patients. Int J Adult Orthod Orthognath Surg, v. 17, n. 4, p. 254-63, 2002. 
82. ZAHROWSKI, J.J.; TURLEY, P.K. Force magnitude effects upon osteoprogenitor cells during premaxillary expansion in rats. Angle Orthod, v. 62, n. 3, p. 197-202, Fall, 1992.

83. ZIMRING, J.F.; ISAACSON, R.J. Forces produced by rapid maxillary expansion. Angle Orthod v. 35, n. 3, p. 178-86, Jul, 1965. 


\section{ABSTRACT}

The use of surgically assisted rapid maxillary expansion for the correction of maxillary transverse deficiency in adult patients is known by surgeons and orthodontists. Its benefits for the patients, in the long term, are the correction of posterior cross-bite, improvements in the facial esthetics and the increase of nasal volume. The objectives of this research is the comparison of two forms of handling the maxillary transverse deficiency under local anesthesia, using the same surgical parameters to observe the technique efficacy, radiographic control and evaluation of the patients' perception of the surgery, including post-operatory evaluation. For this procedure, 24 adult patients were selected with indication of surgically assisted rapid maxillary expansion, divided in 2 groups. Group I was submitted to the technique described by BELL ${ }^{12}$, and group II to the technique described by GLASSMAN ${ }^{31}$. After obtaining all data through $x-$ 
rays and a questionnaire applied to the patients at the end of the surgery and in the first post-operatory control. It is possible to conclude that: (1) All the patients submitted to the surgical technique described by BELL ${ }^{12}$ had a satisfactory orthopedic and surgical results, while only $30 \%$ of the patients submitted to the GLASSMAN's ${ }^{31}$ technique had success; (2) Both techniques were tolerable to the patients under local anesthesia; (3) The technique described by GLASSMAN ${ }^{31}$ had more pain and discomfort during the appliance activation than the patients who undergone by BELL's 12 technique, which had a little or almost no discomfort during this procedure; (4) There were no statistic difference between the two techniques in the patients' perception regarding to the post-operatory edema. 